Final Technical Report

\title{
Aerogel-Based Insulation for Industrial Steam Distribution Systems
}

\section{Award Number: DE-FG36-06G016056}

Project Period: May 1, 2006 to March 31, 2011

Principal Investigator:

John Williams

Phone: (508) 691-1137

jwilliams@aerogel.com

Recipient Organization:

Aspen Aerogels, Inc.

30 Forbes Road, Building B

Northborough, MA 01532

Partners:

Air Liquide

Sproule Manufacturing

ProTherm, Inc.

March 30, 2011 
Acknowledgment:

This report is based upon work supported by the U. S. Department of Energy under Award No. DE-FG36-06GO16056.

\section{Disclaimer:}

Any findings, opinions, and conclusions or recommendations expressed in this report are those of the author(s) and do not necessarily reflect the views of the Department of Energy. 


\section{Table of Contents}

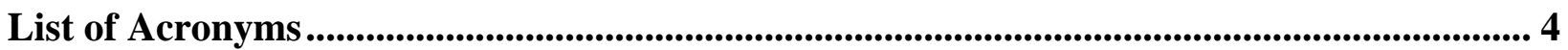

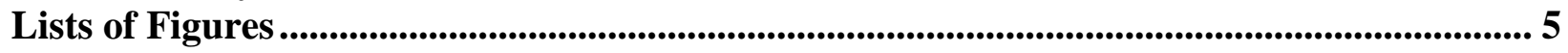

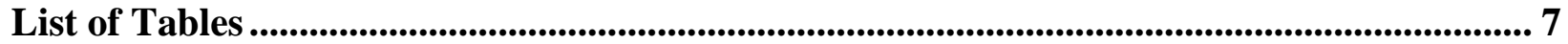

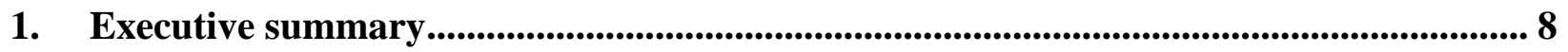

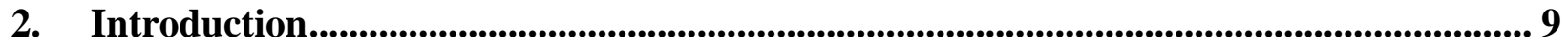

2.1. Energy Benefits, Economic Viability and Environmental Benefits ......................... 11

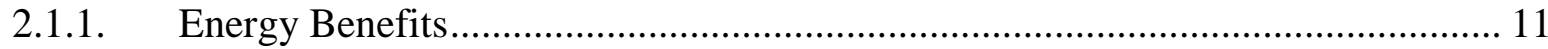

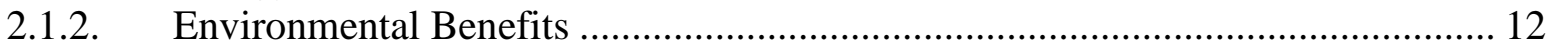

2.2. Industry Involvement and Commercialization Plan ........................................... 12

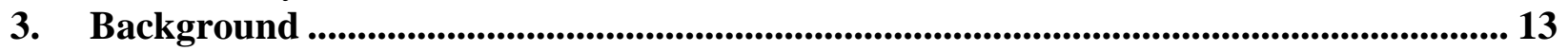

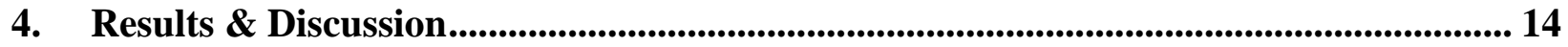

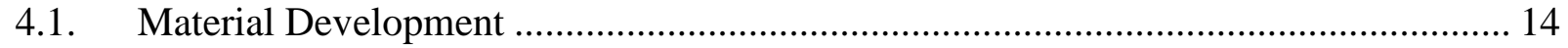

4.1.1. System Requirements....................................................................... 14

4.1.2. Fire Performance.................................................................................... 15

4.1.3. Dimensional Stability....................................................................... 18

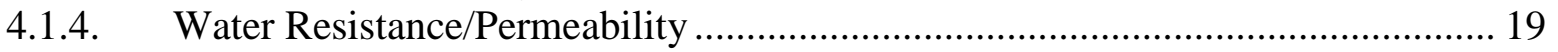

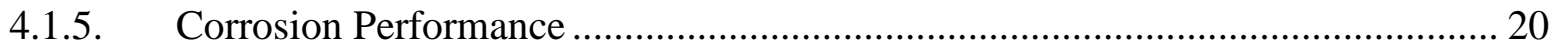

4.1.6. Other Testing .......................................................................................... 21

4.2. Product Improvement and Cost Reduction Activities ............................................ 25

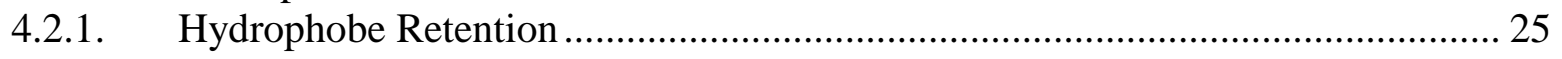

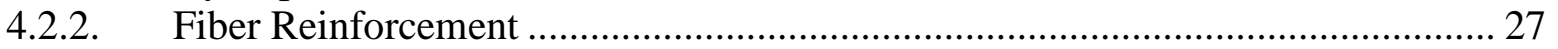

4.2.3. Lattice Strength at High Temperatures ....................................................... 27

4.2.4. Manufacturing Process Scale Up ................................................................ 27

4.2.5. Installation of Unit Operation for Pyrogel XT Additive during Casting ............. 28

4.2.6. Blanket Casting Optimization .................................................................... 28

4.2.7. Increasing Throughput of Pyrogel XT in Aging............................................ 29

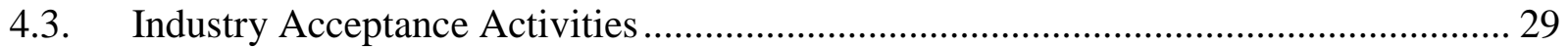

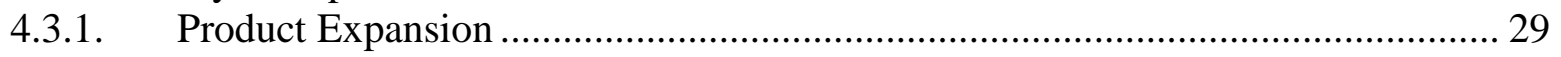

4.3.2. Product Demonstration at Industrial Sites ................................................... 29

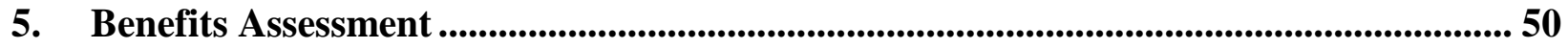

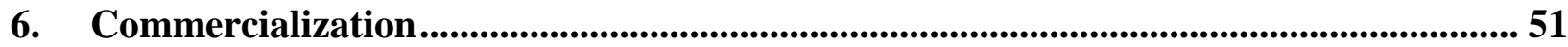

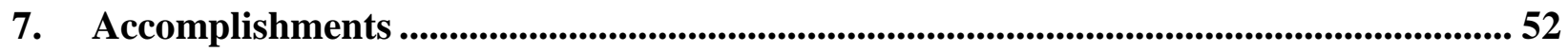

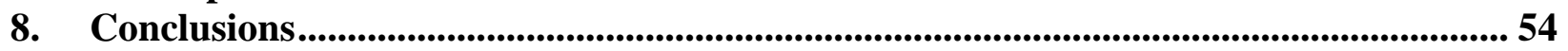

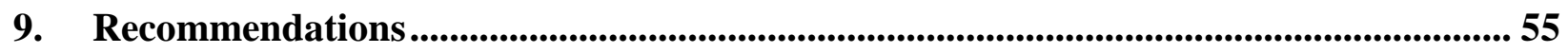

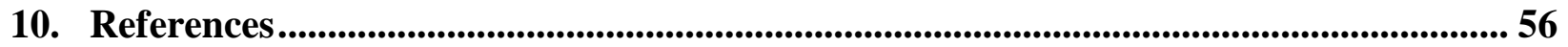




\section{List of Acronyms}

$\begin{array}{ll}\text { ABPI } & \text { Aerogel-based pipe insulation } \\ \text { ASTM } & \text { American Society for Testing Materials } \\ \text { BTU } & \text { British Thermal Unit } \\ \text { CUI } & \text { Corrosion under insulation } \\ \text { DOE } & \text { Department of Energy } \\ \text { ESCO } & \text { Energy Savings Company } \\ \text { ESPC } & \text { Energy Savings Performance Contract } \\ \text { FSI } & \text { Flame Spread Index } \\ \text { ft } & \text { feet } \\ \text { gal } & \text { gallon } \\ \text { hr } & \text { hour } \\ \text { IEP } & \text { Isolectronic points } \\ \text { in } & \text { inch } \\ \text { IR } & \text { Infrared } \\ \text { ISO } & \text { International Standardization Organization } \\ \text { ITP } & \text { Industrial Technologies Program } \\ \text { lbs } & \text { pounds } \\ \text { NFPA } & \text { National Fire Protection Association } \\ \text { mm } & \text { millimeter } \\ \text { MMBtu } & \text { Million BTUs } \\ \text { mph } & \text { miles per hour } \\ \text { NS } & \text { Naval Station } \\ \text { psi } & \text { pounds per square inch } \\ \text { SDI } & \text { Smoke Developed Index } \\ \text { TBTU } & \text { Trillion BTUs } \\ \text { TC } & \text { Thermal Conductivity } \\ \text { UL } & \text { Underwriters Laboratories } \\ \text { yr } & \text { year }\end{array}$




\section{Lists of Figures}

Figure 1. Estimated US industrial steam pipe population by diameter and temperature............ 11

Figure 2. ABPI two-pronged market penetration strategy developed at the project start........... 12

Figure 3. Test results from small scale UL 1709 screening tests performed in June, 2008. ....... 17

Figure 4. Comparative performance in a UL1709 fire test.................................................... 17

Figure 5. Average mid-thickness and surface temperatures of Pyrogel XT (48mm) upon hot-

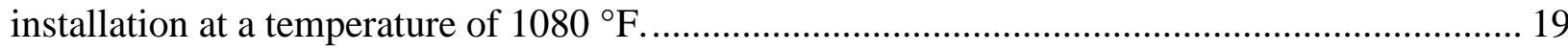

Figure 6. Average surface and mid-thickness temperatures as a function of time for Pyrogel XT

$(60 \mathrm{~mm})$ when hot installed at a temperature of $1200^{\circ} \mathrm{F}$.

Figure 7. A photograph depicting the apparatus (left) and aerogel coupons (right) used to assess

ASTM C692 performance.............................................................................................. 21

Figure 8. Interply temperatures as a function of time for Pyrogel XT $\left(500^{\circ} \mathrm{C}, 40 \mathrm{~mm}\right) \ldots \ldots \ldots \ldots . . .22$

Figure 9. Interply temperatures as a function of time for Pyrogel XT (400C, 30mm)............ 22

Figure 10. Water repellency of material as a function of ply number and mean exposure temperature after 68-day testing.

Figure 11. Extractable $\mathrm{pH}$ as a function of ply number and mean exposure temperature after 68

day testing.

Figure 12. Extractable anion content as a function of ply number and its relation to extractable

$\mathrm{pH}$ values.

Figure 13. Thermal conductivity $\left(37.5^{\circ} \mathrm{C}, 1 \mathrm{~atm}\right)$ and water repellency as a function of ply number after 68-day testing.

Figure 14. Hydrophobicity (water uptake) and thermal conductivity (Tc) of Pyrogel XT

(laboratory prepared) as a function of water content in aging.

Figure 15. Improvements in hydrophobicity for Pyrogel XT as a function of hydrophobe

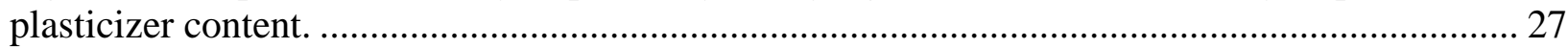

Figure 16. Aspen Aerogels' current flexible blanket manufacturing process. ......................... 28

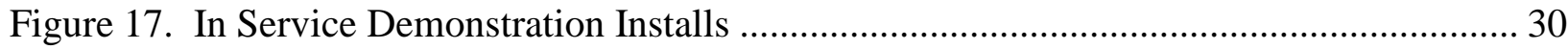

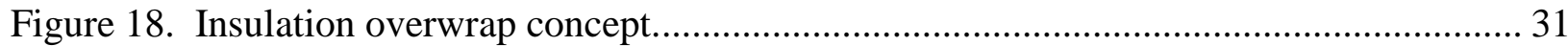

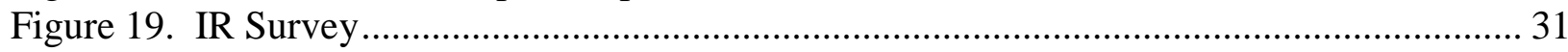

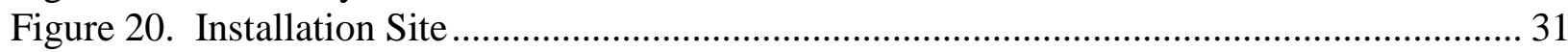

Figure 21. Field Installation and Instrumentation............................................................. 32

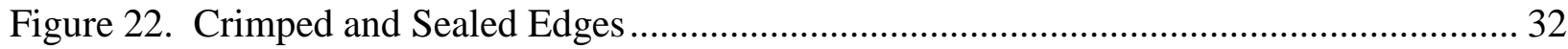

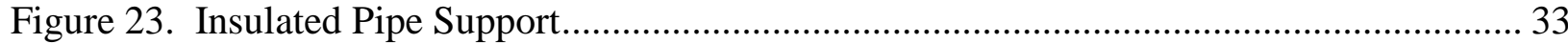

Figure 24. A) Wide view of NS Newport showing boiler location and proposed steam line installation site and B) close up of installation site behind Bldg 1.......................................... 34

Figure 25. A) bare pipe in maintenance cabinet, B) IR image shows $390^{\circ} \mathrm{F}$ surface temperature

Figure 26. A) Visual image of break in trough cover with pipe underneath on North side of installation site, and B) infrared image of pipe with $165^{\circ} \mathrm{F}$ surface temperature.

Figure 27. A) Visual image pipe central to the installation site, and B) infrared image of pipe with $211^{\circ} \mathrm{F}$ surface temperature. ............................................................................ 36

Figure 28. Pipe obstructions encountered in the trench such as this intersecting water line...... 37 Figure 29. Data monitoring schematic - thermocouples were place in same locations at start and

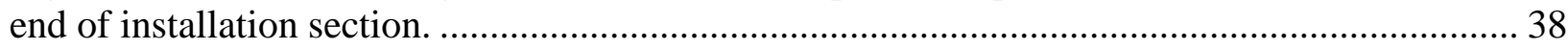

Figure 30. Pipe section (A) before and (B) after application of cellular glass ........................ 38 
Figure 31. Pyrogel XT Aerogel Insulated Test Section Temperature and Mass Flow Plot......... 39

Figure 32. Heat Loss (BTU/ft-hr)/ at the Inlet and Outlet of Pyrogel Test Section .................... 40

Figure 33. Gluten drying equipment in Marshall, MN.................................................... 41

Figure 34. Installation of Pyrogel XT on various sections of ductwork................................. 42

Figure 35. Depiction of pipe installation at ExxonMobil Port Jerome Gravenchon, including

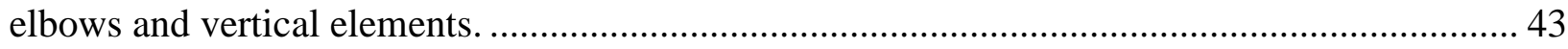

Figure 36. Installation site with pre-existing mineral wool insulation still on the pipe............. 44

Figure 37. Pyrogel installation on straight section............................................................ 44

Figure 38. Fitting a lobster tail elbow section on a $90^{\circ}$ elbow at Port Jerome........................... 44

Figure 39. Fitting a lobster tail elbow section on a $45^{\circ}$ elbow at Port Jerome........................... 45

Figure 40. Thermocouple placement on 8" pipe installation............................................... 45

Figure 41. Installation of Pyrogel XT on "bullet" tank at Port Jerome Refinery: a) full tank

image and b) close up of aerogel installation in progress................................................ 46

Figure 42. Workers installing Pyrogel XT on a bullet tank: a) top half, b) bottom half. ........... 46 Figure 43. PGXT valve cover installation (A) and glass mat valve covers (B) at Pastore Center in Providence, RI. ...................................................................................................... 47

Figure 44. Pyrometer reading and infrared imaging of glass mat valve cover ....................... 47

Figure 45. Pyrometer reading and infrared imaging of Pyrogel XT valve cover .................... 48

Figure 46. Measured thickness of in-use section of 1" glass mat shows the material compressed to $0.78 "$. 


\section{List of Tables}

Table 1. Status of performance requirements for second spriral of development .................... 14

Table 2. ASTM E84 Test Results ..................................................................................... 15

Table 3. ASTM E1559 water wicking results observed for Pyrogel XT................................. 20

Table 4. ASTM C795 results for Pyrogel XT (BLKT1205) ................................................ 21

Table 5. Test data and analysis from overwrap trial at Air Liquide. ....................................... 33

Table 6. Potential savings achieved with Pyrogel XT installation on $300 \mathrm{ft}$ pipe section.......... 36

Table 7. Predicted Performance of Insulation Materials Used at NS Newport ......................... 40

Table 8. Summary Table of Measured Insulation Performance at NS Newport ....................... 41

Table 9. Design calculations for insulation of 8" pipe at ExxonMobil, Port Jerome. ................ 43

Table 10 . Measured and calculated* (with 3EPlus) temperature of glass mat vs. Pyrogel XT

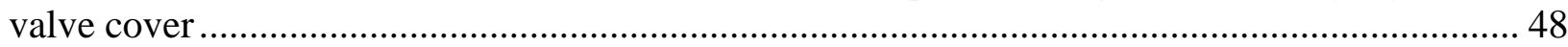




\section{Executive summary}

The innovations addressed in this project revolve around an aerogel-based thermal insulation system applied to industrial steam distribution systems. Thermal losses in this area in the US alone accounts for 977 trillion Btu/year, more than $1 \%$ of total domestic energy consumption. ${ }^{1}$ The successful deployment of this technology into the industrial marketplace could produce annual energy savings of 149 trillion Btu's by the year 2030.

Aspen Aerogels worked with DOE's Industrial Technologies program from 2006-2010 to specify, develop, scale-up, and deliver Pyrogel XT®, an aerogel-based pipe insulation (ABPI), to market to reduce the energy loss experience in industrial steam processing systems. The product developed has become Aspen's best selling flexible aerogel blanket insulation, with sales in excess of $20 \mathrm{MM}$ square feet of material as of the end of 2010. These sales of Pyrogel XT by Aspen have led to over 60 new jobs (mainly in manufacturing) since the project began. Additionally, and very importantly, this product has, so far, delivered more than an estimated 0.537 TBTU of energy savings to the nation based on industrial installations of Pyrogel XT. The commercial success is based on the value proposition for the Pyrogel XT product, that it delivers better thermal performance, improved durability, and faster installation times than the incumbent insulation materials used in industrial steam applications.

The project work was initiated by thoroughly defining the insulation product requirements for the targeted industrial steam line market. Then it validated which of the requirements were already met by the existing aerogel insulation material previously developed by Aspen Aerogels.

Subsequent work focused on improving the aerogel blanket insulation to withstand the hightemperature environment and provide excellent thermal performance at those conditions. Specifically, the aerogel insulation blanket fiber reinforcement material was optimized for performance and cost, the hydrophobic agents which prevent corrosion under insulation were modified, and the aerogel phase of the blanket was strengthened. In parallel to the product development, manufacturing throughput of Pyrogel was increased significantly through extensive optimization of the process steps of additive incorporation into the aerogel phase of the blanket, improvement in casting aerogel precursors into the fiber blanket substrate, and optimization of aerogel aging in the gelled blanket. Additionally, Aspen Aerogels developed complimentary aerogel products to offer a complete pipe insulation system. This was done by working with its partner, Sproule Manufacturing, which designed aerogel coverings for pipe elbows, pipe flanges, and small bore pipes which speed installation and ensure proper fit. Now a complete line of Pyrogel XT products is available to match most standard pipe sizes.

Finally, the product was demonstrated and documented at 5 facilities. The 3 industrial sites included Air Liquide (LaPorte, TX), ExxonMobil (Port Jerome, FRANCE), and Archer Daniels Midland (Marshall, MN); and the 2 government installations were the Pastore Center (Providence, RI) and Naval Station Newport (RI). These demonstrations validated Pyrogel XT's superior performance and cost savings relative to incumbent insulation materials.

This investment by DOE has paid back at least 30-fold in product sales to date, created dozens of U.S. manufacturing jobs, and contributed tens of millions of dollars of exports to the U.S. economy. 


\section{Introduction}

The overall goal of this project was to reduce domestic energy consumption and bolster US exports by developing a revolutionary thermal insulation material - aerogel - for industrial steam systems. This goal was pursued according to a three-pronged approach:

1. development of a set of performance objectives, and the formulation of a basic material architecture that would meet those objectives.

2. product improvements to meet the performance targets and process development reduce the cost of the base material to the point where it was economically competitive with the other players in the market.

3. commercial activities to achieve industry acceptance, including the development of complimentary products, literature and training materials, and conducting demonstration projects. Partners in these field demonstrations of aerogel insulation included Air Liquide, ProTherm, Sproule Manufacturing, ExxonMobil, Archer-Daniels Midland, and Newport Naval Station.

Aerogel, formed of intricate networks of nanoporous silica, possess the lowest thermal conductivity of any known solid. Although this material has been used everywhere from planetary spacecraft to particle accelerators, it is only recently that it has become cheap enough and strong enough to be considered for industrial applications. Industrial steam distribution systems loss energy via heat loss through pipes, valves, traps, and other line components. Thermal losses in this area alone accounts for 977 trillion Btu/year, more than $1 \%$ of total domestic energy consumption.

In 2006, Aspen Aerogels competitively won an R\&D award from the Department of Energy's Industrial Technologies Program to deliver an aerogel-based pipe insulation (ABPI) to market with the goal of reducing the energy loss in these systems. This work culminated in the development and commercial deployment of Pyrogel XT, Aspen Aerogels' best selling flexible aerogel blanket insulation. To date, this product has delivered more than 0.5 TBTU of energy savings to the nation. It is applied to pipes similarly to incumbent technologies such as mineral wool, fiberglass, calcium silicate, perlite, and various foams; however, Pyrogel XT delivers better thermal performance, improved durability, and faster installation times than the incumbents. The record-low thermal conductivity of aerogel, coupled with a strong geometric effect in systems with radial heat flow, enables the insulation to provide equal thermal resistance with 65-95 percent less material. Furthermore, the correspondingly smaller surface area loses less heat through radiation and convection, even at the same touch temperature (typically 120$\left.140^{\circ} \mathrm{F}\right)$.

Pyrogel XT relies on the same field-proven design architecture as existing pipe insulation products. It consists of one or more layers of insulating material applied to the hot pipe surface. These layers are sold in standard thickness increments of $5 \mathrm{~mm}$ and $10 \mathrm{~mm}$. The insulation is then encapsulated by a weather and abrasion resistant overwrap, and mechanically secured in place with circumferential fasteners. Tight fitting lap joints between adjacent parts prevents water infiltration and thermal shunting. In certain circumstances, mastic, caulk, or pressure-sensitive tape can be applied to the joint areas to increase the level of protection. However, Aspen's 
aerogel blankets are both durably hydrophobic, and water vapor permeable. This ensures that if water does penetrate the envelope, it will neither damage the insulation, nor get trapped inside.

The benefits of ABPI to the US industrial sector include:

- Reduced Energy Usage: Aerogel's low conductivity allows thinner insulation; thinner insulation provides less surface area; and less surface area reduces heat loss. For typical pipe insulation applications, the magnitude of this savings will range from $5-40 \%$, representing a considerable costs savings to the plant operator, and a reduction in domestic energy consumption estimated at 149 trillion Btu per year by 2030 .

- Lower Material Costs: Although aerogel is likely to remain more expensive per unit volume than fibrous products, its $30-90 \%$ lower conductivity means that far less material must be used for a given level of thermal protection. This means that aerogel is the lowcost solution for pipe diameters below 6".

- Lower Installation Costs: The combination of a thin material and high strain-to-failure means that aerogel can be rolled on-site to conform to all but the smallest pipe diameters. This enables a one-step installation process in which the aerogel is pre-bonded to the metal sheathing, and the integrated unit is snapped into place and secured. Labor savings from this aspect alone are typically to be in the range of $30-50 \%$.

- Smaller Logistical Footprint: Aspen's flexible blanket form of aerogel allows the material to ship as a flat stack or on a spool, as opposed to the industry standard of preformed annular parts nested in a box. Between that and its intrinsically lower material volume, ABPI requires considerably less shipping and subsequent handling on the jobsite. For example, on a 4 inch pipe requiring 2 inches of calcium silicate insulation, thirty pallets $(48 \times 48 \times 60$ inches) are required for every linear mile. Aerogel would provide the same level of thermal protection with just 4 pallets.

- Lower Total Cost-of-Ownership: Lower installation costs, lower shipping costs, and consistent thermal performance of the material of its lifecycle translate to lower cash outof-pocket for steam system operators wishing to upgrade their thermal protection. That, coupled with dramatic and enduring energy savings, has produced the type of total ownership-costs to garner the rapid and widespread adoption of Pyrogel XT.

- Long Term Water Resistance: Unlike calcium silicate, fiberglass, and some foams, Pyrogel XT is durably and strongly hydrophobic. In addition, its porous structure and vapor transmission characteristics allow it to dry out rapidly, even after prolonged submersion. This has been illustrated convincingly through performance testing performed during the execution of this project.

- Corrosion Under Insulation (CUI): Because of Pyrogel's ability to wick water away from hot pipes, the wet and warm conditions that often lead to corrosion can be prevented. Further, aerogel's chemical stability and composition ensure that it will not decompose into corrosive by-products. It may even be possible, later in the development stages, to dope the aerogel material with corrosion inhibitors like sodium silicate, making it an active defense against CUI.

- Passive Fire Protection: A variant of Pyrogel XT, Pyrogel XTF, can also be used for situations in which the thermal insulation must also act as passive fire proofing. Pyrogel XTF, which is artificially colored gray to make it visually distinct from Pyrogel XT, uses a slightly modified fibrous batting to maintain its structural integrity even during a severe, $2000^{\circ} \mathrm{F}$ fire event. 


\subsection{Energy Benefits, Economic Viability and Environmental Benefits}

Analysis of both the energy and economic benefits of ABPI are predicated on assumptions about the type and distribution of steam piping within US industry. As shown in Figure 1, the total pipe inventory was parsed into discrete bins according to diameter and steam temperature. This analysis is based on Aspen's and Protherm's estimates of relative prevalence, where the unit of measure is pipe length (in miles). This assumes that US steam systems are skewed strongly toward sub- 10 inch plumbing, and sub- $600^{\circ} \mathrm{F}$ steam temperatures.

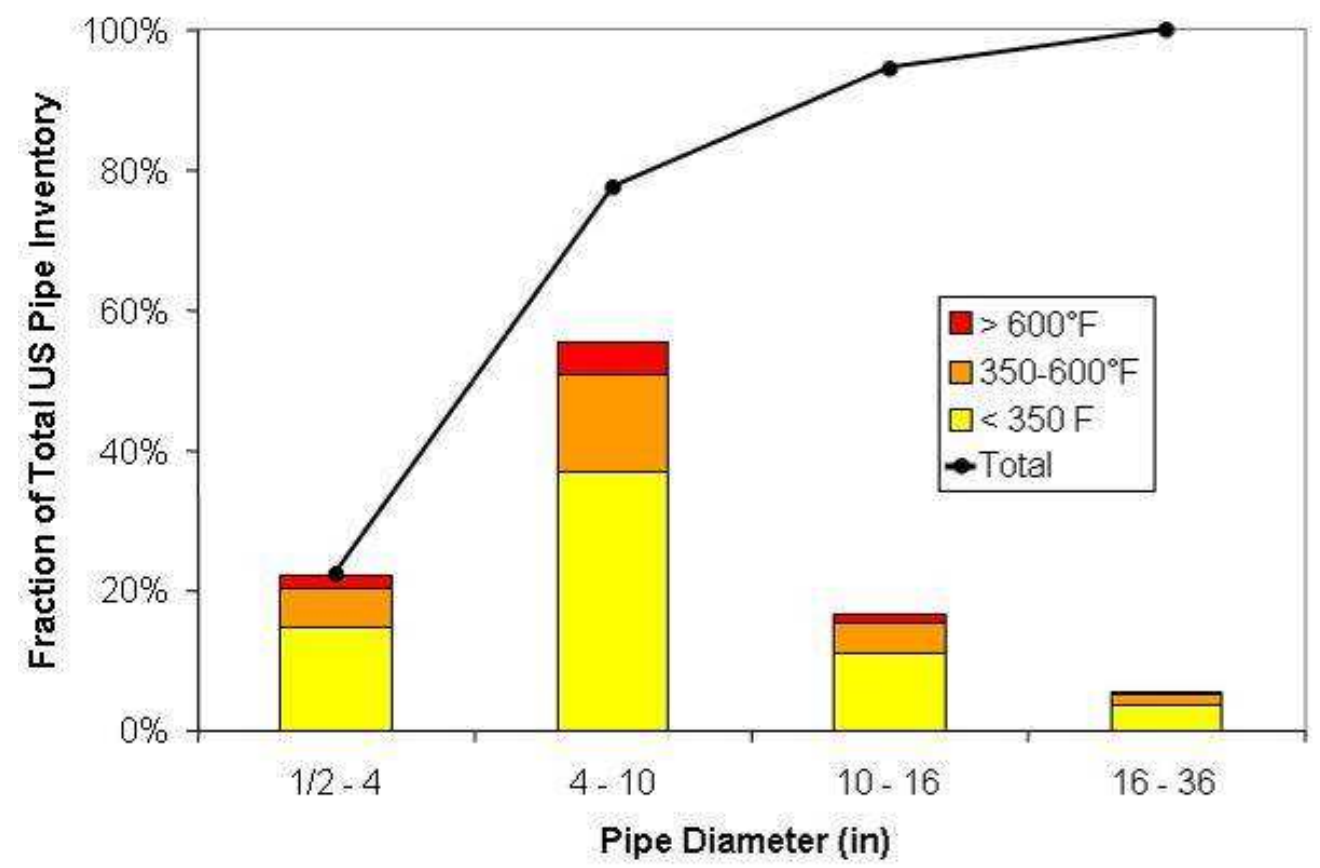

Figure 1. Estimated US industrial steam pipe population by diameter and temperature.

For each of the diameter-temperature bins, 3E Plus ${ }^{\circledR}$ software was used to calculate energy loss per unit length for calcium silicate, mineral wool, and aerogel-based pipe insulation. The calcium silicate and mineral wool values were averaged on the assumption that their aggregate energy performance (in a 50:50 ratio) is representative of the total industry, including fiberglass, perlite, and foams. Assuming line components are a negligible contributor, the incumbent heat loss per unit length was then integrated across diameter and temperature distributions, and set equal to the steam pipe energy losses (977 trillion Btu/year) called out in Ref. 2 . The result is an estimate of approximately 160,000 miles for the total length of steam piping in US industry. (Note that a completely different approach, based on the work in Ref. 3, arrived at a similar value, providing a reasonable level of confidence in the result.) This value was then divided up among the bins to enable detailed energy and economics calculations for each combination of diameter and temperature.

Market penetration was calculated by assuming that 80 percent of the overall steam pipe insulation market could be technically addressed by ABPI, and of that only 50 percent was likely to be captured. This yielded an asymptotic penetration of 40 percent.

\subsubsection{Energy Benefits}

Based on these heat loss and market penetration analyses, the annual reduction in industrial energy consumption was estimated. Aspen calculates that if aerogel insulation was applied to 
$40 \%$ of the 160,000 miles of U.S. industrial steam pipes, annual energy savings of 16 trillion British thermal units and energy cost savings of $\$ 117$ million could be achieved by 2025 .

\subsubsection{Environmental Benefits}

The primary environmental benefit of ABPI is the reduction in atmospheric emissions due to lower energy consumption in boilers. Using typical performance metrics for industrial boilers, cumulative savings of 3.5 million tonnes carbon equivalent $\mathrm{CO}_{2}$, and 85,000 metric tonnes of $\mathrm{SO}_{2}$ and NOx were calculated. Secondary benefits could be claimed from the manufacturing of aerogel instead of incumbent insulation materials, based solely on the fact that aerogel-based insulation requires one-third to one-tenth the material for a given application. All else being equal, less material produced means less waste generated both during production, and for end-oflife disposal. However, since little is known about incumbent manufacturing processes, all else may not be equal. So, for the purposes of this exercise, the net environmental impact from the manufacturing and solid waste side is conservatively assumed to be zero.

\subsection{Industry Involvement and Commercialization Plan}

At the start of the effort, the Aspen team developed a two-pronged commercialization plan to saturate the addressable pipe insulation market by the year 2030. As shown in Figure 2, the first component of this plan was to reduce material costs. Reduced costs would allow ABPI to compete in larger pipe diameters, where the geometric advantage of low conductivity is not as strong. So for example, ABPI entered the market in 2007 being competitive in pipes smaller than 6 inches, and temperatures under $350^{\circ} \mathrm{F}$ - only 18 percent of the total market (in units of pipe length). Within two years, however, the cost-reduction activities would swell the competitive segment of the market to 52 percent.

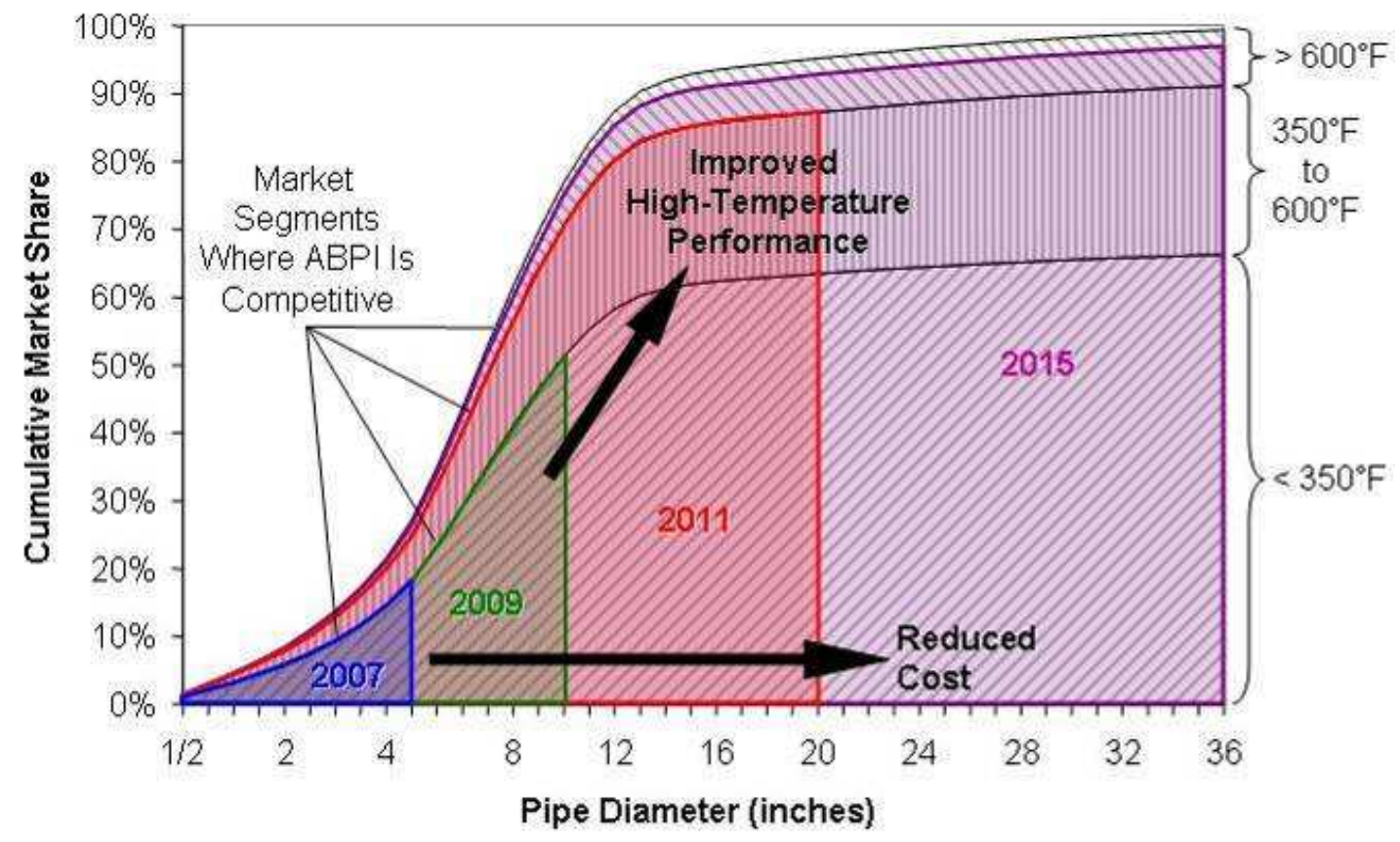

Figure 2. ABPI two-pronged market penetration strategy developed at the project start.

The other prong of the commercialization plan was to increase ABPI performance and durability at high temperatures. Aspen Aerogels had already made significant gains in this regard, and the work performed under this project solidified this position. 


\section{Background}

Little had changed in the industrial pipe insulation market in the last 40 years. Since the introduction of polyurethane foams in the 60's, no major new material systems have been widely adopted. Change has been incremental, and primarily relating to cost reduction. However, no real game-changing performance enhancements have been made in recent history. This is unfortunate, since thermal losses in US industrial steam systems waste the energy-equivalent of one supertanker every four days. ${ }^{45}$

Aspen Aerogels was founded in 2001 with the intent of commercializing its novel, patented aerogel blanket technology. Aspen's first commercial success was delivering aerogel insulation in subsea oil pipeline applications, and shortly thereafter the value of ABPI became apparent, as is described below.

Even with well-designed and -maintained insulation systems, thermal losses approaching $10 \%$ of the bare-pipe values are common. This is because most systems are designed not to minimize flux, but simply to reduce surface temperatures down to $120-140^{\circ} \mathrm{F}$, a safe so-called "touch" temperature. There is also an economic constraint in terms of the cost of insulation vs. the cost of heat loss, although that calculus may be changing as energy prices continue to increase. Annular pipe insulation (as opposed to flat panels or bricks) is particularly sensitive to this balance, because shielding cylindrical heat sources tends to be a process of diminishing returns. The ever expanding surface area renders each, incremental layer of insulation less effective than the last.

ABPI would alter the balance between insulation (capital) costs and energy (operations and maintenance, or O\&M) costs. To do this, ABPI would need to compete in three primary market areas: retrofit, repair, and new construction. The largest domestic market today is in retrofitting existing systems. This market is estimated to cover 160,000 linear miles of US industrial steam pipe, ranging from $1 / 2$ to 36 inches in diameter, and from 200 to $1200^{\circ} \mathrm{F}$. Since steam pipe insulation is typically replaced every 5-20 years, depending on severity of use, it is estimated that more than $5 \%$ of this market is in-play during any given year.

Repair is another area lacking good solutions, where ABPI was targeted. Characterized by smaller jobs and a more improvisational installation process, repair still represents a large market segment. In fact, it has been estimated that, at any given time, more than $20 \%$ of existing refinery pipe insulation is compromised. ${ }^{6}$ New construction can also be potentially significant, especially in the international market, but is more difficult to project out to 2030. Aerogel is expected to play heavily here, since the reduced insulation thickness would allow for tighter, more efficient pipe spacing when designed in from the beginning. 


\section{Results \& Discussion}

This chapter is organized according to the three major prongs of the project: 1) basic material development, 2) product improvements and cost reduction, and 3) industry acceptance. Each of these is described below.

\subsection{Material Development}

\subsubsection{System Requirements}

The development of materials for use in industrial steam systems required a detailed knowledge of the conditions that they would be exposed to as well as the testing requirements desired for material specification by the installer and the end user. The selected performance criteria are summarized in Table 1Error! Reference source not found..

Table 1. Status of performance requirements for second spriral of development

\begin{tabular}{|c|c|c|}
\hline Material Property & Compliance Verification & Target Performance \\
\hline \multicolumn{3}{|c|}{ Non-Combustibility and Fire Performance } \\
\hline Flame Spread Index & ASTM E84 & FSI $<50($ Class A $)$ \\
\hline Smoke Developed Index & ASTM E84 & SDI < 400 (Class A) \\
\hline Calorimetry & ASTM 1354 & informational \\
\hline $\begin{array}{l}\text { Method of test for determining the } \\
\text { non-combustibility performance }\end{array}$ & ISO 1182 & A 2 rating \\
\hline Toxicity & BSS 7239 & informational \\
\hline Rapid-Rise Hydrocarbon Fire & UL 1709 & $>30 \mathrm{~min}$ at $20 \mathrm{~mm}$ \\
\hline \multicolumn{3}{|c|}{ Dimensional Stability } \\
\hline Hot Surface Performance & ASTM C411 at $1200^{\circ} \mathrm{F}\left(650^{\circ} \mathrm{C}\right)$ & Pass \\
\hline Shrinkage at Max. Use Temp. & ASTM C356 & $<2.5 \%$ \\
\hline \multicolumn{3}{|c|}{ Water Permeability } \\
\hline Liquid Water Uptake & ASTM C1511 & No target \\
\hline Water Vapor Absorption & ASTM C1104 & No target \\
\hline Water Wicking & ASTM C1559 & No wicking \\
\hline \multicolumn{3}{|c|}{ Corrosion Performance } \\
\hline Leachable Ions & ASTM C871 & Pass \\
\hline \multicolumn{3}{|c|}{ Mechanical Resilience } \\
\hline Compressive Properties & ASTM C165 & No target \\
\hline Tensile Strength & ASTM D5034 & informational \\
\hline Thermal Conductivity & ASTM C177 & $<25 \mathrm{~mW} / \mathrm{m}-\mathrm{K}$ at $350^{\circ} \mathrm{F}\left(177^{\circ} \mathrm{C}\right)$ \\
\hline Fungal Resistance & ASTM C1338 & Resistant \\
\hline $\begin{array}{l}\text { Stress Corrosion Cracking of } \\
\text { Austenitic Stainless Steel }\end{array}$ & ASTM C795 & Compliant \\
\hline
\end{tabular}




\subsubsection{Fire Performance}

\subsubsection{ASTM E84 - Standard Test Method for Surface Burning Characteristics of Building Materials}

When specifying insulation materials for use in a petrochemical environment, it is not only important to assess combustibility, but material flammability as well. It is vitally important that an insulation material not propagate a flame when subject to a fire event. The traditional measure of flammability is afforded by ASTM E84 (or UL 723), also known as the Steiner Tunnel Test. This test method affords both a flame spread index (FSI) and a smoke developed index (SDI) for a specific material by subjecting a $1.5^{\prime} \times 24^{\prime}$ specimen to flaming fire for a duration of 10 minutes. Shown in Table 2 are the ASTM E84 results for Pyrogel XT in comparison to a number of other common insulation materials. Pyrogel XT exhibited no ignition and no subsequent flame spread for the duration of the test. The flammability performance of Pyrogel XT is in stark contrast to both mineral wool and glass fiber based insulation, which exhibit inferior flame spread indices due to the combustion of binder and/or thermoset resins. Clearly, the results from ASTM E84 and E1354 testing suggest that the use of Pyrogel XT in a petrochemical environment does not pose a significant flammability or combustibility risk when subjected to an intense fire event.

Table 2. ASTM E84 Test Results

\begin{tabular}{|l|c|c|}
\hline \multirow{2}{*}{\multicolumn{1}{|c|}{ Material }} & \multicolumn{2}{|c|}{ ASTM E84 Test Results } \\
\cline { 2 - 3 } & Flame Spread Index & Smoke Developed Index \\
\hline Mineral Wool Pipe Insulation $^{7}$ & 5 & 0 \\
\hline Perlite Pipe Insulation $^{8}$ & 0 & 0 \\
\hline Glass Fiber Pipe Insulation $^{9}$ & 25 & 50 \\
\hline Pyrogel XT Pipe Insulation & 0 & 5 \\
\hline
\end{tabular}

\subsubsection{ASTM E1354 - Standard Test Method for Heat and Visible Smoke Release Rates for Materials and Products Using an Oxygen Consumption Calorimeter}

Pyrogel XT was tested in accordance with ASTM E1354 at an incident heat flux equivalent to a cellulose fire $\left(50 \mathrm{~kW} / \mathrm{m}^{2}\right)$. The testing was performed in triplicate with no signs of ignition for all samples, resulting in a peak heat release rate of $14.0 \mathrm{~kW} / \mathrm{m}^{2}$ and effective heat of combustion of $730 \mathrm{~J} / \mathrm{g}$. Additional ASTM E1354 testing for Pyrogel XT was conducted at the lower incident heat fluxes of 10 and $25 \mathrm{~kW} / \mathrm{m}^{2}$. These heat fluxes were specifically chosen to understand the heat release characteristics of Pyrogel XT when exposed to heat fluxes consistent with a typical field install. The results of this testing revealed that Pyrogel XT exhibited no ignition and peak heat release rates of 1.4 and $5.3 \mathrm{~kW} / \mathrm{m}^{2}$ upon exposure to a heat flux of 10 and $25 \mathrm{~kW} / \mathrm{m}^{2}$. These heat release rates are mild, comparable to mineral or rock -wool type insulation materials, ${ }^{10}$ and consistent with the low fuel content of Pyrogel XT.

\subsubsection{ISO 1716 - Bomb Calorimetry}

The gross calorific potential of Pyrogel XT was determined by the methods outlined in ISO 1716 - Reaction to Fire Tests for Building Products, Heats of Combustion. This test specifically determines the potential maximum heat release of a material when burned completely in an oxygen atmosphere. The testing of five samples revealed that Pyrogel XT exhibits an average 
calorific potential of $1.82 \mathrm{MJ} / \mathrm{kg}$ (433 cal/gram). This value is consistent with other insulation materials that achieve a Euroclass Fire Rating of A1 - (Non-combustible).

\subsubsection{ISO 1182:1990 - Test for Non-Combustibility}

The non-combustibility of Pyrogel XT was assessed via the methods outlined in ISO1182. The mean duration of flaming, average specimen temperature and average furnace temperature for a representative sample of Pyrogel XT was $0 \mathrm{sec}, 32{ }^{\circ} \mathrm{C}$ and $27{ }^{\circ} \mathrm{C}$, respectively. This performance meets the criteria for non-combustibility as set forth in the 1990 edition of ISO1182 and is consistent with a Euroclass A2 Fire classification.

\subsubsection{BSS-7239:88 - Test Method for Toxic Gas Generation by Materials on Combustion}

Quantitative analysis of potential toxic combustion gases was determined for Pyrogel XT via Boeing Support Specification 7239. Specifically, representative production samples were exposed to flaming combustion conditions $\left(25 \mathrm{~kW} / \mathrm{m}^{2}\right)$ as dictated by ASTM E662. The levels of $\mathrm{CO}, \mathrm{HF}, \mathrm{HCl}, \mathrm{NO}_{\mathrm{x}}, \mathrm{SO}_{2}$ and $\mathrm{HCN}$ were determined via Drager colorimetric gas analyses. All of the gases were below the detection limits with the exception of $\mathrm{CO}$ and $\mathrm{NO}_{\mathrm{x}}$, which exhibited levels of 100 and $5.0 \mathrm{ppm}$, respectively. While no specific pass/fail criteria exists for BSS7239, the measured levels of $\mathrm{CO}$ and $\mathrm{NO}_{\mathrm{x}}$ are significantly below the accepted transportation industry standards of 3500 and 100 ppm, respectively.

\subsubsection{UL 1709 - Test Method for Rapid Rise Fire Tests of Protection Materials for Structural Steel}

A series of vertically-oriented carbon steel I-beams, pre-insulated with Pyrogel XT at a nominal thickness of $10,25,35$ and $50 \mathrm{~mm}$, were subjected to a simulated rapid-rise hydrocarbon pool fire $\left(2000^{\circ} \mathrm{F}, 204 \mathrm{~kW} / \mathrm{m}^{2}\right)$. The temperature rise of the steel surface was measured at various elevations along the I-beam. The time to failure was measured for each I-beam, with the failure point being defined as either an average steel surface temperature exceeding $1000^{\circ} \mathrm{F}$, or an individual thermocouple reaching $1200^{\circ} \mathrm{F}$.

Testing of Pyrogel XT has indicated that the fire endurance of this material is independent of material thickness with failure occurring within 30 minutes for all tests. Root cause analysis of this failure has indicated that the substandard fire-endurance behavior of Pyrogel XT is attributed to a gross material degradation (i.e. melting, slagging, shrinking) owing from the use of lowpurity silicate-based fiber reinforcements, known as E-glass.

During this project, work was done to shore up the fire endurance of Pyrogel XT with higher purity fiber reinforcements. This resulting series of sub-scale screening tests assessed four batting variants under consideration for use in Pyrogel XT. The tests were performed using the small scale UL 1709 test method. In this method, the material to be tested is applied to a structural steel tube with a 3/16 inch wall thickness. The steel tube is to be provided with steel caps and covered with the protective material being investigated. The four batting variants were each tested at a thickness of $40 \mathrm{~mm}$. All four variants showed significantly improved fire performance compared to the E-glass baseline, with each passing the 30 minute survivability threshold by up to 48 minutes. Sample results of this testing are shown in Figure 3. 


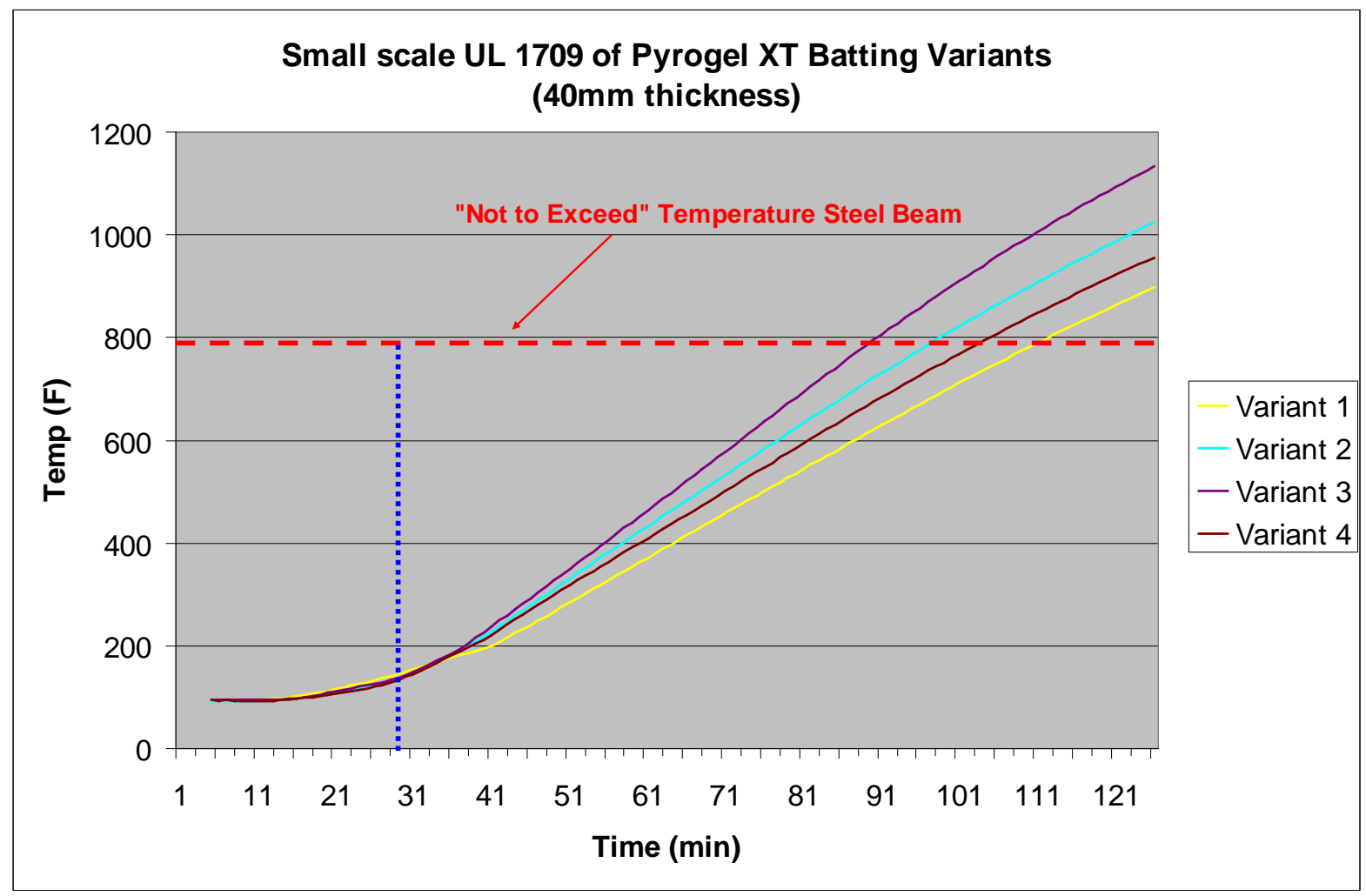

Figure 3. Test results from small scale UL 1709 screening tests performed in June, 2008.

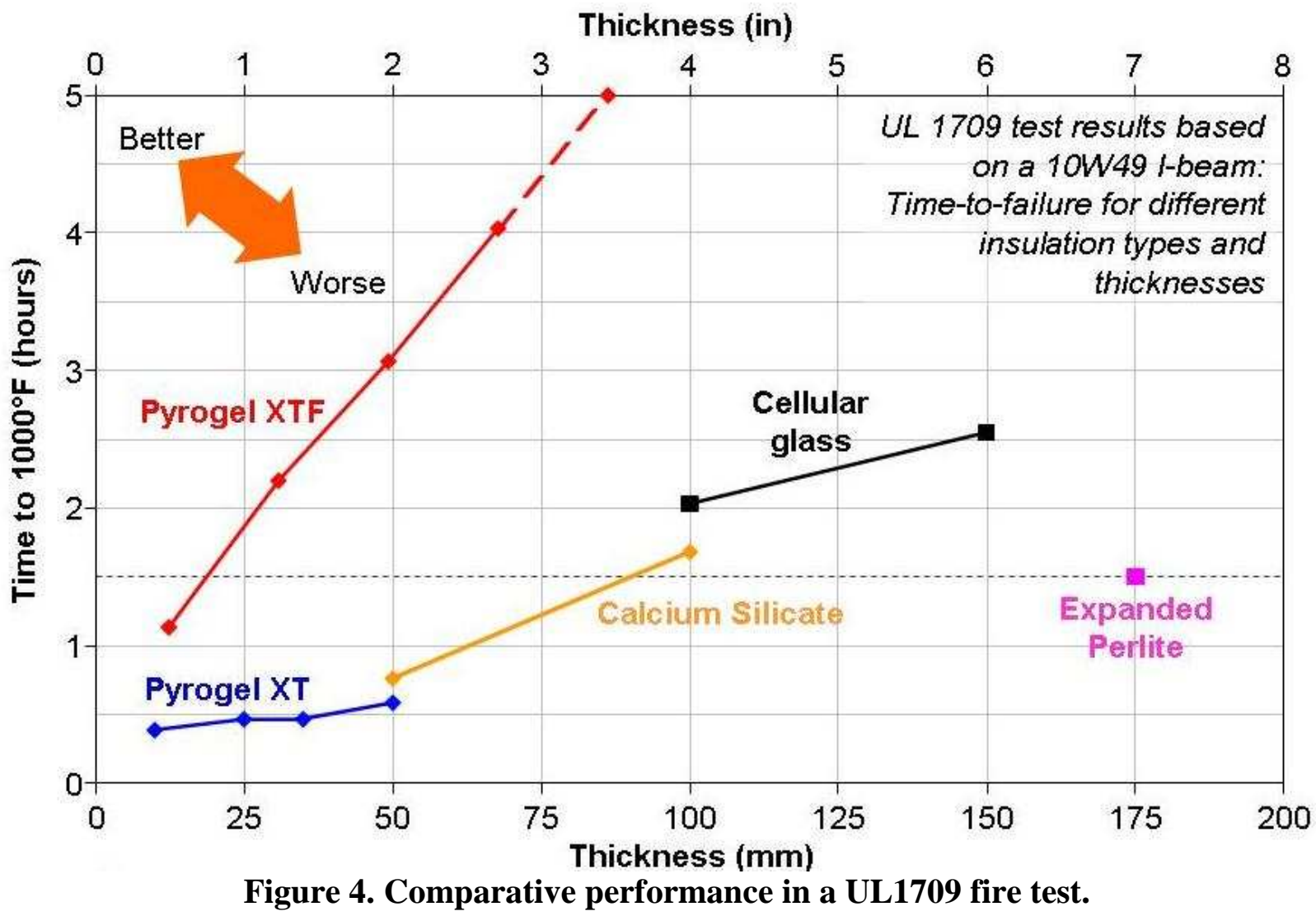




\subsubsection{Dimensional Stability}

\subsubsection{ASTM C411/C447 - Standard Test Method for Hot-Surface Performance of High-Temperature Thermal Insulation}

The installation of insulation material to equipment that is already in service at elevated temperature poses a significant risk for materials containing non-negligible quantities of organic materials. For instance, it is well-known across the insulation industry that binder decomposition in mineral- and rock-wool insulation products can result in an appreciable exothermic heat release upon hot installation. ${ }^{11-12}$ Pyrogel XT has been specifically developed with a minimal amount of organic content in order to simultaneously achieve water repellency and noncombustibility. Although the organic content has been kept at a minimum level, the exceptionally low thermal conductivity of Pyrogel XT could potentially increase the risk of exothermic behavior and thermal runaways during hot installation.

The hot surface performance of Pyrogel XT during hot installation has thus been assessed using the standard methods outlined in ASTM C447 and C411. Specifically, the thermal performance and the extent of thermal degradation were determined for 48 and $60 \mathrm{~mm}$ of Pyrogel XT upon application to a flat plate preheated at $1080^{\circ} \mathrm{F}$ and $1200^{\circ} \mathrm{F}$, respectively. The average midthickness and surface temperatures for each test as a function of time are shown respectively in Figure 5 and Figure 6. The average surface temperature observed during both tests was 43 and $115^{\circ} \mathrm{F}$, values that are well below the limits for personal protection and consistent with the low thermal conductivity of Pyrogel XT as determined by ASTM C177. The average mid-thickness temperature observed during hot installation at $1080^{\circ} \mathrm{F}$ was consistently measured at a value of $710^{\circ} \mathrm{F}$ with no signs of exothermic heat release, cracking, delamination or any other material degradation. A mild exotherm was observed for Pyrogel XT upon hot installation at $1200^{\circ} \mathrm{F}$. This exotherm was of short duration and intensity, localized to the interior of the specimen and never exceeded the process temperature for the duration of the test.

This behavior is in stark contrast to mineral wool type insulation materials which according to the Standard Specification of Mineral Fiber Pipe Insulation (ASTM C547) can exhibit internal temperature rises of up to $111^{\circ} \mathrm{C}\left(200^{\circ} \mathrm{F}\right)$ above process temperature when tested under identical conditions. It is also important to note that this testing was specifically conducted to ascertain the material behavior of Pyrogel XT when installed to equipment already in service (hotinstallation). Previous ASTM C411/C447 testing conducted under ambient conditions and ramped to a temperature of $1200^{\circ} \mathrm{F}$, has indicated that Pyrogel XT will not exhibit exothermic heat release, cracking, delamination or any signs of combustion. Cold installation of Pyrogel XT is thus a safe practice for any process intended to operate at temperatures below $1200^{\circ} \mathrm{F}$. 


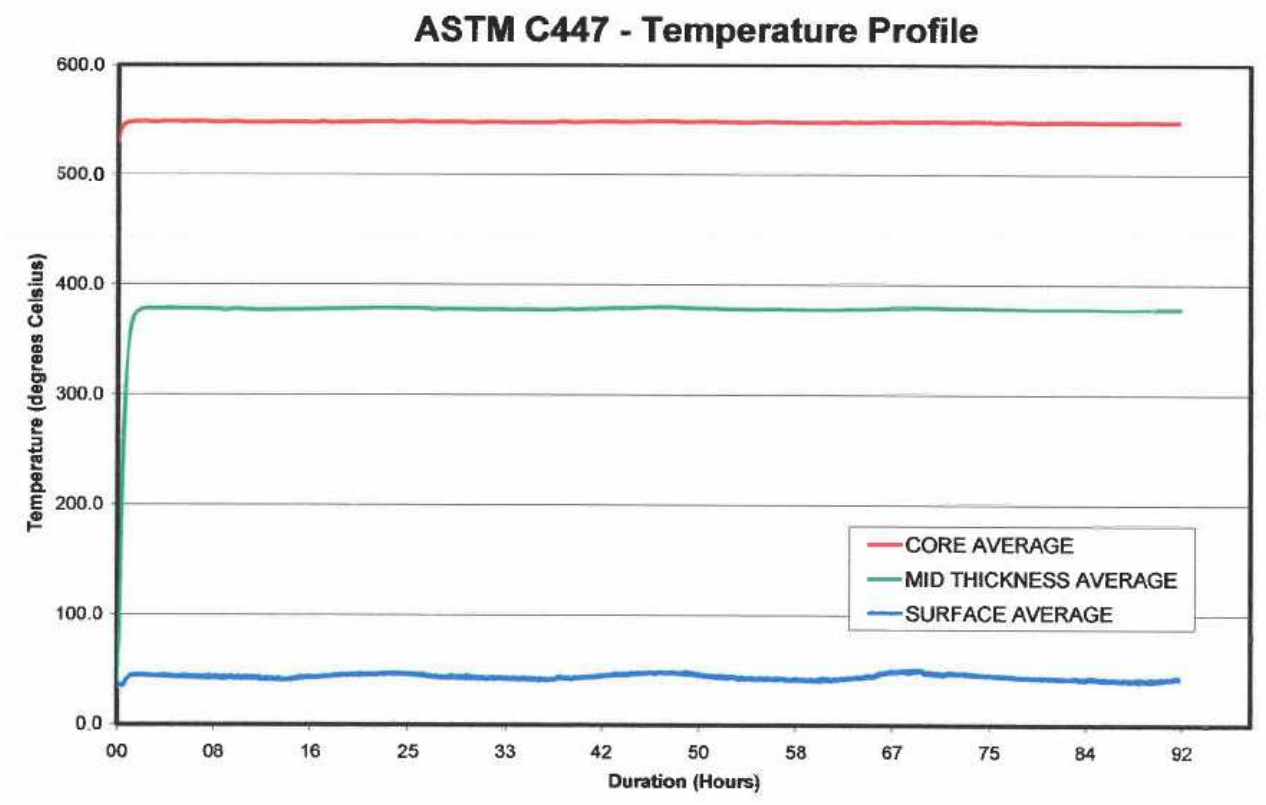

Figure 5. Average mid-thickness and surface temperatures of Pyrogel XT (48mm) upon hot-installation at a temperature of $1080{ }^{\circ} \mathrm{F}$.

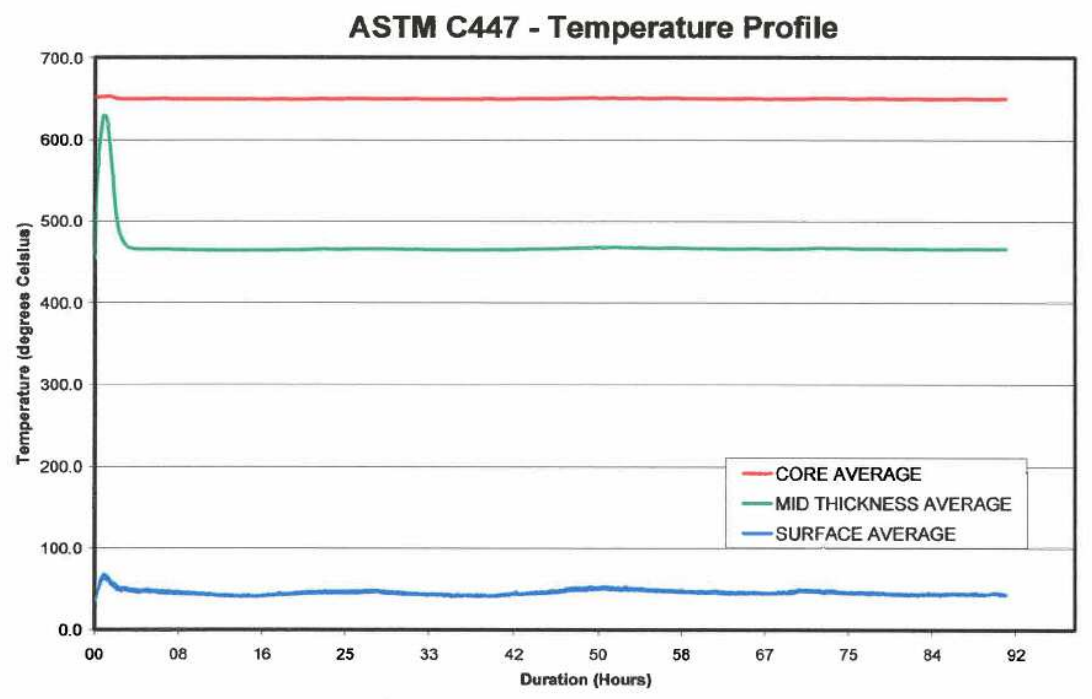

Figure 6. Average surface and mid-thickness temperatures as a function of time for Pyrogel XT (60 mm) when hot installed at a temperature of $1200{ }^{\circ} \mathrm{F}$.

\subsubsection{Water Resistance/Permeability}

\subsubsection{ASTM C1559 - Standard Test Method for Determining Wicking of Fibrous Glass Blanket Insulation (Aircraft Type)}

It is widely accepted that corrosion under insulation (CUI) is exacerbated by materials that readily wick and absorb water. We have thus subjected Pyrogel XT to test methods outlined in ASTM C1559-04 - The Standard Test Method for Determining Wicking of Glass Fiber Blanket Insulation. In this test, insulation materials measuring $125 \mathrm{~mm}$ in length are suspended in water and the distance that water wicks is measured over a period of $168 \mathrm{hrs}$ at a temperature of 68 and 
$122^{\circ} \mathrm{F}$. This wicking procedure is performed for as received samples, samples aged at $160{ }^{\circ} \mathrm{F}$ for $336 \mathrm{hrs}$ and samples leached in water for $24 \mathrm{hrs}$ and dried. Shown in Table 3 are the water wicking results (expressed as $\mathrm{mm}$ ) as a function of time for all three sample sets. In all cases the materials exhibit zero or negligible wicking $(<2 \%)$, consistent with the highly hydrophobic nature of Pyrogel XT.

Table 3. ASTM E1559 water wicking results observed for Pyrogel XT.

\begin{tabular}{ccccccc}
\hline \multirow{2}{*}{$\begin{array}{c}\text { Duration } \\
\text { (hours) }\end{array}$} & \multicolumn{6}{c}{ Max Height (mm) } \\
\cline { 2 - 7 } & $\mathbf{2 0}{ }^{\circ} \mathbf{C}$ & $\mathbf{5 0}{ }^{\circ} \mathbf{C}$ & $\mathbf{2 0}{ }^{\circ} \mathbf{C}$ & $\mathbf{5 0}{ }^{\circ} \mathbf{C}$ & $\mathbf{2 0}{ }^{\circ} \mathbf{C}$ & $\mathbf{5 0}{ }^{\circ} \mathbf{C}$ \\
\hline 24 & 0 & 0 & 0 & 1 & 0 & 0 \\
48 & 0 & 0 & 0 & 1 & 0 & 0 \\
72 & 0 & 0 & 0 & 1 & 0 & 1 \\
96 & 0 & 0 & 0 & 1 & 0 & 1 \\
168 & 0 & 0 & 0 & 2 & 0 & 1 \\
\hline
\end{tabular}

\subsubsection{ASTM E1338 - Standard Test Method for Determining Fungi Resistance of Insulation Materials and Facings}

Any insulation material that is periodically exposed to conditions of high humidity is subject to detrimental fungal growth during long-term use. In order to ascertain the propensity of Pyrogel XT to support fungal growth, samples were tested according to the methods outlined in ASTM E1338 - The Standard Test Method to Determine the Fungal Resistance of Insulation Materials and Facings. Specifically, triplicate samples of Pyrogel XT were exposed to an inoculum of various fungi. Materials were incubated at $86^{\circ} \mathrm{F}$ for 4 weeks and examined weekly to assess the extent of any fungal growth. Materials were then assigned a value of 0 to 4 depending on the extent of fungal growth relative to a positive control sample. In all three cases, Pyrogel XT was assigned a value of zero, indicating the complete absence of any fungal growth when tested according to this standard. This behavior is consistent with the high water repellency and relatively low organic content of this material.

\subsubsection{Corrosion Performance}

\subsubsection{ASTM C795 - Standard Specification for Thermal Insulation for Use in Contact with Austenitic Stainless Stee1}

Aspen Aerogels optimized the compatibility of Pyrogel XT with austenitic stainless steel. Specifically, we evaluated formulations and processes aimed at achieving compliance with ASTM C795, the "Standard Specification for Thermal Insulation for Use in Contact with Austenitic Stainless Steel". This standard involves two sets of distinct testing:

1. Measurement of extractable $\mathrm{pH}$, sodium, silicate, chloride, and fluoride according to ASTM C871 and...

2. 28-day corrosion testing of material according to ASTM C692.

The formulation for Pyrogel XT has been specifically modified to consistently afford alkaline extractable $\mathrm{pH}$ values. This was achieved via the incorporation of an insoluble additive possessing high isolectronic points (IEP) at loadings less than $1 \mathrm{wt} \%$. The use of this additive 
has been shown to consistently afford extractable $\mathrm{pH}$ values in excess of 8.0 with no detrimental impact to key material properties and product yield. Although the mechanism for chlorideinduced stress corrosion cracking of austenitic stainless steel is not completely understood, it has been shown that crack initiation time (time to corrosion) and crack frequency are highly $\mathrm{pH}$ dependent $^{13}$. It is thus reasonable to assume that thermal insulation materials exhibiting alkaline extractable $\mathrm{pH}$ values and low levels of chloride, such as Pyrogel XT, will perform well when tested according to ASTM C692, "Standard Test Method for Evaluating the Influence of Thermal Insulations on External Stress Corrosion Cracking Tendency of Austenitic Stainless Steel". Aspen thus assessed the stainless steel corrosion performance of Pyrogel XT according to the methods outlined in ASTM C795 and ASTM C692. Specifically, four sets of Pyrogel XT coupons were fitted over sensitized coupons of 304 grade stainless steel that were stressed at fixed tension in a U-configuration (Figure 7). After subjecting the aerogel coupons to a constant flow of deionized water for 28 days, the stainless steel coupons were examined macro- and microscopically for any evidence of corrosion.

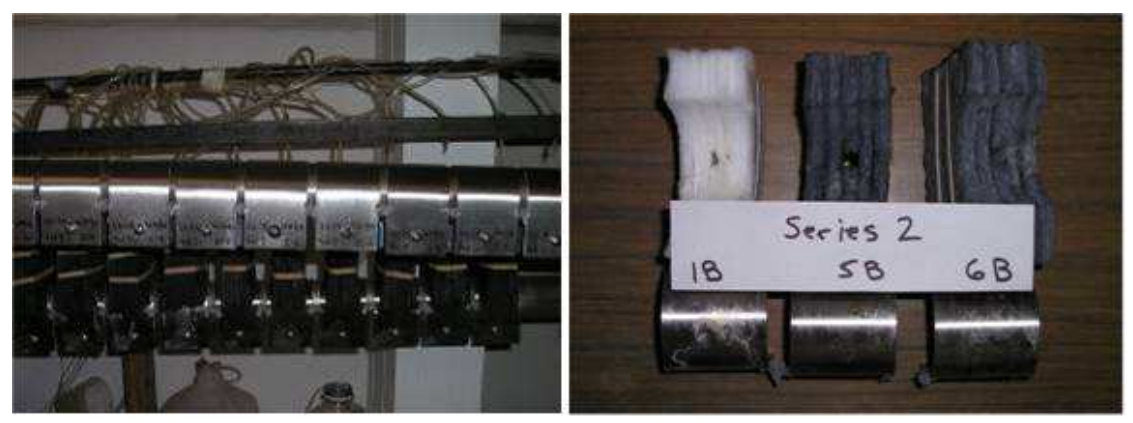

Figure 7. A photograph depicting the apparatus (left) and aerogel coupons (right) used to assess ASTM C692 performance.

Shown in Table 4 are the ASTM C692 results for Pyrogel XT in conjunction with ASTM C871 results for the same lot of material. Because the extractable ions and $\mathrm{pH}$ for Pyrogel XT fall well within the chemical requirements for ASTM C795 and there was no evidence of corrosion after 28 days when tested to ASTM C692, it is evident that this insulation material is optimized for compatibility with austenitic stainless steel and that Pyrogel XT is compliant with ASTM C795.

Table 4. ASTM C795 results for Pyrogel XT (BLKT1205)

\begin{tabular}{ccccccc}
\hline \multicolumn{5}{c}{ ASTM C871 Results } & C \\
\cline { 1 - 4 } Sodium & Silicate & Chloride & Fluoride & pH & ASTM C692 Results \\
\hline 41 & 7349 & 33 & 9 & 8.8 & $\begin{array}{c}\text { No signs of stress } \\
\text { corrosion cracking } \\
\text { were observed for all } \\
\text { four coupons }\end{array}$ \\
\hline
\end{tabular}

\subsubsection{Other Testing}

\subsubsection{System Level Testing of Pyrogel XT with Alkaline Modifiers.}

Aspen Aerogels performed extensive system level testing to assess long-term durability of the hydrophobe additive, and to assess any changes in material $\mathrm{pH}$ after being in service for extended durations. Utilizing a heated pipe rig developed specifically for this project, Aspen 
Aerogels conducted two system level tests of Pyrogel XT at 500 and $400{ }^{\circ} \mathrm{C}$ at a nominal thickness of 40 and $30 \mathrm{~mm}$, respectively. Shown in Figure 8 and Figure 9 are the interply temperatures as a function of time for both system level tests. Remarkably, the cold face temperatures for all pipe rigs remained absolutely stable throughout the 68 day exposure period, indicating that no loss in system-level thermal performance has occurred. Additionally, the interply temperatures experienced little to no change over the course of the experiment, indicating the absence of any gross material degradation. This testing clearly suggests that the long-term thermal performance of Pyrogel XT is robust to temperatures up to $500{ }^{\circ} \mathrm{C}$.

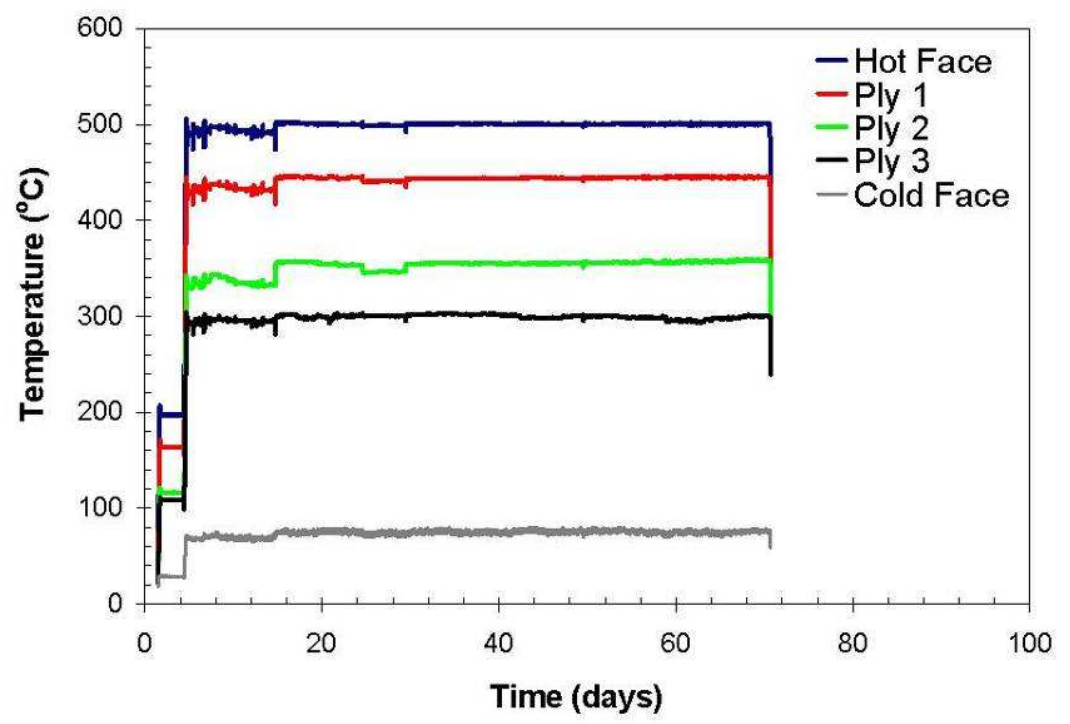

Figure 8. Interply temperatures as a function of time for Pyrogel XT $\left(5_{00}^{\circ} \mathrm{C}, 40 \mathrm{~mm}\right)$

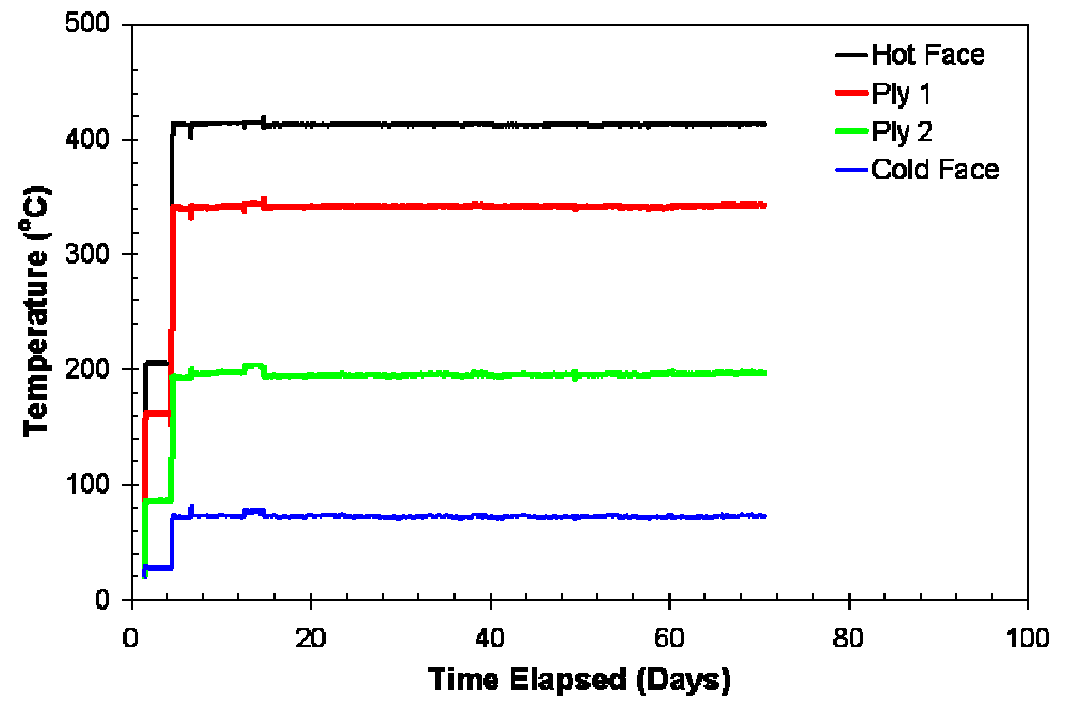

Figure 9. Interply temperatures as a function of time for Pyrogel XT (400C, 30mm)

\subsubsection{Hydrophobe Durability of Materials - Post Testing}

In order to prevent the occurrence of corrosion under insulation (CUI), it is imperative that thermal insulation material exhibit little to no water wicking or absorption while in use. Although CUI is most evident in equipment operating at temperatures from 0 to $150{ }^{\circ} \mathrm{C}$, the 
occurrence of periodic shutdowns due to scheduled maintenance suggests that higher temperature applications could also be susceptible to water absorption and subsequent CUI issues. Aspen Aerogels has thus completed a water repellency assessment of Pyrogel XT material (containing corrosion mitigants) sampled from long-term system level pipe testing. Specifically, the water repellency of samples after 68-day testing at 400 and $500{ }^{\circ} \mathrm{C}$ were assessed on a per-ply basis using the test methods outlined in ASTM C1511. Specifically, water uptake values were determined after submersing samples in 6" of deionized water for a period of 15 minutes. Shown in Error! Reference source not found. are the determined water uptake values as a function of ply number and mean exposure temperature. It is evident from this data, that Pyrogel XT exhibits long-term hydrophobe durability at or below a mean temperature of 300 ${ }^{\circ} \mathrm{C}(572 \mathrm{~F})$. All plies exposed to a mean temperature at or below $300{ }^{\circ} \mathrm{C}$ exhibited minimal water uptake.

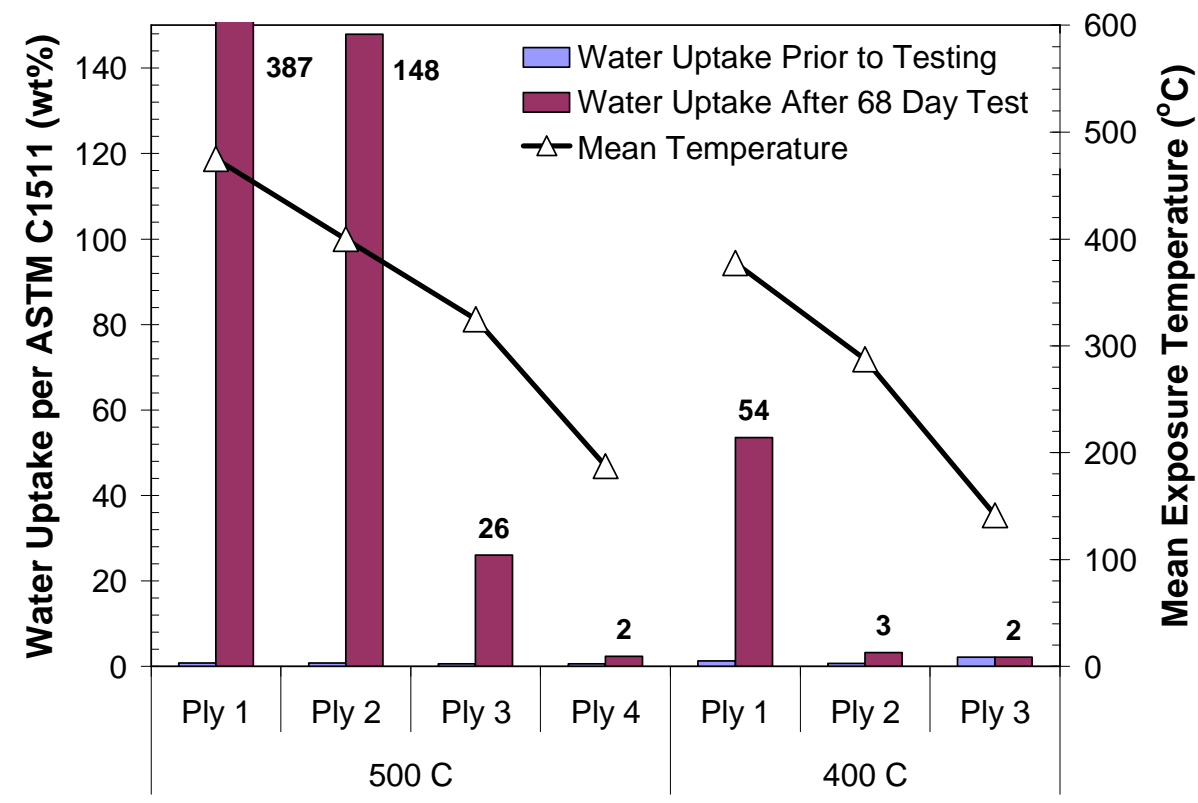

Figure 10. Water repellency of material as a function of ply number and mean exposure temperature after 68-day testing.

The extractable $\mathrm{pH}$ of Pyrogel XT after being in service for a significant period of time was determined according to the methods outlined in ASTM C871. Shown in Figure 11 are the extractable $\mathrm{pH}$ values as a function of mean temperature exposure for Pyrogel XT after longterm system level testing for 68 days. Interestingly, all plies with the exception of the outer ply (at $500{ }^{\circ} \mathrm{C}$ pipe temperature) exhibited $\mathrm{pH}$ values nearly identical to those observed for pristine material (>8.0). At face value, the lower $\mathrm{pH}$ for the outer ply during $500^{\circ} \mathrm{C}$ pipe testing may seem somewhat surprising. However, Aspen Aerogels experience has shown that the salt byproducts (ammonium phosphate and sulfate) of aerogel manufacturing thermally decompose at temperatures in excess of $250{ }^{\circ} \mathrm{C}$. This decomposition usually occurs via loss of ammonia to produce minute quantities of the parent acids (orthophosphoric and sulfuric acid) originally used during aerogel precursor sol preparation. Shown in Figure 12 are the phosphate and sulfate content (as determined via ion chromatography) as a function of ply number for both systemlevel tests. While the sulfate content remained essentially constant for each test, a steady increase in phosphate content was observed, increasing from inner to outer plies. One may thus surmise that due to the increased volatility of orthophosphoric acid (relative to sulfuric) that the 
products of this thermal decomposition essentially condense on the underside of the jacketing material, resulting in the accumulation of small amounts of phosphorous oxides on the outer plies for both tests. It appears that the levels of these acidic contaminants are highly dependent on both the volume of material installed and the temperature of exposure. Clearly for the case of the $500{ }^{\circ} \mathrm{C}$ system level test, the levels of phosphorous oxides accumulated under the jacketing exceeded the buffering capacity of the insoluble corrosion mitigant, resulting in a substandard extractable $\mathrm{pH}$ value for this outer ply.

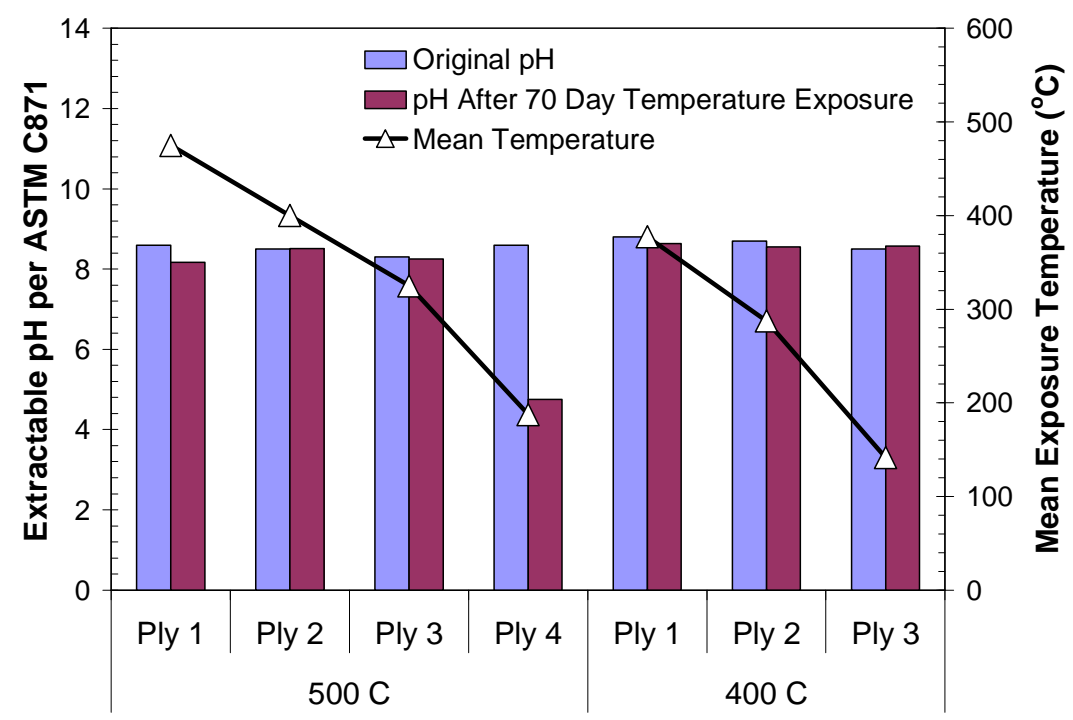

Figure 11. Extractable pH as a function of ply number and mean exposure temperature after 68 day testing.

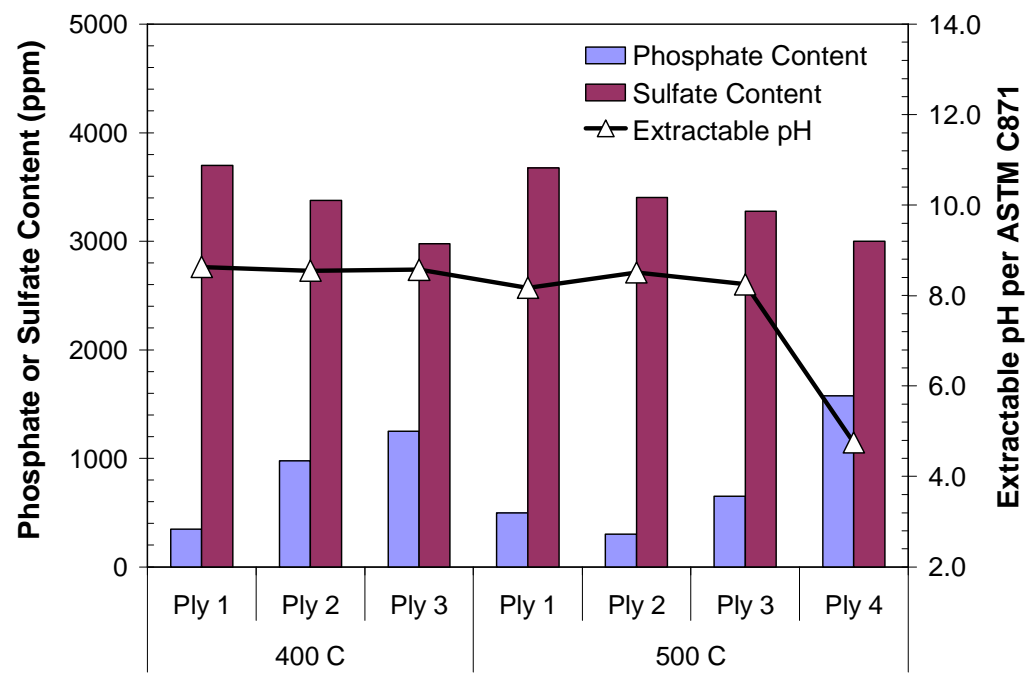

Figure 12. Extractable anion content as a function of ply number and its relation to extractable $\mathbf{p H}$ values. 
Illustrated in Figure 13 are the changes in ambient thermal conductivity values for Pyrogel XT materials before and after long-term system level testing at $400{ }^{\circ} \mathrm{C}$ and $500{ }^{\circ} \mathrm{C}$. Materials that are subject to mean temperatures greater than $300{ }^{\circ} \mathrm{C}$ appear to exhibit a slight increase in thermal conductivity after exposure to high temperatures. This increase is likely attributed to a partial degradation of hydrophobe and a concurrent increase in water uptake values. Long term exposure of the thermal insulation system at $400{ }^{\circ} \mathrm{C}$ appeared to have little overall effect on the ambient thermal conductivity values. This suggests that these materials will retain long-term thermal performance in field applications. It also suggests that Pyrogel XT retains sufficient hydrophobicity at these exposure temperatures to prevent catastrophic water ingress and collapse of the aerogel pore morphology.

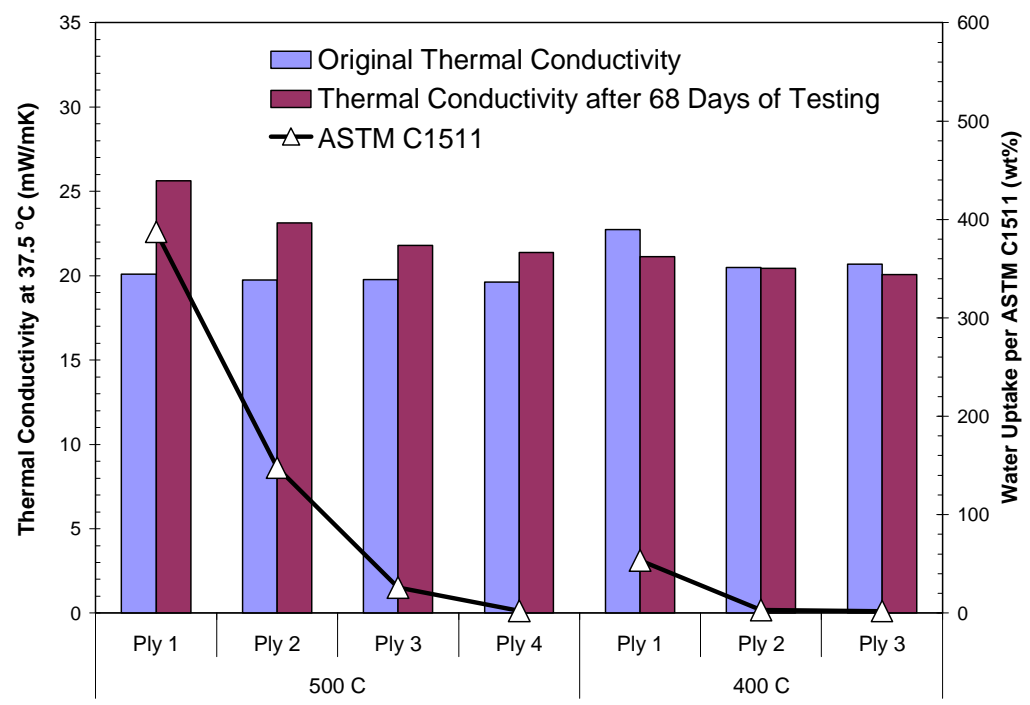

Figure 13. Thermal conductivity $\left(37.5^{\circ} \mathrm{C}, 1 \mathrm{~atm}\right)$ and water repellency as a function of ply number after 68-day testing.

\subsection{Product Improvement and Cost Reduction Activities}

\subsubsection{Hydrophobe Retention}

Aspen Aerogels also focused on the further improvement of yield during production of Pyrogel XT. Yield loss from earlier production runs were originally attributed to inadequate hydrophobe retention, attributed to an unforseen extraction of hydrophobe from the wet gel structure upon exposure to compressive and tensile stresses caused by exposure to super critical $\mathrm{CO}^{2}$ during the manufacturing process. Minor modifications in the gel formulation significantly improved the hydrophobe retention for early production runs of Pyrogel XT and resulted in a moderate improvement in product yield. It was observed, however, that portions of an aerogel blanket subjected to non-ideal aging conditions could exhibit reduced hydrophobicity upon extraction. This situation is particularly important for materials located in the inner portion of a production roll, as these materials are subject to reduced or restricted aging flows. Demonstration of this on the laboratory scale is exemplified by the data shown in Figure 14 which summarizes the influence of aging chemistry (water content) on the material outcomes for Pyrogel XT. This data clearly shows that mild excursions in water content can result in drastic decreases in water repellency. Further laboratory testing has also revealed similar dependencies on time, temperature and $\mathrm{pH}$. Specifically, conditions that promote silanol condensation reactions and consolidation of the gel structure lead to robust hydrophobic properties. Any deviations from 
these ideal aging conditions will eventually lead to diminished hydrophobicity. This situation unfortunately necessitates the constant use of a high purity alcohol source and excessively long aging times ( $>18$ hours), conditions that are not achievable using the current manufacturing process for Pyrogel XT. In order to enable large scale manufacture of Pyrogel XT, a supplemental hydrophobe agent is instead added during the aging process. While the use of this agent eliminates most of the aging sensitivities of the baseline chemistry, it does present some notable disadvantages. The use of a hydrophobe additive external to the gel not only adds cost to the product, but it also necessitates the implementation of strict quality controls and careful monitoring of aging chemistry in order to ensure that the overall organic content of Pyrogel XT does not exceed specifications. Efficient grafting of this external reagent is also time dependent, necessitating a minimum aging time of 14 hours to produce product in high yield. Aspen Aerogels identified chemical remedies that are capable of imparting hydrophobic properties to Pyrogel XT when aged under conditions that deviate from the ideal (elevated water, low temperature, reduced $\mathrm{pH}$ ).

Aspen Aerogels has fortunately discovered that modification of the hydrophobe agent in Pyrogel XT to improve conformational flexibility will eliminate any sensitivity to aging chemistry. Specifically, substitution of the current hydrophobe agent with a low-cost plasticizer at levels as low as $10 \%$ can allow for the production of hydrophobic Pyrogel XT materials when subject to aging conditions that deviate significantly from the ideal (Figure 15). For instance, highly hydrophobic materials were obtained in 8 hours at lower than normal aging temperatures $\left(45^{\circ} \mathrm{C}\right)$. This modification has been shown to completely eliminate the need for an external hydrophobe agent and extended aging times.

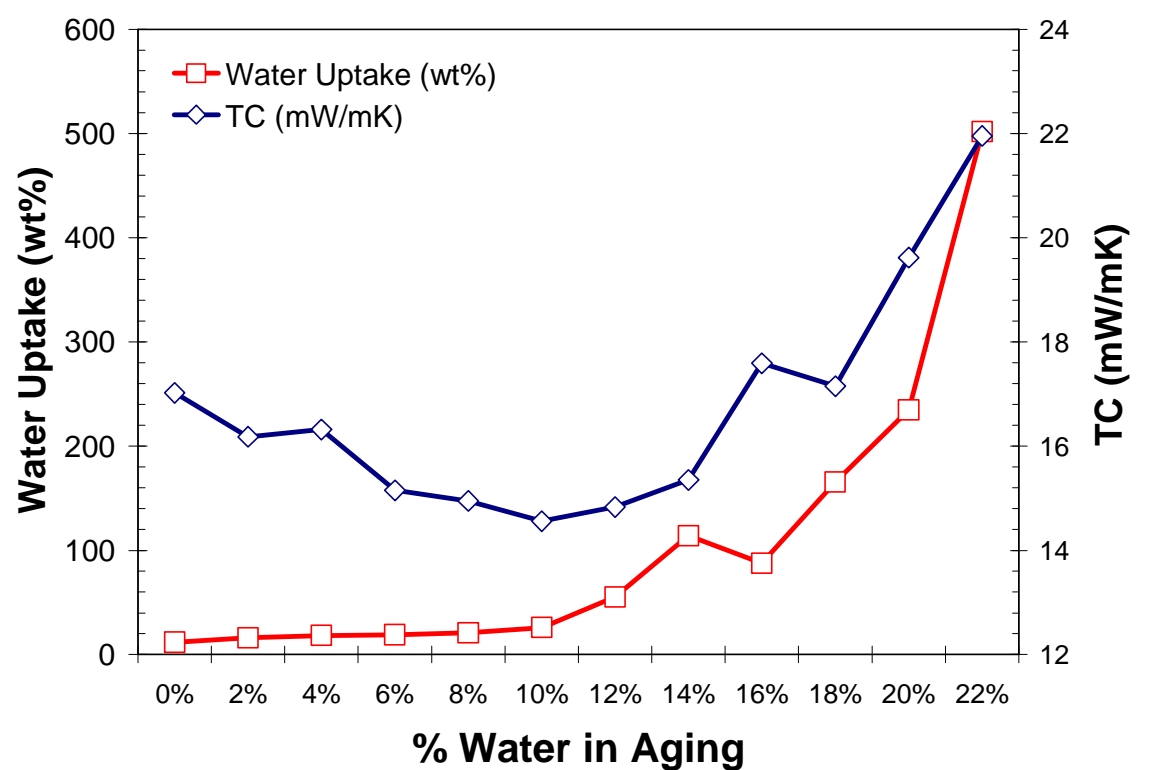

Figure 14. Hydrophobicity (water uptake) and thermal conductivity (Tc) of Pyrogel XT (laboratory prepared) as a function of water content in aging. 


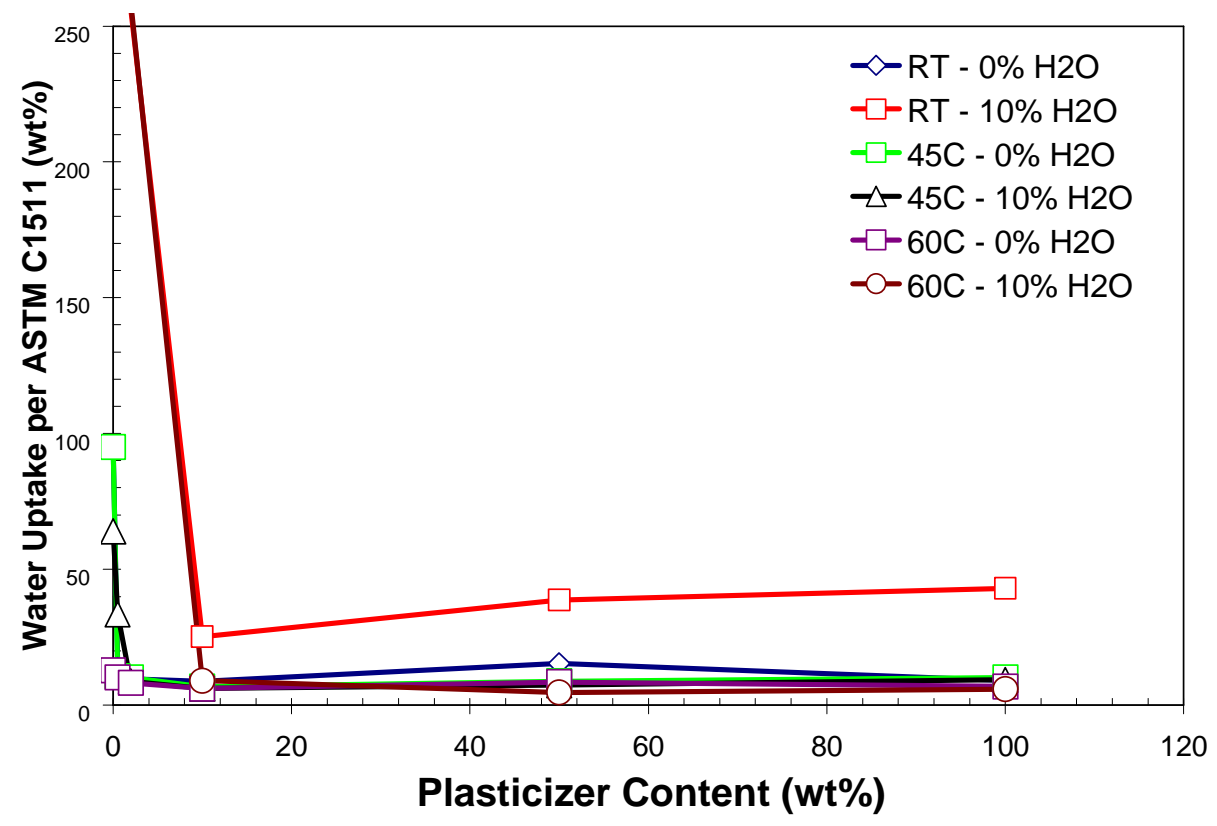

Figure 15. Improvements in hydrophobicity for Pyrogel XT as a function of hydrophobe plasticizer content.

\subsubsection{Fiber Reinforcement}

At the outset of this project, Aspen's standard aerogel products used organic fiber reinforcement stable to $390{ }^{\circ} \mathrm{F}$. To go beyond this point, Aspen employed both carbon felt and quartz fibers. These battings exhibit low density and good mechanical properties, but are generally too expensive to achieve broad penetration of the pipe insulation market. To produce low-cost, hightemperature aerogels, Aspen successfully investigated and adopted low-cost 100\% fiberglass (eglass) batt material and eliminated more expensive carbon fiber from the Pyrogel XT product.

\subsubsection{Lattice Strength at High Temperatures}

Resistance to moisture and thermal cycling can also be obtained by increasing the strength of the aerogel cell structure. Stronger aerogels have been prepared by aging the gels in solutions containing additional silica sources. During aging, these sources deposit silica in the necks between particles and act as cement that strengthens the aerogel structure. We also investigated this approach for preparing thermally stable, moisture-resistant aerogels. Stronger aerogels also experience less shrinkage during aging and drying, allow us to produce products with the desired density. Being able to prepare aerogels with minimal shrinkage during processing also reduces volumetric costs. During this task Aspen developed processes to introduce these materials resulting in improvements in both product performance and manufacturing cycle time.

\subsubsection{Manufacturing Process Scale Up}

Aspen Aerogels' plant operations team concentrated on improving the throughput rate of Pyrogel $\mathrm{XT}$ in the manufacturing plant, consistent with Figure 16. These efforts were focused in the following areas. 


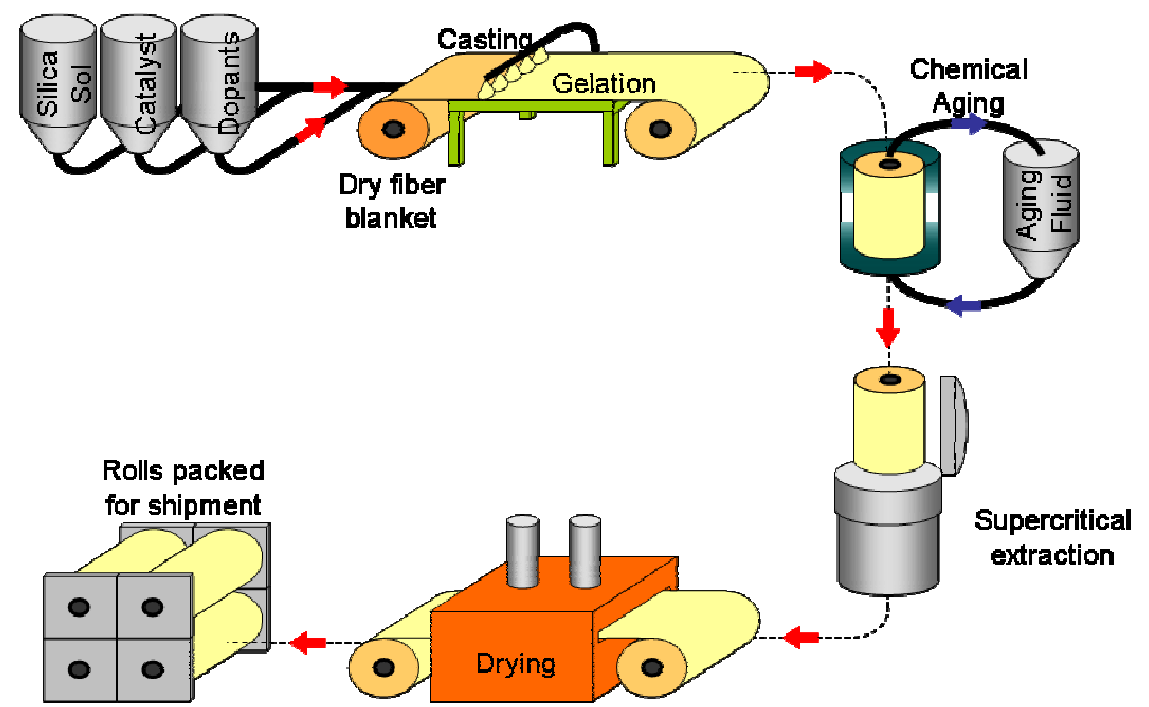

Figure 16. Aspen Aerogels' current flexible blanket manufacturing process.

\subsubsection{Installation of Unit Operation for Pyrogel XT Additive during Casting}

Pyrogel XT requires a combination of several proprietary additives during the blanket casting process. These additives are received in solid form and must be blended in alcohol solvent prior to being precisely metered to the casting operation. The additive stream contributes to the thermal performance of the XT materials, specifically by metering in additives to the casting process that improving insulation performance via infrared radiation and mitigating loss of performance at elevated temperatures.

A new unit operation was installed to receive the solid additives and the blending solvent, disperse the solids kinetically in the fluid, and meter this stream accurately to the casting line. The system consists of a process vessel to contain the fluid plus additives; a solids addition station by which the additives may be weighed and added to the vessel; an alcohol solvent receiving station in which a prescribed amount of solvent may be metered into the tank; and a discharge station through which the blended additive plus solvent stream may be metered to casting. The process vessel has a specially designed high shear agitator and is fully instrumented and automated to allow operation via the plant distributed control system.

\subsubsection{Blanket Casting Optimization}

Aspen Aerogels' aerogel blanket may be considered a fiber reinforced aerogel composite, i.e. a silica aerogel which is structurally reinforced by fibrous batting. To create this aerogel composite, the free flowing silica containing sol plus additive mixture coats and impregnates the fibrous batting, and after a prescribed time period the catalyzed sol increases in viscosity and forms a gel composite, referred to as an alcogel blanket. This occurs during the casting operation. The alcogel blanket travels through the manufacturing process and is turned into an aerogel blanket when the liquid solvent is removed via supercritical carbon dioxide during the extraction operation. It is important for product yield that the silica sol thoroughly impregnates the fibrous batting, thereby ensuring uniformity within the aerogel blanket. This is particularly significant for high temperature materials such as Pyrogel XT.

Aspen's engineers improved the rate at which the casting process produces alcogel blankets to ensure that there is no loss in product quality as the line speed of the casting process increases. 
This is a highly iterative exercise, as the team runs a number of blankets at the greater line speed with the necessary improvements in fluid flow profiles and impregnation; then observes the results of the finished aerogel blanket in terms of thermal performance, product form factor etc; and finally evaluates the success of these casting modifications. This process continues until the casting operation may be run at a higher rate without negatively affecting product performance. Aspen was able to increase the rate of blanket casting by $12 \%$.

\subsubsection{Increasing Throughput of Pyrogel XT in Aging}

The operations group has focused on reducing the cycle time necessary for aging of Pyrogel XT material. This has involved conducting numerous production scale trials using Design of Experiments methodology to investigate the effects of cycle time, aging reactant level, and temperature on successful product outcome. The trialed products are tested thoroughly for performance according to Aspen's quality specifications. This shall be an ongoing effort in the manufacturing facility to continuously drive down the cycle time of the aging process and thereby increase the production rate of XT in the current manufacturing line. These efforts are considered part of Aspen Aerogels' continuous improvement process and are expected to continue beyond the scope and schedule of this project.

Aspen Aerogels increased the production capacity of Pyrogel XT in our Rhode Island manufacturing plant by twenty percent in 2010. In addition, the construction for doubling the manufacturing capacity by mid-2011 via installation of a second manufacturing train is currently in process.

\subsection{Industry Acceptance Activities}

This section comprises two activities: 1) development of additional aerogel parts for elbows and small diameter pipes, to expand the product range; and 2) demonstration of the new product in real-world applications.

\subsubsection{Development of Product Line Accessories}

To offer a complete pipe insulation system, it was necessary to develop accessories specifically for insulating fittings. This was done by working with Sproule Manufacturing, which developed all the necessary patterns, cutting techniques, and packaging, as well as the distribution chain necessary to get product into the field. These products include lobster-tail patterns for long- and short-radius elbows, "diapers" for socket weld fittings and tees, V-grooved insulation for smallbore pipe, and pre-engineered head segments for tanks and towers. Now a complete line of Pyrogel XT accessories is available to match all standard pipe sizes.

\subsubsection{Product Demonstration at Industrial Sites}

The demonstration sites for this project were chosen based on the following criteria: appropriate operating conditions allowing Pyrogel XT to show its value; willingness of the site to allow Aspen to measure results; and Aspen gaining a fairly broad distribution of site owners and industrial processes.

\subsubsection{Air Liquide Installation}

To accomplish the project's goals, an aggressive demonstration schedule was pursued. This strategy offered the fastest method for evaluating the field performance of aerogel insulating 
blankets, as well as providing an extended period for evaluation of the materials long term stability and performance in an actual application. To achieve these goals, the cooperation and participation of a strong project partner was required, offering a facility for use as a test bed. Air Liquide's steam production facility in La Porte, Texas offers a great location, and Air Liquide's interest and willingness to participate in the project completed the equation. Additionally, Protherm had an insulation maintenance contract with Air Liquide, completely closing the loop on site selection and availability.

Air Liquide offered contributions to the project, purchasing and installing aerogel insulation materials inside the scope of the project. Examples of installations at this facility are shown in Figure 17.
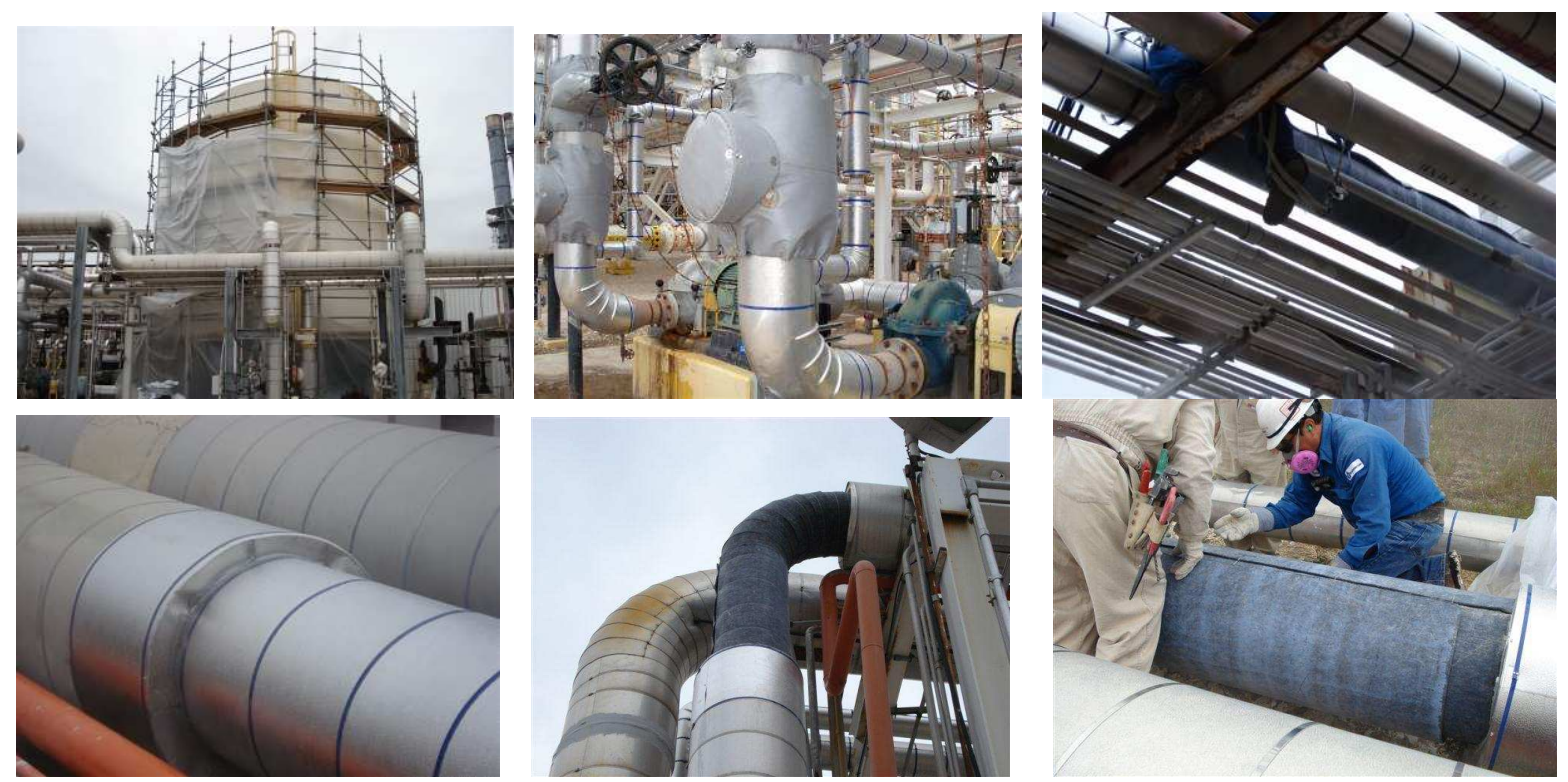

Figure 17. In Service Demonstration Installs

In December of 2006, a project was initiated at an Air Liquide steam generation facility in La Porte, TX. This project was to investigate a maintenance concept in which a single layer of $6 \mathrm{~mm}$ Pyrogel could be installed over the top of degraded insulation to improve its thermal performance. The advantages of this strategy were two-fold. First, by upgrading the insulation performance in situ, it avoided the cost, time, and operational disruption associated with stripping and re-insulating the equipment. Second, to the extent that the underlying insulation has become saturated with water, the additional layer of insulation would serve to drive moisture out. Cellular and fibrous insulation products are highly sensitive to water content and can lose more than half of their efficiency with as little as $4 \%$ moisture uptake. Thus by driving out moisture, some of the original performance can be recaptured, as illustrated in Figure 18.

In addition to the sections installed by Air Liquide, an Infrared (IR) survey was done on a section of Air Liquide's 5 mile steam delivery line in order to identify a test bed location for the installation of a 100' section of Pyrogel 6350 (an older name for the product that would become Pyrogel XT) over the top of their existing steam line insulation. This was accomplished on December $5^{\text {th }}$, 2006. Sample photos from the IR survey are shown in Figure 19. 
The IR survey showed significant underperformance in the insulation on the steam line, and there were multiple locations where a demonstration was feasible. The selected sight can be accessed easily from a service road, and was chosen for both its performance and accessibility. The location is shown in Figure 20.

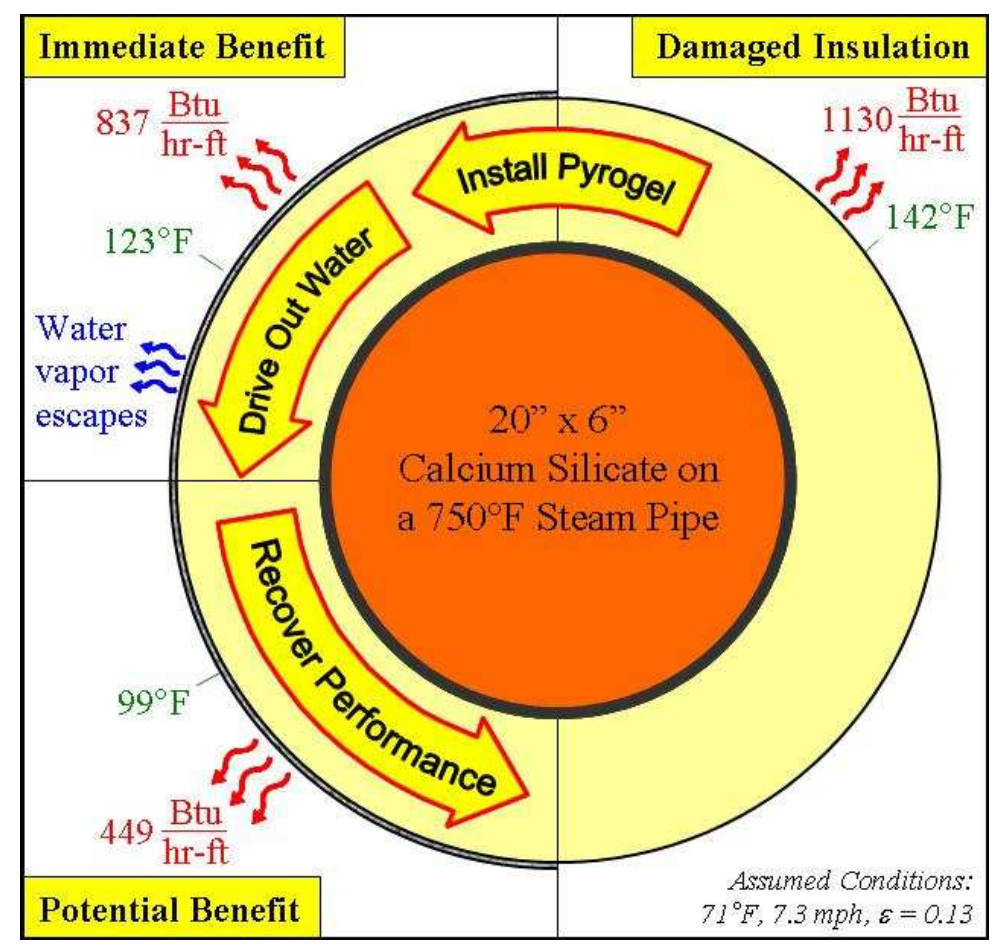

Figure 18. Insulation overwrap concept.
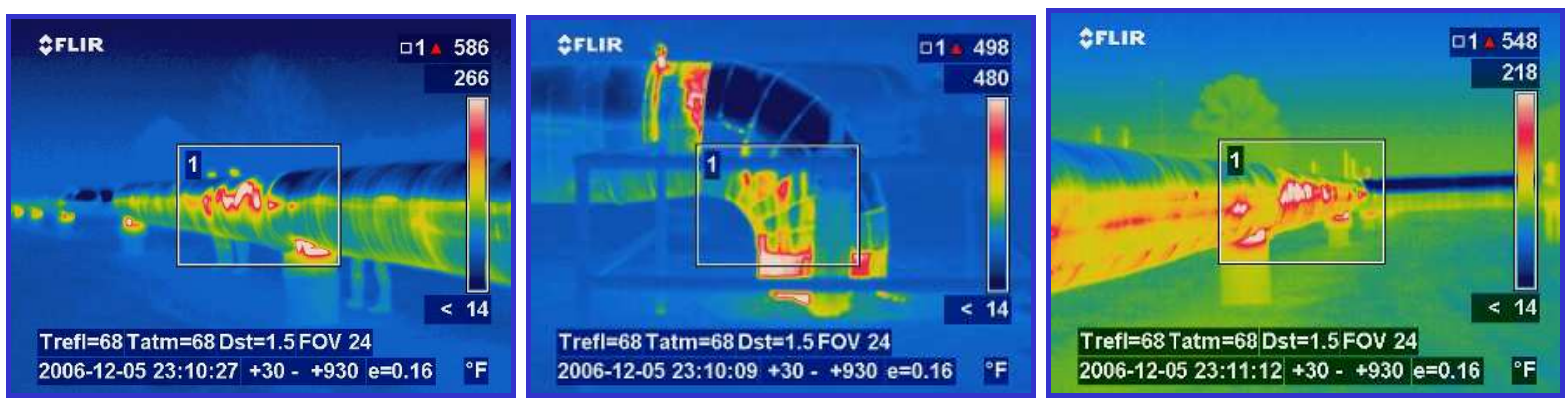

Figure 19. IR Survey
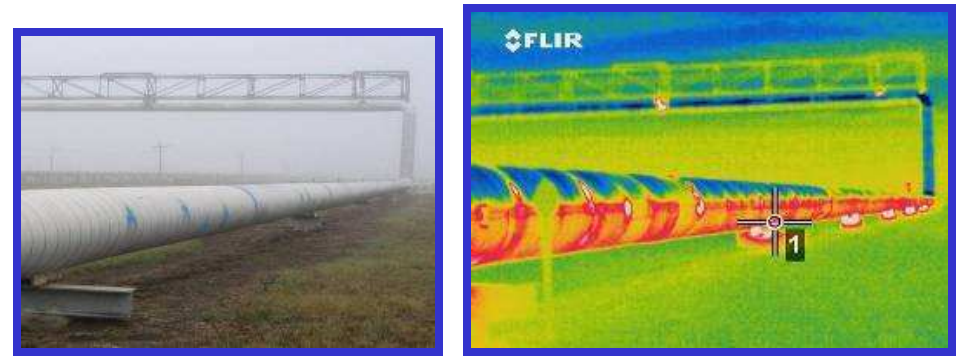

Figure 20. Installation Site 
The areas identified as "hot spots" where the insulation was showing clear signs of damage or underperformance were marked on the line with a blue spray painted "A". These markings offer the opportunity to evaluate the touch temperature performance of the insulation following the application of Pyrogel 6350.

Twelve days after the site survey, an experienced crew of insulators from Protherm came to the demonstration site to install a single ply of Pyrogel 6350 to the existing steam line. Three insulators applied the aerogel insulating blanket to the pipe, and one insulator transferred the hot location markings during the installation. The markings were transferred from the original cladding to the outer layer of the retrofit so that periodic inspections can be performed on the same locations. This allowed us to monitor performance over time. The last section that was insulated utilized two plies of aerogel insulation for comparative performance purposes. Additionally, Aspen personnel installed thermocouples in key locations for performance monitoring. The aerogel was applied to the pipe in $<45$ minutes, including instrumentation. Photos of the installation are shown in Figure 21.
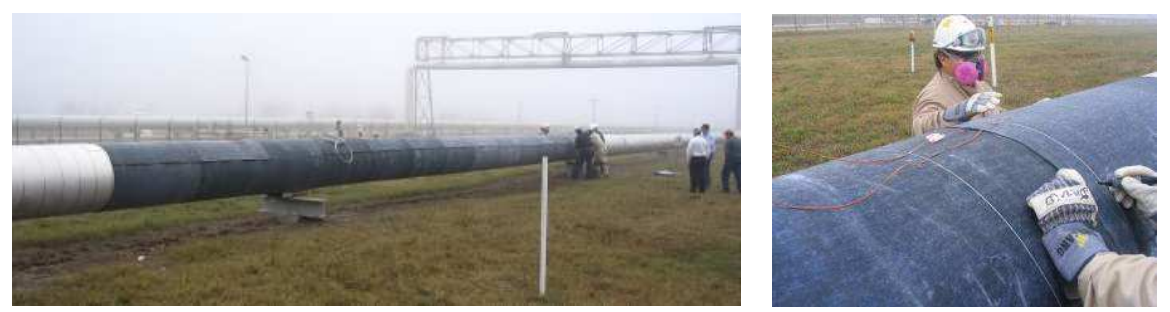

Figure 21. Field Installation and Instrumentation

Following the aerogel installation, the pipe was jacketed with standard 0.016" aluminum jacketing, and banding. The thermocouple leads were pulled through the jacketing for continuous access. The leading and trailing edges of the jacketing installation were crimped and sealed with silicone sealant, shown in Figure 22. Additionally, one of the pipe supports was insulated to reduce its touch temperature, shown in Figure 23.

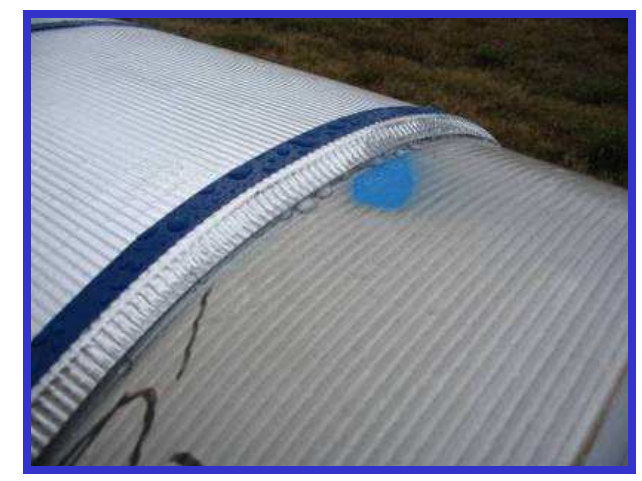

Figure 22. Crimped and Sealed Edges 


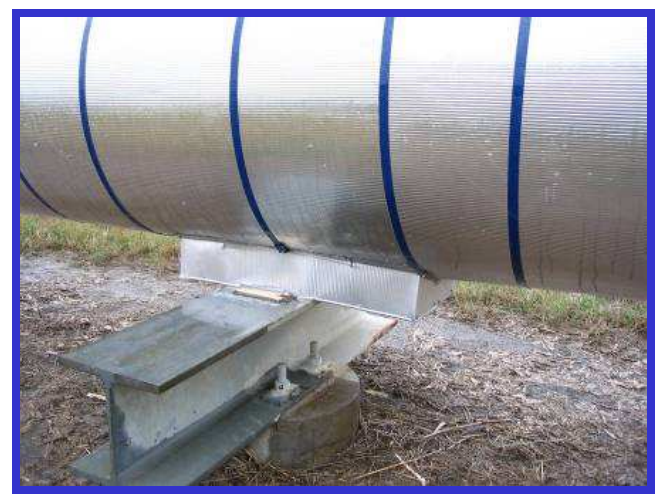

Figure 23. Insulated Pipe Support

The measured temperature changes to the section of insulated pipe are given in Table 5 .

Table 5. Test data and analysis from overwrap trial at Air Liquide.

\begin{tabular}{|c|c|c|c|c|}
\hline Parameters & $\begin{array}{c}\text { Pre- } \\
\text { Overwrap* }\end{array}$ & $\begin{array}{l}\text { Dec 17, } \\
2006\end{array}$ & $\begin{array}{l}\text { Dec 10, } \\
2007\end{array}$ & Comments \\
\hline Process Temp. $\left({ }^{\circ} \mathrm{F}\right)$ & 708 & 708 & 708.8 & \\
\hline Ambient Temp. $\left({ }^{\circ} \mathrm{F}\right)$ & 68 & 68 & 78.6 & \\
\hline Wind Speed (mph) & 10 & 10 & 10 & \\
\hline Interface Temp $\left({ }^{\circ} \mathrm{F}\right)$ & N/A & 256 & 274.5 & $\begin{array}{l}\text { Between the calcium silicate and } \\
\text { Pyrogel }\end{array}$ \\
\hline Surface Temp. $\left({ }^{\circ} \mathrm{F}\right)$ & 111.9 & 96 & 114.8 & $\begin{array}{l}\text { Between the Pyrogel and the } \\
\text { new cladding }\end{array}$ \\
\hline Heat Loss $(\mathrm{Btu} / \mathrm{hr}-\mathrm{ft})^{*}$ & 851.3 & 672.5 & 664.2 & \\
\hline U-Value (Btu/hr-ft- $\left.{ }^{\circ} \mathrm{F}\right)$ & 1.33 & 1.05 & 1.05 & \\
\hline Calsil Efficiency* & $44 \%$ & $44 \%$ & $44 \%$ & $\begin{array}{l}\text { Relative to pristine calcium } \\
\text { silicate (ASTM C533) }\end{array}$ \\
\hline $\begin{array}{l}\text { Overall Efficiency } \\
\text { Improvement }\end{array}$ & - & $+21 \%$ & $+21 \%$ & $\begin{array}{l}\text { Relative to the performance of } \\
\text { the line prior to Dec. } 17,2006\end{array}$ \\
\hline
\end{tabular}

* Estimated with the heat transfer analysis program $3 E-P l u s$

What these data indicate are that the overwrap did provide a $21 \%$ boost in the efficiency of the line immediately upon installation. If that was applied to the entire 3.6 miles of line, it would save Air Liquide 24,500 MMBtu/yr or about $\$ 230,000 / \mathrm{yr}$ at current energy prices. This is the equivalent energy consumption of 700 typical homes in the Houston metro area.

What was not seen in the data is any evidence of additional performance recovery through dryout of the degraded calsil between December 2006 and December 2007. There could be a number of reasons for this, but the most likely is that calcium silicate may not have been wet. Although the effective conductivity of the calsil was calculated to have increased by $125 \%$ since it was installed, this is not necessarily due to the presence of liquid water. It is recommended 
that for future work, the moisture content of the calsil be measured directly before and after overwrap, rather than being inferred indirectly by temperature measurements.

\subsubsection{Naval Station Newport}

Aspen Aerogels worked with utility managers at Naval Station Newport to replace a section of damaged insulation and pipe cladding with Pyrogel XT. The purpose of this installation was to demonstrate: 1) energy savings achievable with this new material, and 2) installation methods and materials to fit the Pyrogel XT on pipelines. Engineers from Aspen performed a site audit to measure the thermal performance on the pipeline. Newport operates their steam distribution system from mid September to mid April. There are two main branches to the base steam distribution system, supplying the south and north side of the base. The installation site is located on the north distribution line approximately $900 \mathrm{ft}$ upstream of the boiler. Figure 24A provides an overview of the installation site and its location relative to the boiler plant. During the audit on 26 February, 2010, the ambient temperature was $33^{\circ} \mathrm{F}$ and relative humidity was approximately $90 \%$. At that time, $24,000 \mathrm{lbs} / \mathrm{hr}$ of steam was being delivered to the north distribution line. Factoring in the steam demand for two buildings which branch off the mainline before the installation site, approximately $22,000 \mathrm{lbs} / \mathrm{hr}$ of steam was flowing through the line at the installation site. Steam leaves the plant at $450^{\circ} \mathrm{F}$ under $60 \mathrm{psi}$ of pressure. The surface temperature of the pipeline measured at the closest access to the installation site was measured at an expansion joint bend in an outdoor access cabinet (marked in Figure 24A). The audit identified severe performance loss in the existing insulation on the section of pipe line identified as the installation site in Figure 24B; the pipe run is shown in red in the figure.

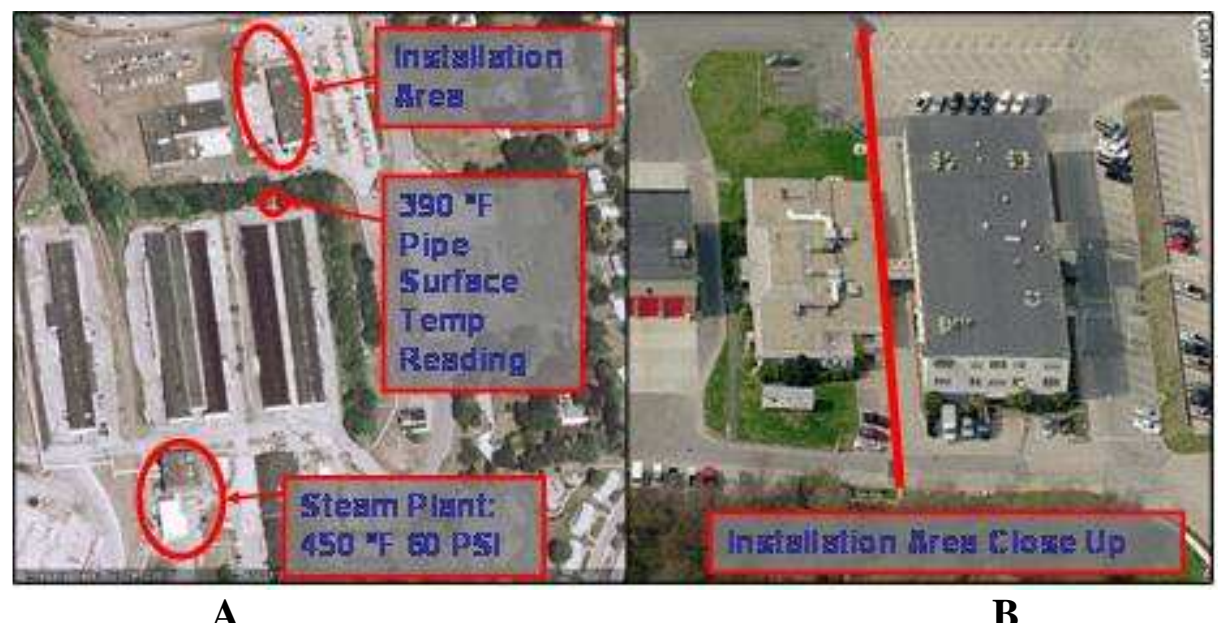

A

B

Figure 24. A) Wide view of NS Newport showing boiler location and proposed steam line installation site and B) close up of installation site behind Bldg 1.

The section of the steam pipe which was exposed with no cladding inside a maintenance cabinet close to the installation site provides the most accurate measurement of pipe surface temperature at the installation site. Visual and infrared images of the exposed pipeline are show in Figure 25. It should be noted that the temperature reading from the IR camera was calibrated to consider the emissivity of the pipe surface and the ambient temperature in the maintenance cabinet using FLIR software after the IR image was captured. This explains the variation in the temperature reading displayed on the console in the visual image. 


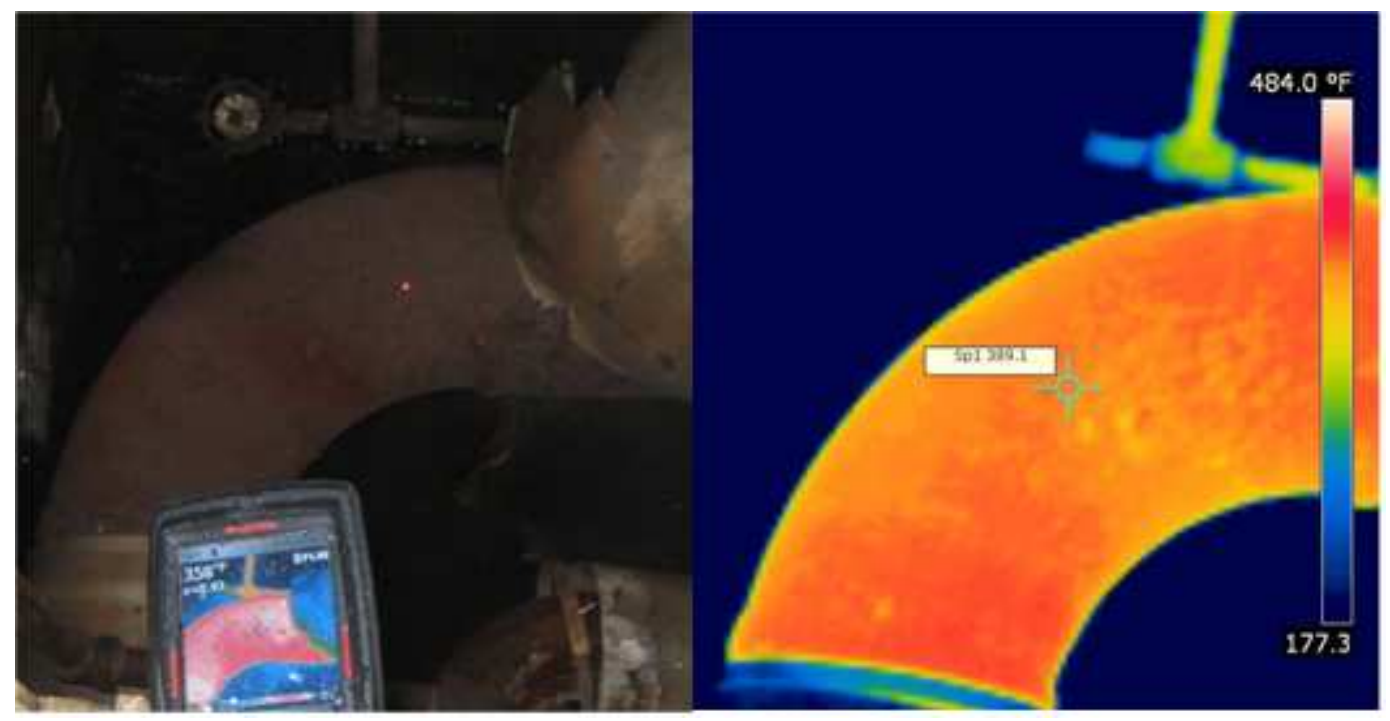

A)

B)

Figure 25. A) bare pipe in maintenance cabinet, B) IR image shows $390^{\circ} \mathrm{F}$ surface temperature

Surface temperature measurements of the pipe cladding ranged from $165^{\circ} \mathrm{F}$ at the northernmost point of the installation to $211^{\circ} \mathrm{F}$ at the center, as shown in Figure 26 and Figure 27. According to the thermal utility manager, a 3 inch layer of fibrous insulation was applied to the pipe in the 1980 's. These cladding surface temperatures indicate significant damage to the insulation likely caused during trench flooding. The temperatures were used to model the thermal losses experienced over the $300 \mathrm{ft}$ section of the pipeline that was inspected. A process pipe temperature of $315^{\circ} \mathrm{F}$ was assumed for the installation area. This is based on the $390^{\circ} \mathrm{F}$ nearby surface temperature; assuming more heat loss occurs between this point and the start of the pipeline section planned for refit, and a temperature reading of $315^{\circ} \mathrm{F}$ on an un-insulated flange in the middle of the planned installation site.

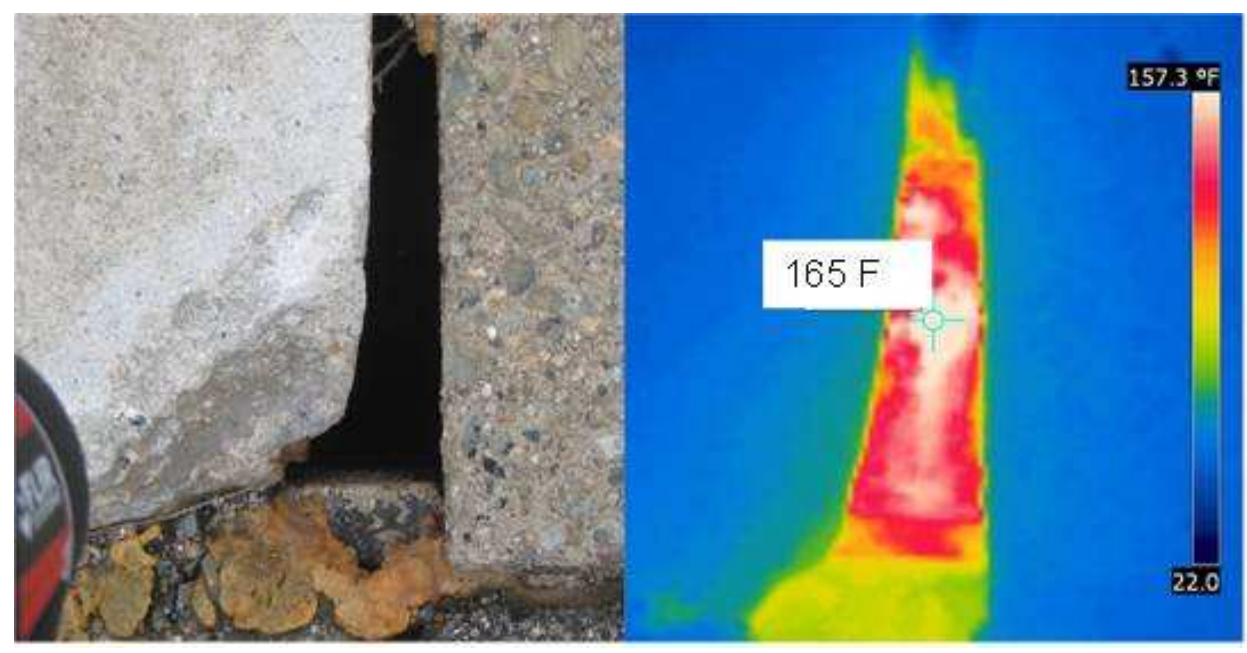

A

B

Figure 26. A) Visual image of break in trough cover with pipe underneath on North side of installation site, and B) infrared image of pipe with $165^{\circ} \mathrm{F}$ surface temperature. 


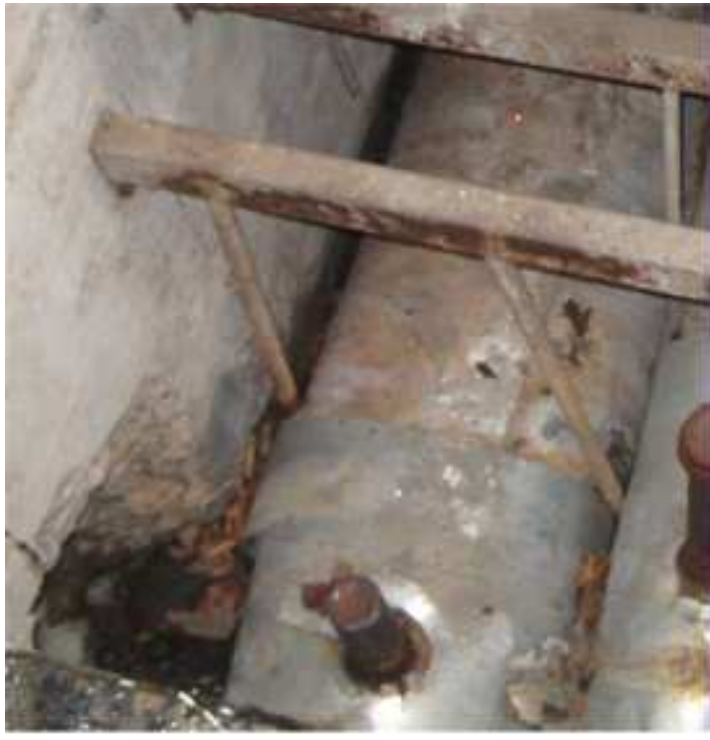

A

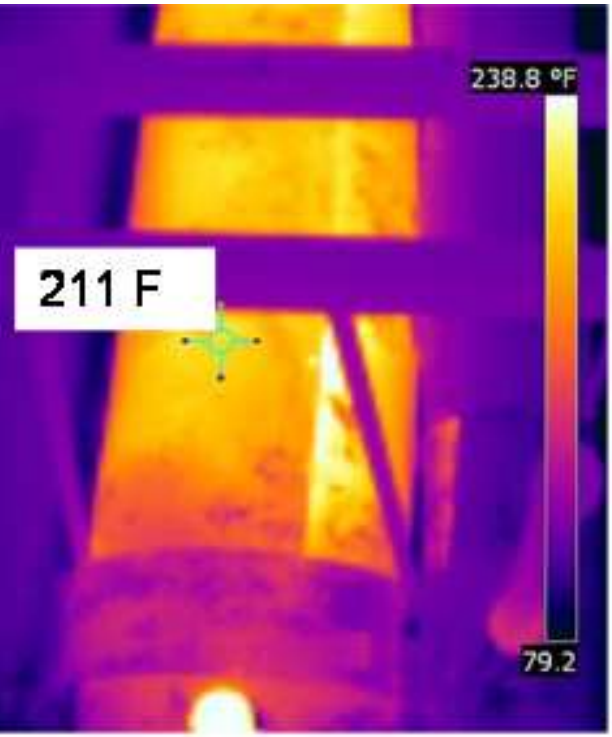

B

Figure 27. A) Visual image pipe central to the installation site, and B) infrared image of pipe with $211^{\circ} \mathrm{F}$ surface temperature.

The energy audit data was used to model previous heat loss on the pipe line and estimate the performance improvement expected by applying 2 layers of Pyrogel XT10 (20mm total). The model calculated best and worst case scenarios for thermal performance of the existing insulation, based on the audit temperature measurements. The pipeline lost between 610 and $1210 \mathrm{MBtu}$ of energy during the seven months of the year it was operating. The $20 \mathrm{~mm}$ of Pyrogel was expected to reduce these losses to $166 \mathrm{MBtu}$, or a potential fuel savings between 3,770 and 8,770 gallons of heating oil each year. Based on the average retail costs of No. 2 heating oil in New England during the 2009-2010 winter (not considering taxes), Naval Station Newport would save between $\$ 10,500$ and $\$ 24,600$ each year in fuel costs after aerogel installation. This translates to a payback period between 2 and 5.25 years based on the total cost of installation, as shown in Table 6.

Table 6. Potential savings achieved with Pyrogel XT installation on $300 \mathrm{ft}$ pipe section.

\begin{tabular}{|c|c|c|c|}
\hline \multicolumn{4}{|c|}{$\begin{array}{l}\text { In-service Thermal Performance vs. Performance with } \\
\text { Aerogel Installation }\end{array}$} \\
\hline & Fiberglass & in-service & Aerogel \\
\hline Property & Best-case & Worst-case & PGXT, 20mm \\
\hline Surface Temp [F] & 149 & 217 & 97.4 \\
\hline Heat Loss [million BTU/yr] & 614 & 1,209 & 166 \\
\hline Energy savings [million BTU/yr] & 448 & 1,043 & $\mathrm{n} / \mathrm{a}$ \\
\hline Fuel Savings per year (gal) & 3767 & 8771 & $\mathrm{n} / \mathrm{a}$ \\
\hline Cost Savings per Year (\$) & $\$ 10,548.71$ & $\$ 24,558.72$ & $\mathrm{n} / \mathrm{a}$ \\
\hline Estimated Payback & \multicolumn{2}{|c|}{$2-5.25$ years } & \\
\hline
\end{tabular}

\subsection{Aerogel Installation Summary}

Aspen Aerogels removed the damaged insulation and pipe cladding on the section of pipeline behind Building \#1 at Naval Station Newport and replaced it with Pyrogel XT. After the old 
material was removed, two layers of Pyrogel XT (each $10 \mathrm{~mm}$ thick) were installed on the 10" pipeline. Approximately 1500 square feet of the material was needed to complete the installation. The material was cut into sheets prior to delivering it to the work site. All the material needed for the installation fit onto a single pallet. To meet the same heat lost performance, 2 to 2.5 " of cellular glass would be required, more than doubling the logistical foot print for the material. Since this material is rigid, it must be pre-shaped by the manufacturer to match the pipe contour. This further reduces packing efficiency and requires unique part numbers to cover pipes of different sizes, elbows, etc. Since Pyrogel XT is a flexible blanket product that can be cut to fit any size pipe on site, it significantly reduces the logistical burden (and hence cost) for installation, especially where different sized pipes are encountered.

After the old pipe cladding and insulation was removed, a three person crew installed the aerogel material in 1-1/2 working days, a rate of $\sim 18$ linear feet per hour. Some areas of the trench were packed with debris from flooding over the years which allowed very little clearance between the bottom of the pipe and the mud and dirt. There were also other obstructions such as intersecting pipe runs, shown in Figure 28. In order to fit a thicker material around the pipeline, the trench would have needed to be dug out, and in circumstances such as intersecting pipelines, thicker insulations would need to be thinned in order to fit. There was enough room to fit the full $20 \mathrm{~mm}$ of Pyrogel XT across the entire installation site.

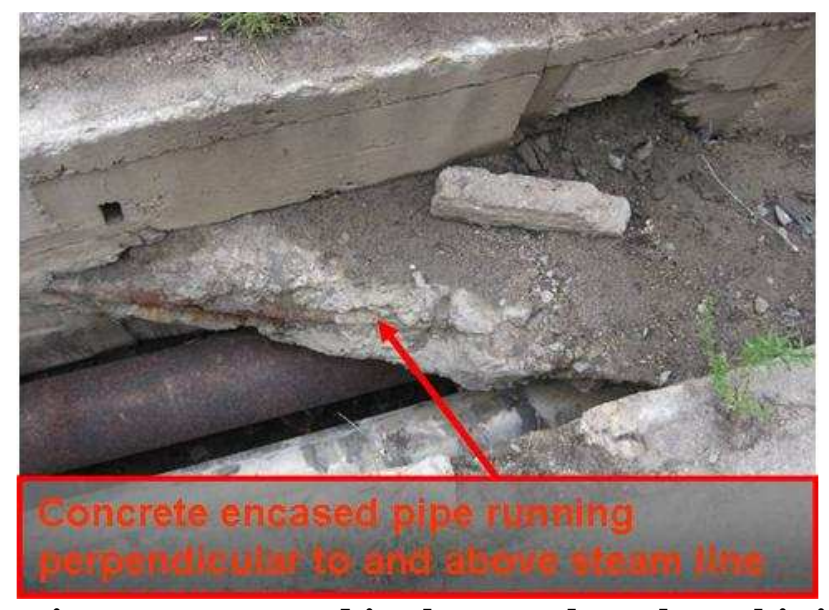

Figure 28. Pipe obstructions encountered in the trench such as this intersecting water line.

While the installers were applying the Pyrogel XT, engineers from Aspen Aerogels were installing data monitoring equipment. Thermocouples were installed at the beginning and end of the treated section of the pipeline. The thermocouples were placed directly on the surface of the process pipe, between the insulation and the cladding, and on the outer surface of the cladding. The ambient temperature of the trench was also being monitored at both the start and the end of the treated section. Finally, the outside ambient temperature was being monitored at the site. All the thermocouples were attached to an Omega OM-CP-OCTTEMP-A data logger set to record data points every 10 minutes. A schematic of the thermocouple placement is shown in Figure 29. 


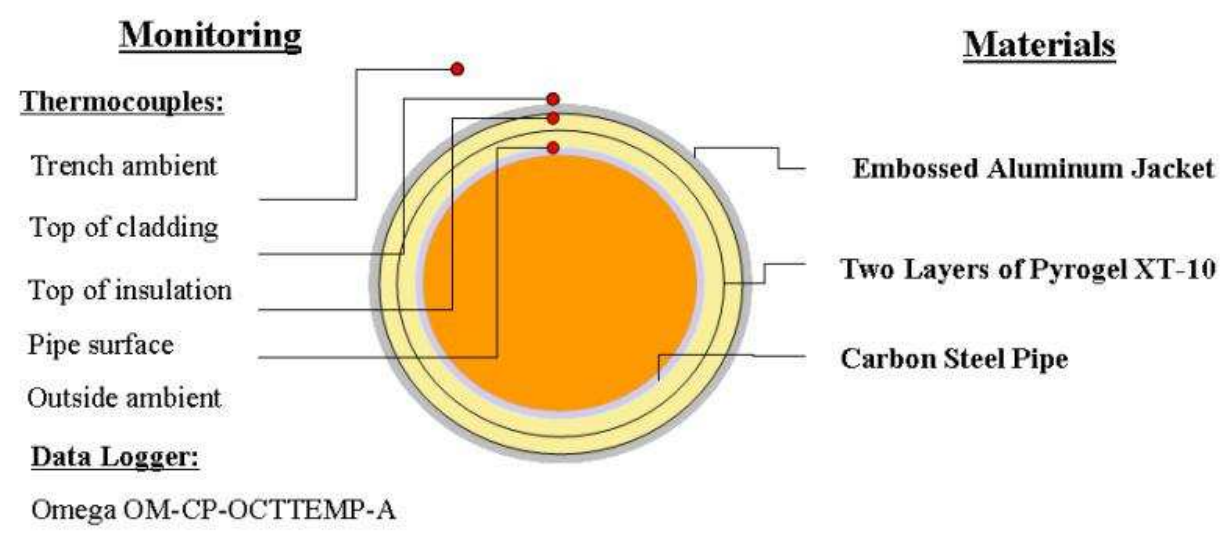

Figure 29. Data monitoring schematic - thermocouples were place in same locations at start and end of installation section.

\subsection{Installation of Incumbent Material}

In order to provide a side by side comparison with an incumbent insulation material that is used on the steam line at Newport, a section of pipeline in an outdoor cabinet near the aerogel installation site was insulated with 2" cellular glass which should deliver matched thermal insulation value. Thermocouples were applied to this section of pipe in the same fashion as the section insulated with aerogel. This is the same spot where surface pipe temperature readings were collected during the energy audit. Due to the tight proximity of the condensate return line, the foam glass was shaved in this section in order to fit the tight space between pipes. The same shaping would have been required at the aerogel installation site should a thicker material have been used; however, the full aerogel thickness could have been applied at either site without interference from adjacent equipment or objects. Figure 30 shows the foam glass installation site before and after the material was applied. The section of pipe was approximately 10 ' long with two $90^{\circ}$ elbows at the top and bottom of the section. All four elbows and the entire 10' of straight pipe length were covered with cellular glass. The thermocouples were applied in the center of the installation length and the section will be monitored in the same fashion as the aerogel installation.

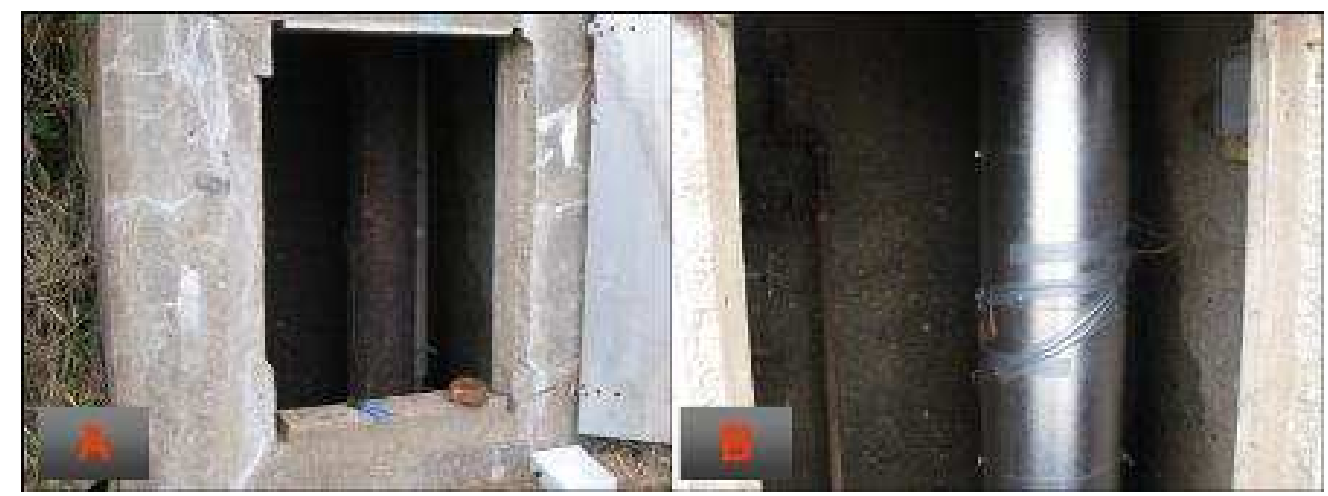

Figure 30. Pipe section (A) before and (B) after application of cellular glass

The installation at Naval Station Newport demonstrated the performance of Aspen Aerogels' Pyrogel XT insulation material and introduced the product to energy managers in the Department of the Navy. Steam distribution systems are a common heating system used on military installations. In the process of coordinating this demonstration installation at the Newport site, Aspen Aerogels interfaced with representatives in the Energy and Utilities Department of the 
Naval Facilities Engineering Service Center, responsible for evaluating energy efficiency products for use across all Navy facilities. Because this work followed the Navy recommendations for evaluation of a new energy efficiency product, it will help expand the acceptance of Pyrogel XT across a large user group.

\subsection{Results of Pyrogel Installation}

Two methods of analysis were used to evaluate the data collected by the thermocouple datalogger unit. The experimental design for the aerogel insulated test section provided temperature data at both in start and finish of the test section and because the run of aerogel was of sufficient length, it was possible to measure a temperature drop (approximate $\Delta \mathrm{T} \sim 5^{\circ} \mathrm{F}$ ) between these monitoring stations. This temperature was enough to provide data that could be correlated to the available mass flow from the NS Newport steam plant on an hourly basis. Therefore, the full thermocouple data set was truncated to match with the mass flow data available during times when the steam plant was actively heating the NS Newport buildings. Figure 31 shows the temperature profiles and associated mass flow for the analyzed time period of 11/2/2010 through 12/10/2010.

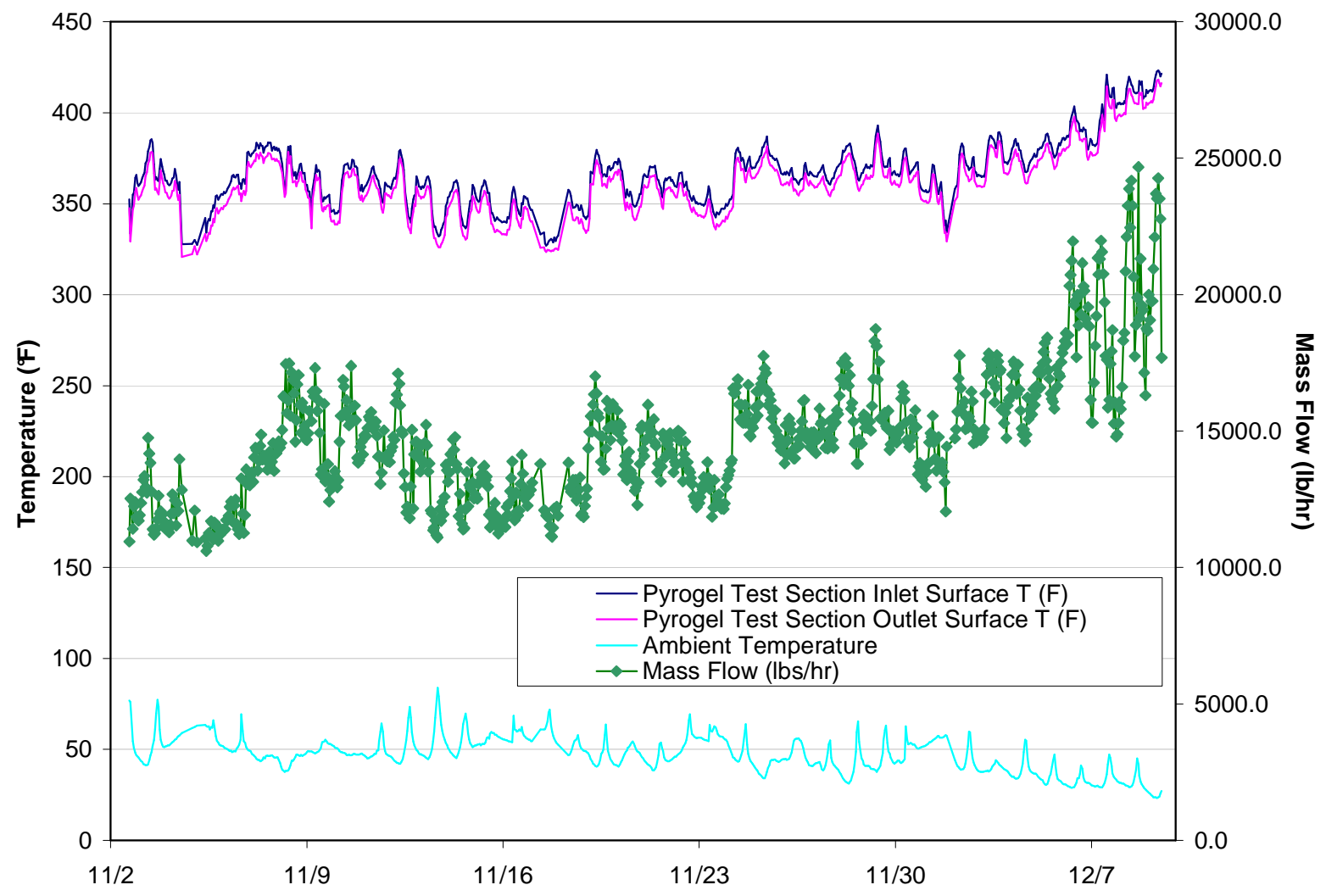

Figure 31. Pyrogel XT Aerogel Insulated Test Section Temperature and Mass Flow Plot

Knowing the hourly mass flow allowed an energy balance to be performed on the system. This showed good agreement with an ASTM C680 heat loss calculation performed using the pipe surface temperature and cladding temperature at each point. The corresponding heat loss is plotted in Figure 32 on an hourly basis for each day of the analysis. This shows some evidence of diurnal cycles of changing heat loss based on ambient temperature changes. 


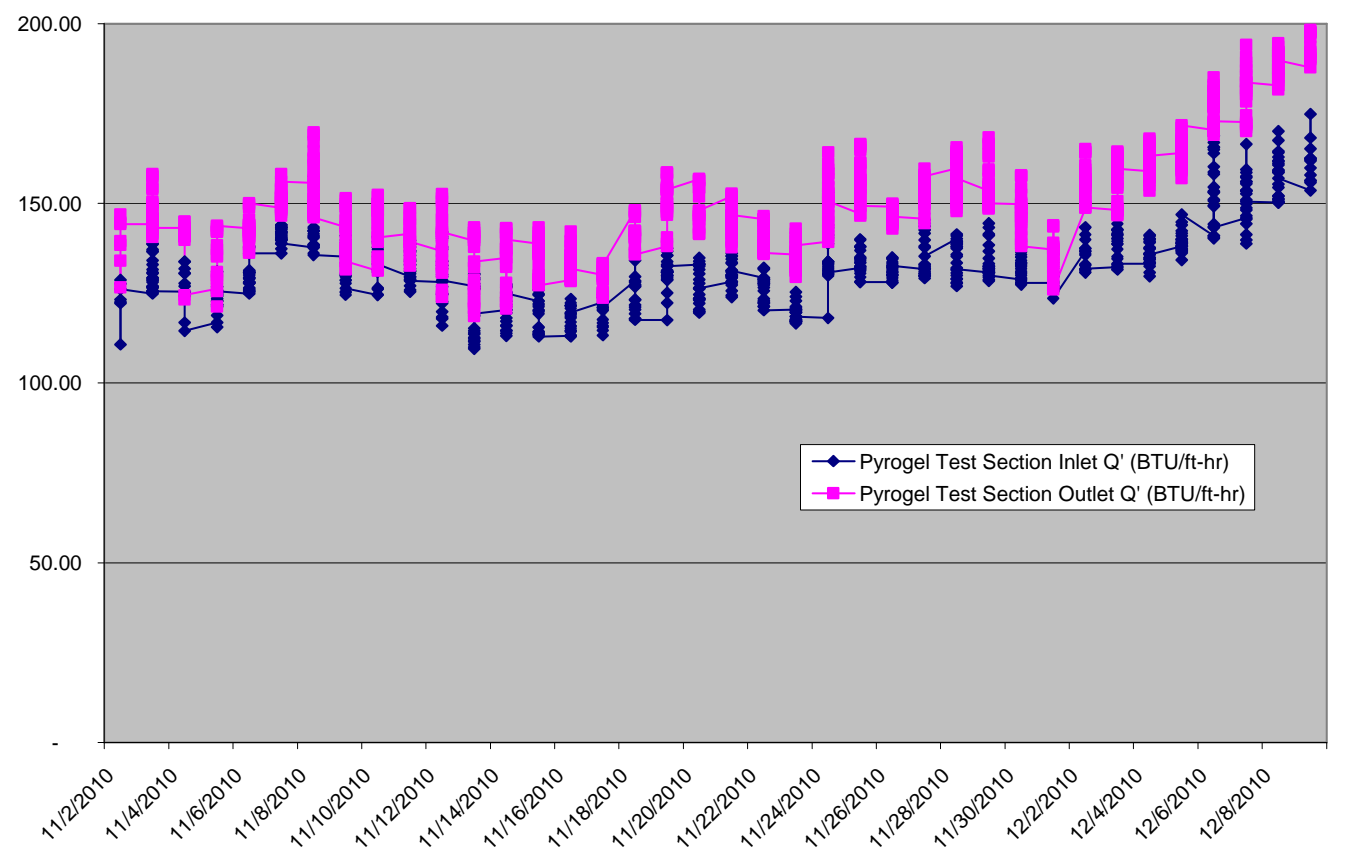

Figure 32. Heat Loss (BTU/ft-hr)/ at the Inlet and Outlet of Pyrogel Test Section

The cellular glass test section was analyzed using only the ASTM C680 heat loss calculation, as there is enough run length to provide the temperature data required for a mass balance. However, the Foamglass material showed good agreement with predicted performance, which was expected to be similar to the $20 \mathrm{~mm}$ Pyrogel XT. As discussed earlier, cellular glass of 2 inches thickness was required to provide similar heat loss protection compared with 0.8 inches Pyrogel XT. This provides significant advantage when space is limited and it may not be possible to use an extra 4 inches of material to insulate the service pipe. The results are shown in Table 7.

Table 7. Predicted Performance of Insulation Materials Used at NS Newport

\begin{tabular}{|c|c|c|c|c|}
\hline & Thickness (in) & $\mathbf{Q}^{\prime}$ (Btu/hr-ft) & $\boldsymbol{\Delta Q}^{\prime}$ & T_surf (F) \\
\hline Cellular Glass & 2.0 & 179.8 & - & 109.4 \\
\hline Pyrogel XT & 0.8 & 178.2 & $+1 \%$ & 115.6 \\
\hline
\end{tabular}

Note: Pyrogel XT thickness determined to maintain similar heat loss as 2inches cellular glass

The table below (Table 8) is a summary of average thermal performance observed during the test period. Note that Newport NS normally runs steam from October 15 through May 15. The aerogel results are listed in two ways based on the two methods of analysis described above. Based on the potential for heat leakage through non-insulation related means (support shoes, air infiltration, etc.) and the very likely potential for variation in steam mass flow, it is fair to say that these two results show a range of expected performance for the Pyrogel XT installation and good agreement. The observed heat loss is in good agreement with predicted values from Table 7. This means that the predicted payback period (2-5 years) can be achieved if the incumbent insulation were replaced entirely. Additionally, as this demonstration was installed on 300 linear feet of pipe, we calculated the annual benefit per mile of pipe on an installation site at 8000 MMBtu. 
Table 8. Summary Table of Measured Insulation Performance at NS Newport

\begin{tabular}{|l|c|c|c|}
\hline \multicolumn{2}{|c|}{ In-Service Thermal Performance vs. Performance with Aerogel Installation } \\
\hline \multicolumn{1}{|c|}{ Property } & \multicolumn{3}{c|}{ Measured Performance } \\
\hline Insulation Product & $\begin{array}{c}\text { Aerogel } \\
\text { PGXT, 0.8 in }\end{array}$ & $\begin{array}{c}\text { Aerogel } \\
\text { PGXT, 0.8 in }\end{array}$ & $\begin{array}{c}\text { Cellular Glass } \\
\mathbf{2 . 0} \text { in Foamglass }\end{array}$ \\
\hline Analysis Technique & Temperature & Mass Flow & Temperature \\
\hline Cladding Surface Temp [F] & 145 & 145 & 105 \\
\hline Heat Loss [million BTU/yr] & 140 & 166 & 170 \\
\hline
\end{tabular}

\subsubsection{Installation at Archer-Daniels Midland facility in Marshall, $M N$}

A major installation was carried at an Archer-Daniels Midland facility in Marshall, MN in September 2009. This facility is a corn-processing plant which processes corn from all over the Midwest. One of the processes the grain goes through is called gluten drying, where it is exposed to air streams ranging from 200 to $700^{\circ} \mathrm{F}$. The ductwork on these dryers (pictured in Figure 33) must be insulated, both to conserve energy, and to prevent condensation from occurring within the duct.
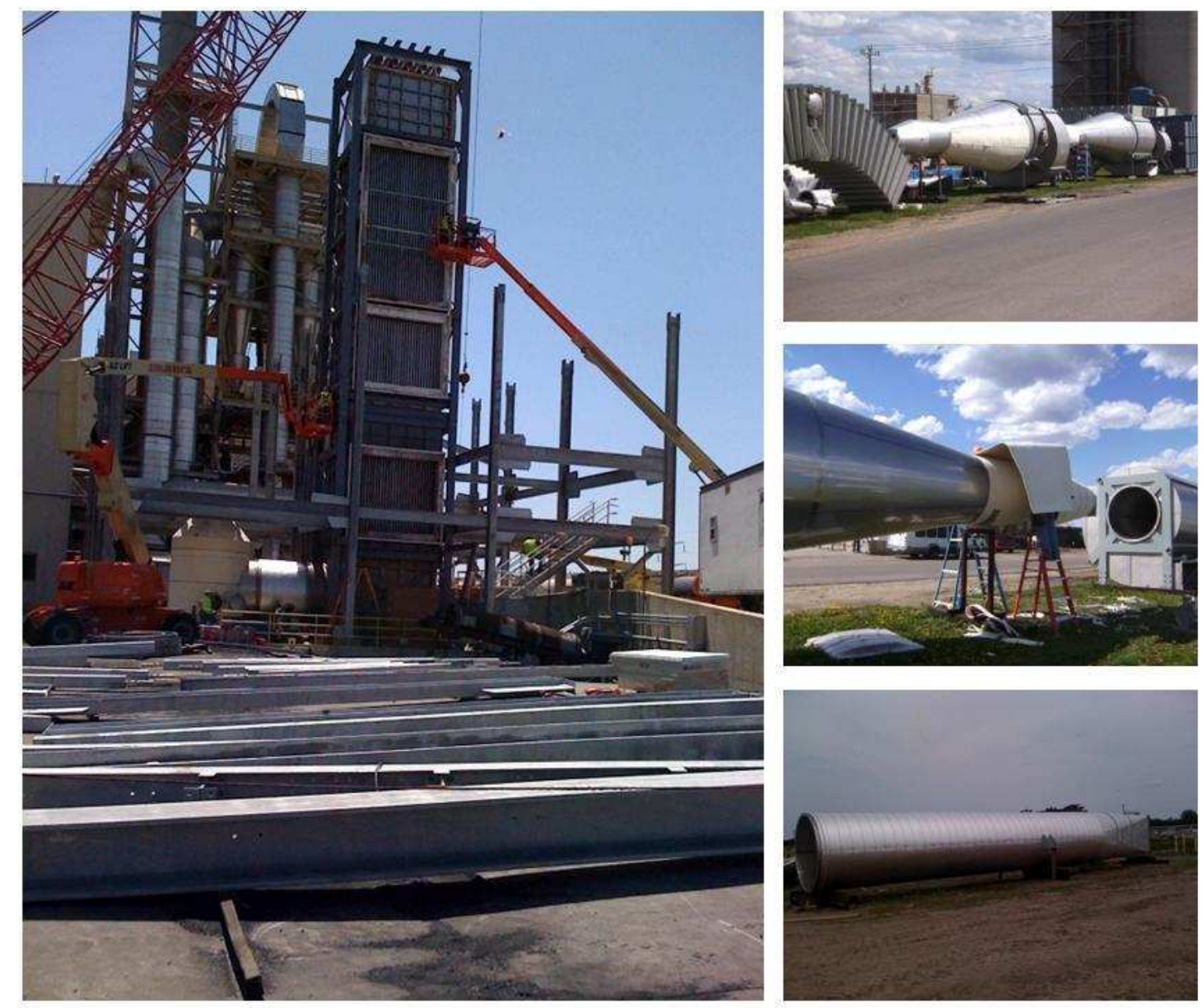

Figure 33. Gluten drying equipment in Marshall, MN. 
This installation is significant because it represents one of the first major jobs where Pyrogel XT was able to directly replace mineral wool, which is the global market leader and, not coincidentally, the cheapest industrial insulation product available. According to the owner, the primary reason for the replacement was that previous installations of mineral had gotten wet and heavy, resulting in corrosion, loss of efficiency, and increased structural loads. That Pyrogel XT could prevail, despite costing 2-3 times more, indicates that this project's emphasis on quality, performance, and hydrophobicity is paying off.
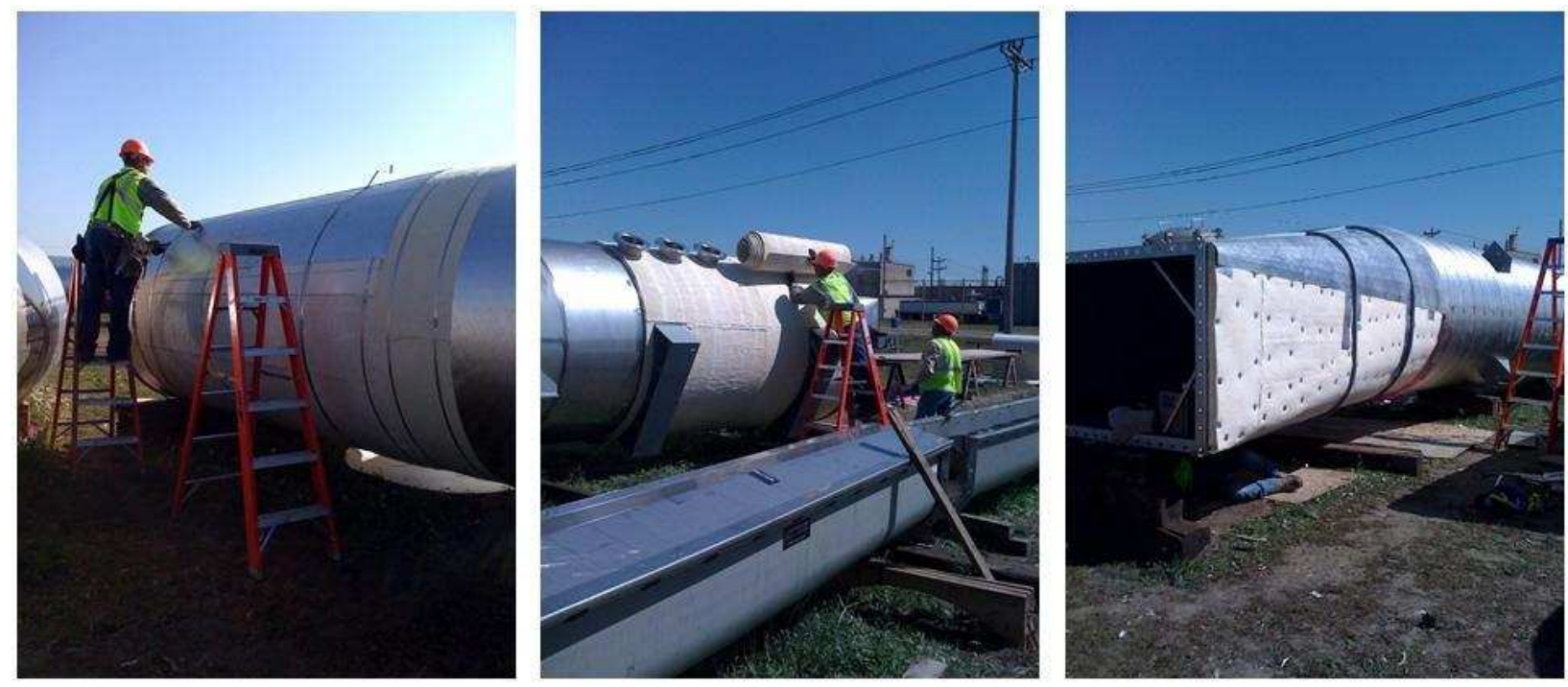

Figure 34. Installation of Pyrogel XT on various sections of ductwork.

\subsubsection{Field Trials at ExxonMobil in Port Jerome, France}

During this project, Aspen Aerogels worked with ExxonMobil to identify a field test location at one of their global refineries. Their facility in Port Jerome, France, was identified as the best site, as it offered the opportunity to test several different parameters of the in-use operating conditions that Pyrogel XT will be subjected to including hot installation, and exposure to water. Three pipelines were selected for the installation trials, totaling approximately 150 linear feet of pipe. The completed installation is discussed in more detail below.

\subsection{Hot Install on a $734^{\circ} \mathrm{F}$ Steam Line}

The first pipeline to be fitted with aerogel was an 8 " outer diameter pipe. The pipeline maintains a process temperature of $734^{\circ} \mathrm{F}$ and is suspended approximately 5 meters off the ground in a network of pipe racks. The line had a pre-exiting mineral wool insulation covering it to a thickness of $110 \mathrm{~mm}$. Of the total 30 meters identified for installation, the first half of the line was refitted with mineral wool (preformed shells) and the second half with Pyrogel as shown in Figure 35. The thickness of both materials was selected so that the heat losses are comparable (and provide the desired insulation for the process). Aspen's engineers calculated the thickness of the aerogel insulation to match the heat losses of the mineral wool installation. The design calculations are detailed in Table 9. The pre-existing mineral wool was removed and new products (Pyrogel XT and mineral wool) were applied directly to the surface of the pipe. 


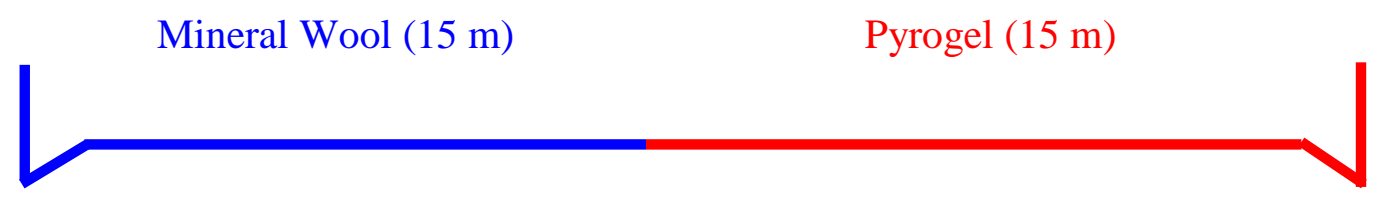

Figure 35. Depiction of pipe installation at ExxonMobil Port Jerome Gravenchon, including elbows and vertical elements.

Table 9. Design calculations for insulation of 8" pipe at ExxonMobil, Port Jerome.

\begin{tabular}{|c|c|c|}
\hline Parameters & Values & Notes \& Comments \\
\hline NPS (in): & 8 & \\
\hline Length $(m)$ : & 10 & $15 \mathrm{~m}$ mineral wool, $15 \mathrm{~m}$ Pyrogel \\
\hline No. of L90's: & 0 & Based on 20 L90's total \\
\hline No/ of L45's: & 0 & 45 degree elbows \\
\hline No. of Valves: & 0 & Based on three valves total \\
\hline Process Temperature $\left({ }^{\circ} \mathrm{C}\right)$ : & 390 & \\
\hline Surface Emissivity: & 0,1 & Weathered aluminum or galvanized steel (Uginox F17) \\
\hline Fluid: & Steam & \\
\hline Internal Flow rate $(\mathrm{kg} / \mathrm{s})$ : & N/A & Line is too short for end-to-end $\Delta T$ to be a factor \\
\hline Heat Traced?: & No & \\
\hline Surface Temperature Limit $\left({ }^{\circ} \mathrm{C}\right)$ : & 60 & Industry standard \\
\hline Cost of Energy $(€ / G J):$ & $€ 4,74$ & Includes $85 \%$ boiler/distribution efficiency \\
\hline
\end{tabular}

\begin{tabular}{|c|c|c|c|c|c|c|c|}
\hline Assumed Conditions $^{1}$ & Winter Storm & \multicolumn{4}{|c|}{ Annual Average } & \multicolumn{2}{|c|}{ Hot, Still Day } \\
\hline Design Criteria: & 15) & \multicolumn{4}{|c|}{ Heat conservation } & \multicolumn{2}{|c|}{ Personnel } \\
\hline Ambient Temperature $\left({ }^{\circ} \mathrm{C}\right)$ : & Wh & \multicolumn{4}{|c|}{11} & \multicolumn{2}{|c|}{35} \\
\hline Wind Speed $(\mathrm{m} / \mathrm{s})$ & W & \multicolumn{4}{|c|}{4,5} & \multicolumn{2}{|c|}{1} \\
\hline $\begin{array}{l}\text { Insulation } \\
\text { Design }\end{array}$ & \begin{tabular}{|c|c|} 
Heat Loss & Efficiency \\
$(\mathrm{W} / \mathrm{m})$ & vs. Base \\
\end{tabular} & \begin{tabular}{|c|} 
Heat Loss \\
$(\mathrm{W} / \mathrm{m})$ \\
\end{tabular} & \begin{tabular}{|c|} 
Efficiency \\
vs. Base \\
\end{tabular} & \begin{tabular}{|c|} 
Energy \\
Cost $(€ / \mathrm{yr})$ \\
\end{tabular} & \begin{tabular}{|c|}
$\Delta$ Energy \\
Cost $(€ / \mathrm{yr})$ \\
\end{tabular} & \begin{tabular}{|c|} 
Surface \\
Temp $\left({ }^{\circ} \mathrm{C}\right)$ \\
\end{tabular} & $\begin{array}{l}\Delta \text { Temp } \\
\left({ }^{\circ} \mathrm{C}\right) \\
\end{array}$ \\
\hline 110 mm MW Pipe Cover (Base): & & 229,0 & - & $€ 357$ & - & 58,3 & - \\
\hline 25 mm Pyrogel XT: & Z & 268,3 & $-17 \%$ & $€ 418$ & $€ 61$ & 71,0 & $+12,7$ \\
\hline $30 \mathrm{~mm}$ Pyrogel XT: & 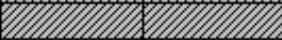 & 229,1 & $+0 \%$ & $€ 357$ & $€ 0$ & 65,4 & $+7,1$ \\
\hline $35 \mathrm{~mm}$ Pyrogel XT: & & 200,8 & $+12 \%$ & $€ 313$ & $-€ 44$ & 61,4 & $+3,1$ \\
\hline$\rightarrow 40 \mathrm{~mm}$ Pyrogel XT: & & 179,4 & $+22 \%$ & $€ 279$ & $-€ 77$ & 58,2 & $-0,1$ \\
\hline $45 \mathrm{~mm}$ Pyrogel XT: & & 162,7 & $+29 \%$ & $€ 253$ & $-€ 103$ & 55,7 & $-2,6$ \\
\hline Notes \& Comments: & $\begin{array}{l}\text { 1. Based on } 2006 \text { wea } \\
\text { 2. Assumes } 110 \mathrm{~mm} n \\
\text { 3. Recommended Pyrc } \\
\text { 4. Pyrogel material req } \\
\text { 5. This thickness of Py } \\
\text { - Roughly equal touc } \\
\text { - } € 77(22 \%) \text { annual } \\
-31 \% \text { reduction in a }\end{array}$ & $\begin{array}{l}\text { her data for } \\
\text { hineral wool } \\
\text { gel thicknes } \\
\text { uirement (e) } \\
\text { rogel shoulc } \\
\text { h temperatu } \\
\text { energy savin } \\
\text { ccessory co }\end{array}$ & $\begin{array}{l}\text { Le Havre, F } \\
\text { pipe cover } \\
\text { ss is } 40 \mathrm{~mm} \\
\text { xcluding fitti } \\
\text { d provide: } \\
\text { ires } \\
\text { gis on a } 15 \\
\text { sts (claddin }\end{array}$ & $\begin{array}{l}\text { France (http: } \\
\text { (4 layers a } \\
\text { ings) is } 38 \mathrm{~s} \\
\mathrm{~m} \text { line } \\
\mathrm{g} \text {, bands, et }\end{array}$ & $\begin{array}{l}\text { //www.weat } \\
\text { t } 10 \mathrm{~mm} \text { ) } \\
q m \text { of PGXT }\end{array}$ & erunderg & d.com) \\
\hline
\end{tabular}

The mineral wool insulation that covered the pipe showed significant wear before being stripped off for the new installation. The pipeline prior to the new installation is shown in Figure 36. Following the removal of the old mineral wool, new Pyrogel XT and Mineral Wool were applied directly to the surface of the pipe to provide a side-by-side comparison. The pipe with Pyrogel $\mathrm{XT}$ installed is shown in Figure 37.

This section also required fitted elbows to be installed on the line. Both $45^{\circ}$ and $90^{\circ}$ elbows were covered using material cut into the lobster tail design. Using this cut design, the sections are cut to a taper so that the flat material will form fit the elbow. The spine of the lobster tail is placed 
on the outside radius ("heel") of the pipe elbow. Next, each tail section is joined on the inside Figure 38 demonstrates the progressive work required to install a lobster tail on a $90^{\circ}$ elbow. Figure 39 shows the same work on a $45^{\circ}$ elbow.

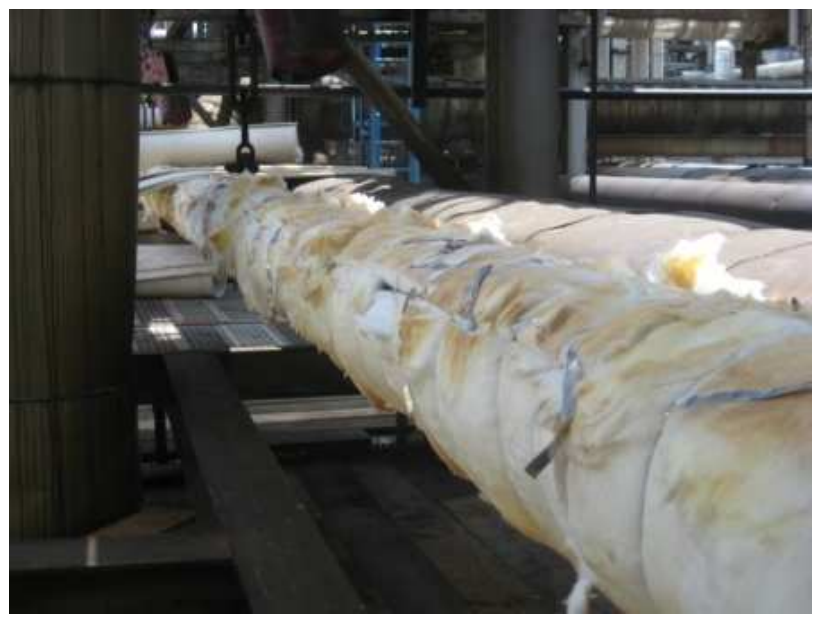

Figure 36. Installation site with pre-existing mineral wool insulation still on the pipe.

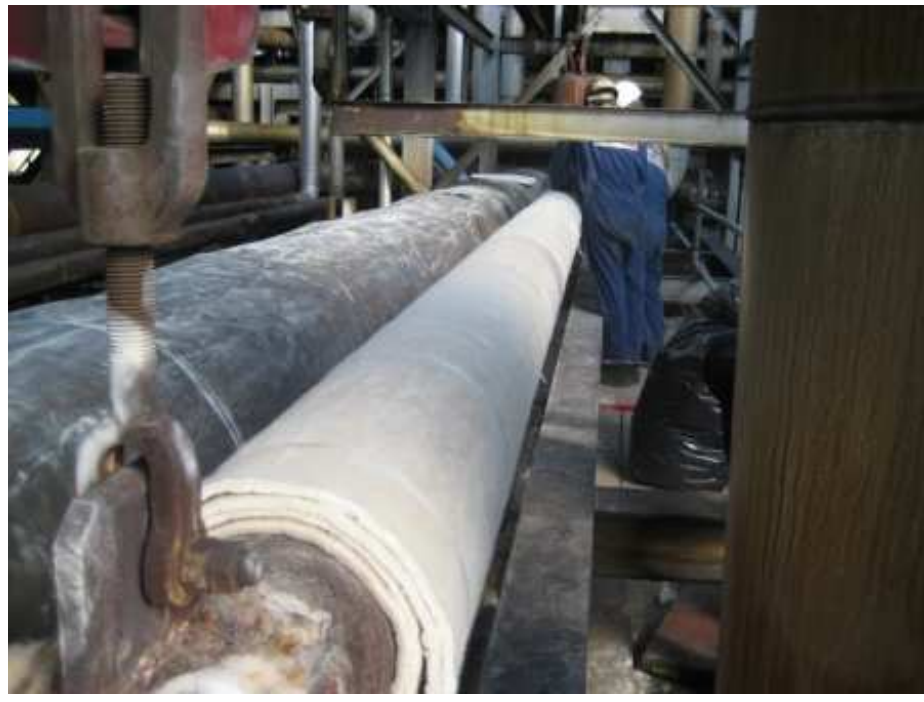

Figure 37. Pyrogel installation on straight section.

1
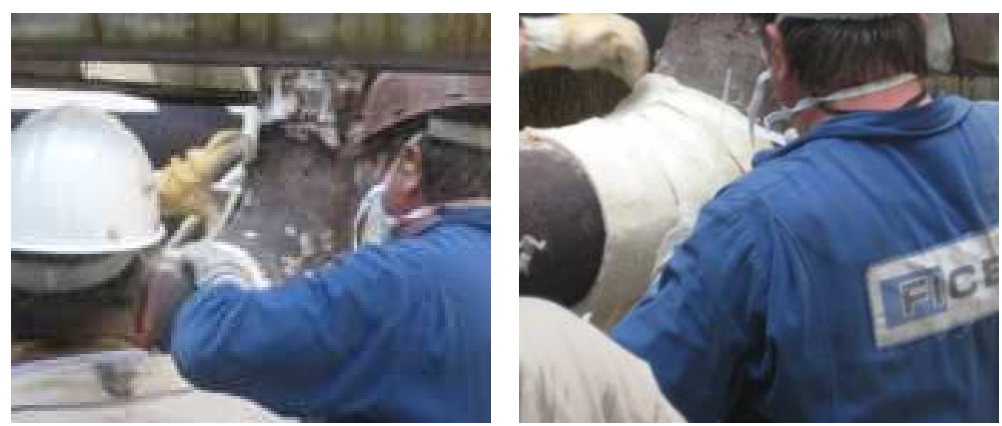

3

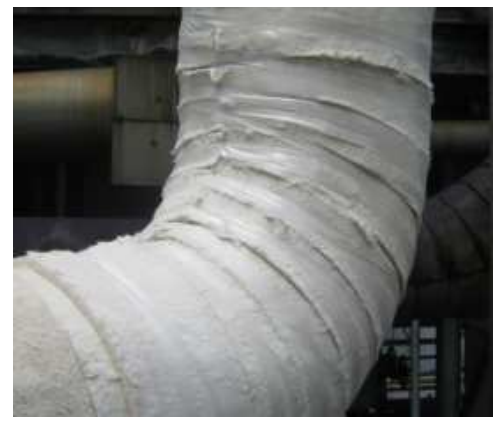

Figure 38. Fitting a lobster tail elbow section on a $90^{\circ}$ elbow at Port Jerome. 
1

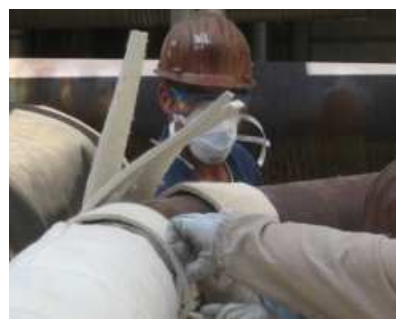

3

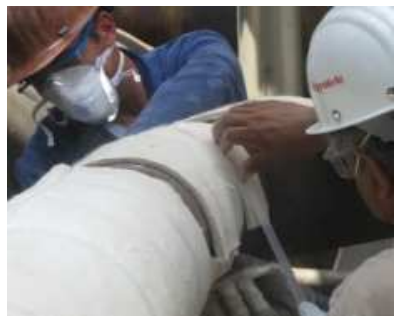

2

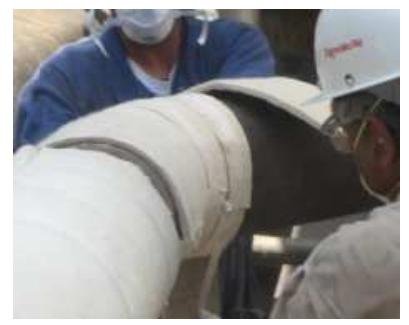

4

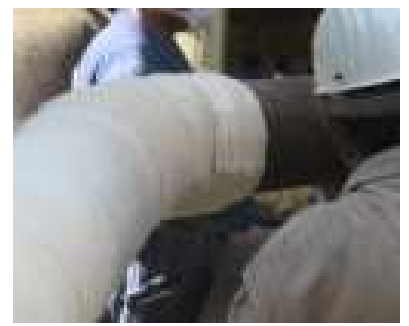

Figure 39. Fitting a lobster tail elbow section on a $45^{\circ}$ elbow at Port Jerome.

Four (4) temperature measurement locations (T1-T4, see simplified drawing shown in Figure 40) were identified prior to performing the work, one at the start and end of each of the two isolated section. Before insulation of the Pryogel, skin thermometers were installed on locations T1-T4 (with local read-out). The TC measurement sites were selected to ensure that the measurement locations on each material are subjected to comparable environmental conditions, such as wind, rain, sun, and radiated heat from other equipment.

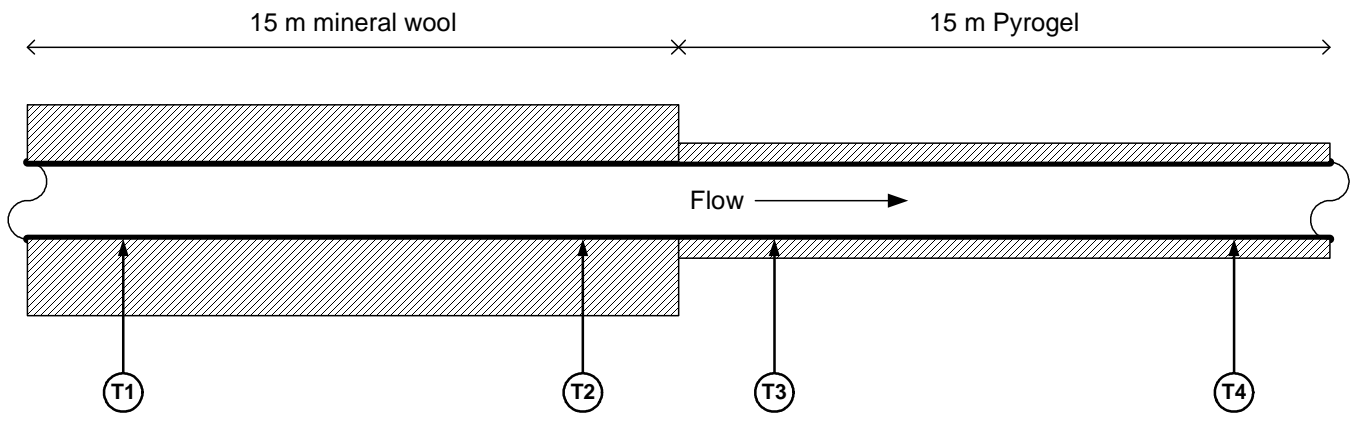

Figure 40. Thermocouple placement on 8 " pipe installation.

After completion of the insulation installation, temperature readings were taken from T1-T4 every day for 3 weeks at 7.30 AM. The cladding temperatures were monitored at the same location using an IR thermometer, and the ambient conditions during the temperature measurements will be recorded.

A long horizontal tank known as a "bullet" was insulated at ExxonMobil's Port Jerome Gravenchon refinery in France. Half of the tank was insulated with Pyrogel XT and the other half with mineral wool blanket. Images of this installation are shown in Figure 41 and Figure 42. 


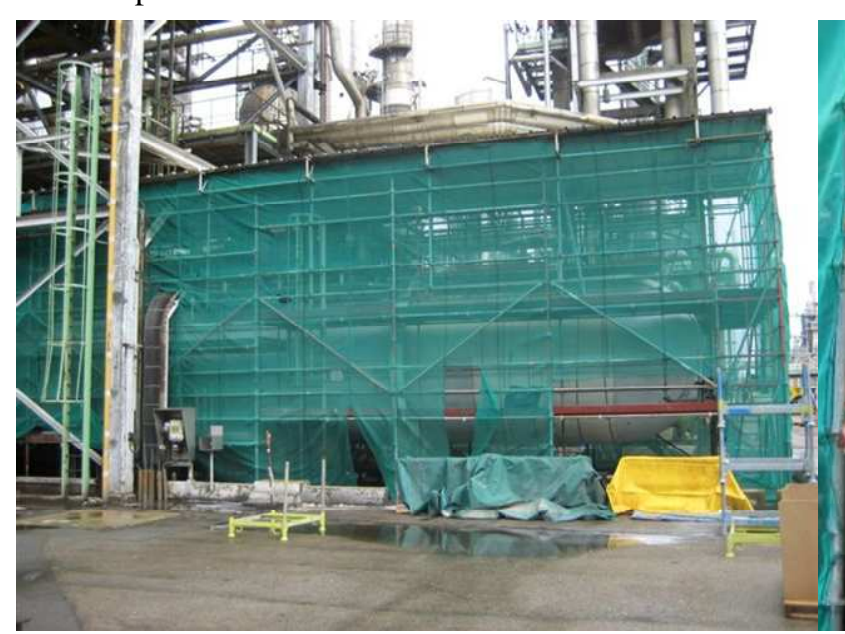

a

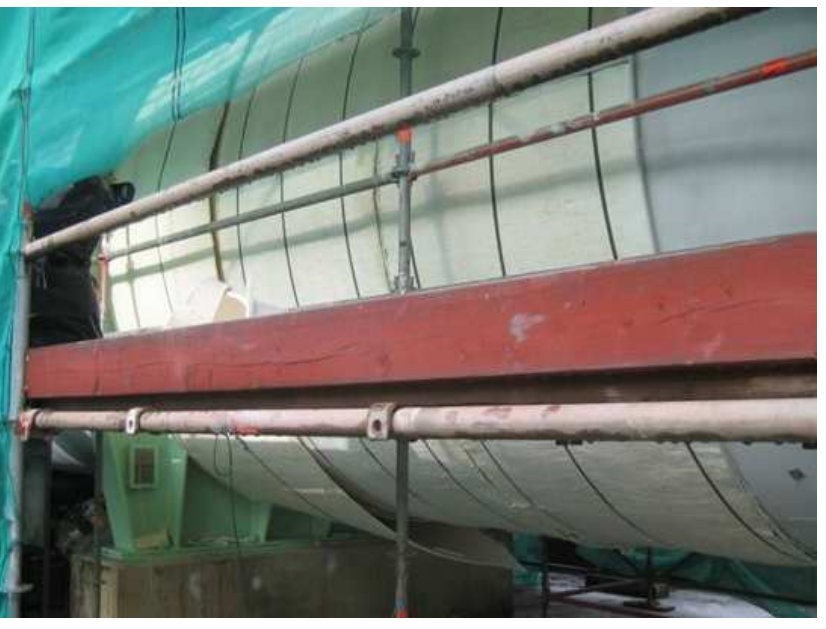

b

Figure 41. Installation of Pyrogel XT on "bullet" tank at Port Jerome Refinery: a) full tank image and b) close up of aerogel installation in progress.

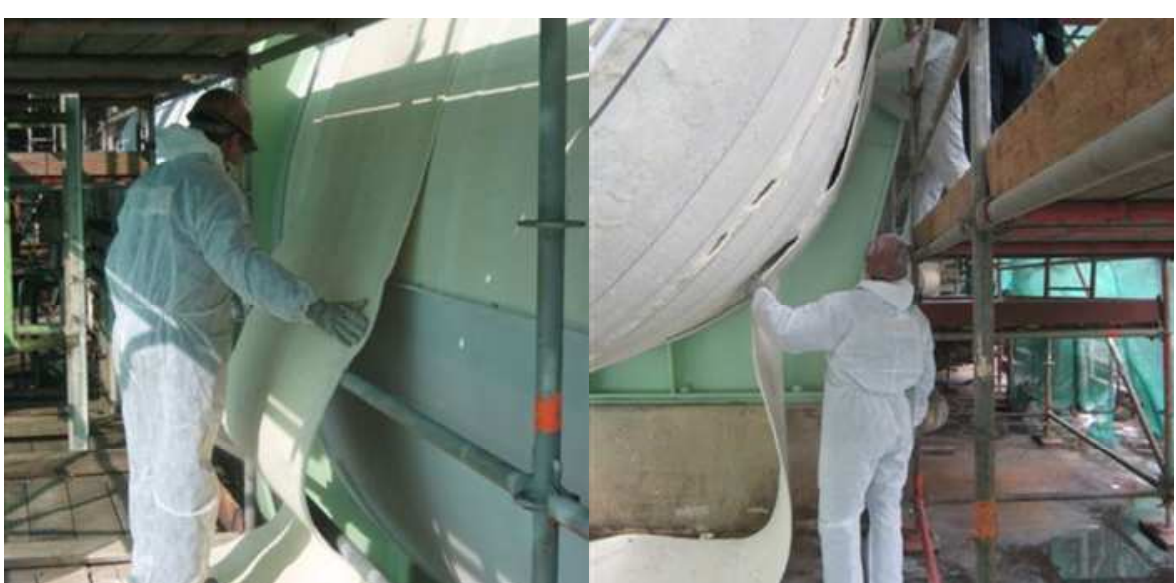

$\mathbf{a}$ b

Figure 42. Workers installing Pyrogel XT on a bullet tank: a) top half, b) bottom half.

The results of this test showed that, for this particular situation of four layers of $10 \mathrm{~mm}$ Pyrogel XT against one layer of $100 \mathrm{~mm}$ mineral wool blanket, the mineral wool offered the faster installation, by approximately 2:1. Although disappointing, this result is consistent with our understanding of labor productivity with flexible blanket materials. The redeeming factor here is that the ExxonMobil global specification actually precludes the use of mineral blanket in this kind of service because of its tendency to crush, sag, and get wet.

Effectively, this trial showed that Pyrogel XT will be more expensive to install than the cheapest and lowest quality competitive product on the market, mineral wool blanket. This is a point that we cannot and would not dispute. In terms of thermal efficiency and heat loss, the two systems show approximately the same level of performance at the beginning of their service life. However, we do expect some vindication as the relative thermal performance of the two insulation products begins to diverge over time, since Pyrogel XT has the more convincing track record of in-service durability. 


\subsubsection{In service Installation at Pastore Center in Providence, Rhode Island}

Anchor Insulation, one of Aspen Aerogels' installation partners in the industrial insulation market, performed an installation trial at the Pastor Center in East Providence, Rhode Island. The Pastore Center is a state-run campus with correctional and mental health facilities on the property. The buildings are heated via an onsite steam generation plant which feeds a campuswide steam distribution system. The steam plant is owned by the state and operated by Noresco, an Energy Savings Company (ESCO) that is certified under the DOE run Energy Savings Performance Contracting (ESPC) program.

To demonstrate how Pyrogel XT can be used in custom installations, Anchor fabricated a valve cover using Pyrogel XT which was installed on a system operating at $600^{\circ} \mathrm{F}(70 \mathrm{psi}$ steam). There were six valves operating in parallel at the installation site. The Pyrogel XT valve cover was fabricated with one layer of PGXT-10 as shown in Figure 43A, Aspen's 10mm (0.4 in) material. The other valves were covered with a 2 inch glass mat material (Figure 43B).

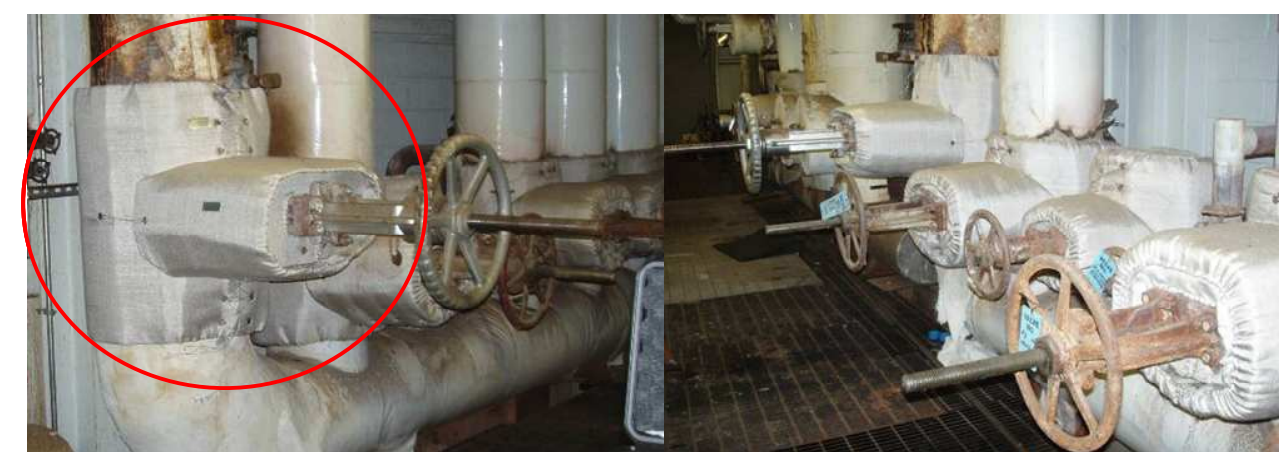

A
B

Figure 43. PGXT valve cover installation (A) and glass mat valve covers (B) at Pastore Center in Providence, RI.

The thermal performance of both the PGXT and glass mat valve cover was calculated using the 3EPlus software program. This program calculates an expected surface temperature using industry accepted thermal conductivities for standard materials, such as glass mat. The program also allows the user to enter thermal conductivities for user-defined materials. The thermal curve values for Pyrogel XT were entered into the program using the ASTM C-177 test values that were obtained during the material qualification portion of the project. The actual surface temperature for each material was measure using a pyrometer. Figure 44 illustrates the actual measurements that were performed on the glass mat valve cover. Figure 45 shows the same measurements being performed on the Pyrogel XT valve cover.

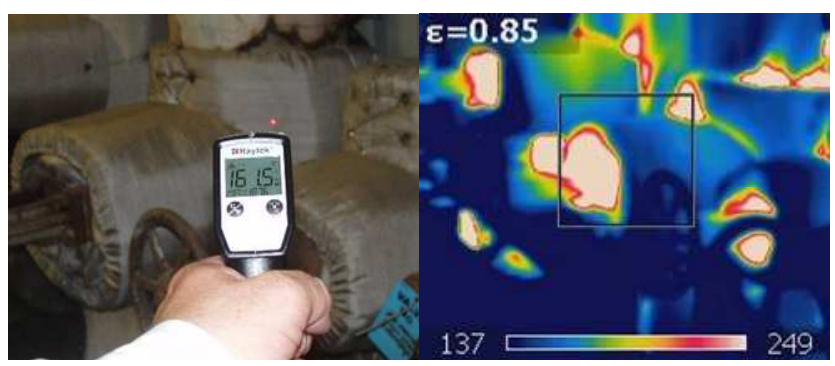

Figure 44. Pyrometer reading and infrared imaging of glass mat valve cover 


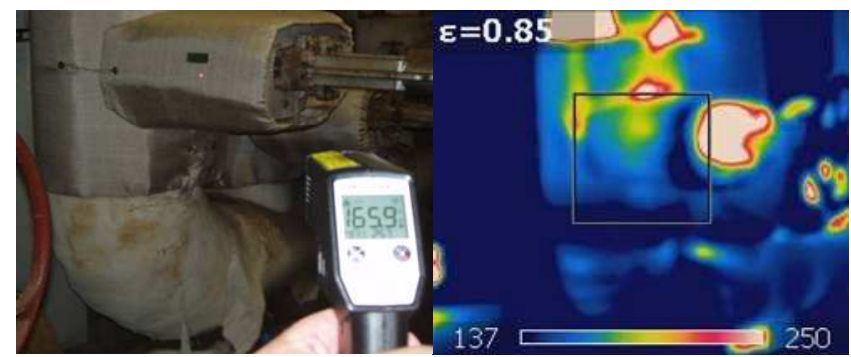

Figure 45. Pyrometer reading and infrared imaging of Pyrogel XT valve cover

\subsubsection{Results and Conclusions}

The results of this in service thermal assessment, listed in Table 10, confirm the thermal performance advantage that is achieved with Pyrogel XT. Less than 1/2" of Pyrogel XT resulted in a surface temperature that was within $5^{\circ} \mathrm{F}$ of the performance achieved using 2 " of glass mat.

\section{Table 10 . Measured and calculated* (with 3EPlus) temperature of glass mat vs. Pyrogel $\mathrm{XT}$ valve cover}

\begin{tabular}{|l|l|l|l|l|}
\hline \multirow{2}{*}{ Material } & \multirow{2}{*}{$\begin{array}{c}\text { Areal } \\
\text { Weight }\end{array}$} & \multirow{2}{*}{ Thickness } & \multicolumn{2}{|c|}{ Surface Temperature } \\
\cline { 4 - 5 } & & & Calculated $^{*}$ & \multicolumn{1}{|c|}{ Measured } \\
\hline Glass Mat & $10 \mathrm{oz} / \mathrm{sq} \mathrm{ft}$ & 2 inches & $120.7^{\circ} \mathrm{F}$ & $161.5^{\circ} \mathrm{F}$ \\
\hline Pyrogel XT & $6.5 \mathrm{oz} / \mathrm{sq} \mathrm{ft}$ & 0.4 inches & $163.9^{\circ} \mathrm{F}$ & $165.9^{\circ} \mathrm{F}$ \\
\hline
\end{tabular}

It is important to note that the 3EPlus calculation for the glass mat product calculated an expected surface temperature that was $40.8^{\circ} \mathrm{F}$ lower than the measured performance temperature. The calculated and measured surface temperatures for Pyrogel XT were within $2^{\circ} \mathrm{F}$. 3EPlus is a free-ware product that is developed and distributions by the National Insulation Association. It is an industry accepted tool that is often used to design an insulation solution for industrial process pipelines.

The large difference in the measured and calculated value for glass mat illustrates the disconnect that can occur between real-world performance and calculated design performance. This can lead to energy losses that far exceed those specified in the insulation system design. The performance deltas can be explained by understanding the material properties of insulations such as glass mat. First, the insulation value of glass mat relies in part on its fibrous loft; however, it is compressible and will lose loft over time. The specified 2" of insulation that was applied to this system has lost a portion of its performance based on this loss of loft. This compression is illustrated in Figure 46. The pipe was insulated with 2 layers of glass mat, each 1" thick. Over time the vertical pipe insulation has lost $22 \%$ of its loft. 


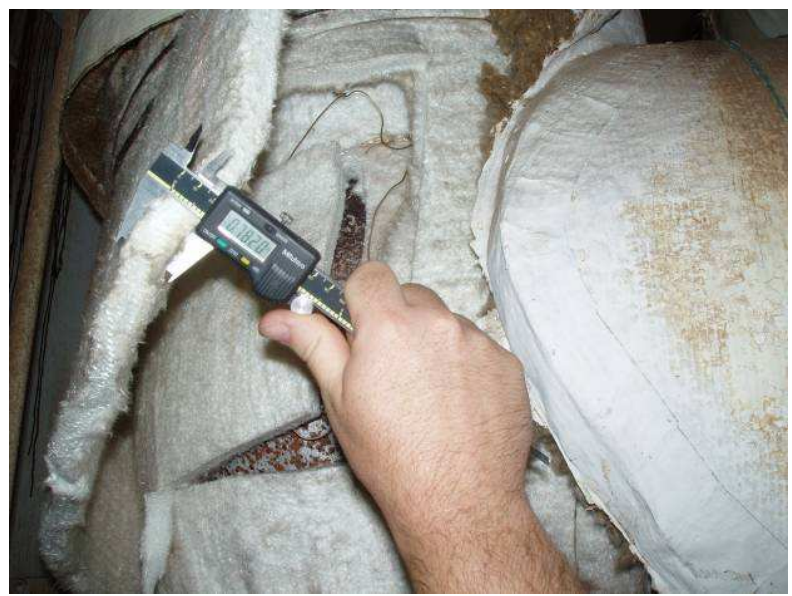

Figure 46. Measured thickness of in-use section of 1 " glass mat shows the material compressed to 0.78 "

The second factor to consider is water uptake. In a humid environment, such as a steam plant, insulations like glass mat will retain water. This further decreases the thermal performance of the insulation. Pyrogel XT reduces this delta because the material properties remain consistent from the installation through the in-use lifecycle. Pyrogel's compression resistance ensures that the material thickness is maintained over time, thus ensuring that the insulation design specification are met throughout the life expectancy of the system. Second, Pyrogel's hydrophobic surface doesn't allow liquid water to build up within the material. Since the Pyrogel maintains its permeability to water vapor, any water that may drip behind the insulation through seam cracks will be released as water vapor. 


\section{Benefits Assessment}

The primary environmental benefit of ABPI is the reduction in atmospheric emissions due to lower energy consumption in boilers. Based on the methodology of Section 2.1, this includes cumulative savings of 3.5 million tonnes carbon equivalent $\mathrm{CO}_{2}$, and 85,000 metric tonnes of $\mathrm{SO}_{2}$ and NOx through the year 2030. Secondary benefits could be claimed from the manufacturing of aerogel instead of incumbent insulation materials, based solely on the fact that aerogel-based insulation requires one-third to one-tenth the material for a given application. All else being equal, less material produced means less waste generated both during production, and for end-of-life disposal. However, since little is known about incumbent manufacturing processes, all else may not be equal. So, for the purposes of this exercise, the net environmental impact from the manufacturing and solid waste side is conservatively assumed to be zero.

Based on the heat loss and market penetration analyses from Section 2, the annual reduction in industrial energy consumption was estimated. By the year 2025, this savings will reach 16 trillion Btus per year. At an average energy cost of $\$ 3.59 / \mathrm{MMBtu}$ for industrial boilers, this equates to $\$ 117$ million per year (2011 dollars).

The very significant energy savings results achieved came quite close to the expected performance calculations done following the product requirements portion of the project. From a commercial perspective, the project and resulting sales of Pyrogel XT exceeded Aspen Aerogels' expectations. 


\section{Commercialization}

The network of distribution and installation partners that Aspen has developed for ABPI has grown appreciably during the project, and this has significantly accelerated this growth rate. Aspen does not install its insulation at sites and often does not supply it, unless orders are of sufficient size. Therefore the network of over 40 distribution partners which now exist throughout the world are critical to getting Pyrogel sold to and installed at industrial sites. Existing pipe insulation vendors and installers are carrying ABPI as a standard product, and will have converted better than half of their new installs to this material system by 2015 .

Through these steps, Aspen hopes to dominate the steam pipe insulation market with Pyrogel products, dramatically reducing domestic energy consumption. Within its first three years, Pyrogel XT has already grabbed $10 \%$ of the domestic market for steam pipe insulation, outselling all North American manufacturers of expanded perlite combined. Pyrogel XT will over the next 18 months eclipse the sales of the next most popular insulation material, calcium silicate. Within five years, Aspen projects that Pyrogel XT will grow to be comparable to fiberglass and mineral in terms of total share of the market for steam pipe insulation. 


\section{Accomplishments}

The project objectives that were met that enable the overall commercial success of Pyrogel XT in the marketplace were a combination of technical and product demonstration, manufacturing, and business:

Technical and Product Demonstration Objectives:

- Assembled comprehensive set of system requirements for the petroleum refineries.

- Built a design tool for straight pipe sections for various sizes and temperatures.

- Developed sheathing, fasteners, and sealing components and procedures.

- Installed a test section on a representative pipe run at ExxonMobil.

- Demonstrated ABPI's durability and thermal performance in a stressing environment.

- Validate thermal performance equal to or better than predicted

- No material degradation or visible corrosion on pipe

- Projected 5-year costs equal to or better than main competitors for all pipe sizes

Manufacturing Objectives

- Identified and sourced non-quartz batting for high temperature product.

- Reduced production costs by $\$ 0.10$ per square foot.

- Opened aerogel Production Plant \#2.

Business Objectives

- Got formal commitment from ExxonMobil, Air Liquide, Naval Station Newport, the Pastore Center, and Archer-Daniels Midland to install Pyrogel XT at their facilities, a significant result at a wide variety of sites.

- Secured first domestic and first international sales orders.

- Established co-marketing and product distribution network.

- Increase visibility through tradeshows, advertising, and write-ups in publications such as Hydrocarbon Processing.

Aspen Aerogels worked with Anchor Insulation on a district energy steam pipe project at Brown University, to replace the poor quality fiberglass on pipes in a confined space. The project went very smoothly and Brown submitted the project to the Associated Builders and Contractors (ABC) Excellence in Construction awards contest for outstanding projects in 2010. The project won the Rhode Island chapter competition and was submitted to the National ABC awards competition, with winners to be announced in Feb 2011. A link to the completion webpage is:

\section{http://www.abc.org/Business_Development/Awards/Excellence_in_Construction_Awards.aspx}

This project was a great example of Aspen's advantage in this area, highlighting the safety and congestion aspects of confined space work with Pyrogel XT.

Other publications relevant to Pyrogel XT include:

○ Spring 2007, Power \& Energy Technology, "Nanotechnology comes to Industrial Insulation" 
- Fall 2007, The Chemical Engineer, "Space material meets industry - How your plant can benefit from the world's best thermal insulator"

○ July 2008, Hydrocarbon Engineering Magazine, "Keeping the Heat In - A new insulation solution for high temperature industrial applications"

- April 2011, BIC Magazine, "Pyrogel XT: A superior insulation solution to CUI" 


\section{Conclusions}

Aspen Aerogels delivered Pyrogel XT ${ }^{\mathrm{TM}}$, an aerogel-based pipe insulation (ABPI), to market to reduce the energy loss experience in industrial steam processing systems. The product became Aspen's best selling flexible aerogel blanket insulation, and to date, has delivered more than 0.7 TBtu of domestic energy savings primarily through it's durability against water, heat and mechanical abuse; compared to incumbent insulation materials, the efficiency of Pyrogel XT simply does not degrade over time. Pyrogel XT sales have been due to better thermal performance, improved durability, and faster installation times than the incumbent insulation materials. This 4 year project thoroughly achieved the following:

- Defined the insulation product requirements for the specific industrial market segment targeted and then validated which of the requirements were already met by the material.

- Improved the aerogel blanket insulation to withstand the environment, including hightemperatures (to $1200^{\circ} \mathrm{F}$ ), moisture and water, etc. Specifically, the aerogel blanket fiber reinforcement material was optimized for performance under these conditions and cost; the hydrophobic agents were modified to resist moisture durably at high temperatures, and the aerogel phase of the insulation was strengthened through formulation optimization.

- Increased throughput of Pyrogel significantly in the manufacturing environment through extensive work on process steps including additive incorporation techniques and optimization, improvements in casting aerogel precursors onto the fiber blanket, and optimization of the aging process to strengthen the aerogel composition.

- Demonstrated and documented Pyrogel XT installations at 5 facilities, 3 industrial and 2 government, to validate its superior performance and cost savings relative to incumbent insulation materials.

The $\$ 2$ million investment by DOE has paid back handsomely: 1) $\$ 60$ million in sales of Pyrogel XT have been recorded to date; 2) roughly $60 \%$ of the Pyrogel XT sales have been exported ( $\$ 36$ million); and 3) at least 50 manufacturing jobs have been created in Aspen's East Providence, RI plant that can be attributed to production of Pyrogel XT. 


\section{Recommendations}

Future product development efforts should focus on improving the high-temperature thermal conductivity and reducing the dust generation levels of Pyrogel XT. In addition, the XT family should eventually be extended to address the following adjacent market segments:

- Fire protection for structures, ducting, and cable trays

- Acoustic insulation for industrial facilities

- Hull-board insulation for marine applications

- Heating, ventilation and air conditioning applications 


\section{References}

1. Energy Use, Loss and Opportunities Analysis: U.S. Manufacturing \& Mining, U.S. Department of Energy, Energy Efficiency and Renewable Energy Industrial Technologies Program, Dec. 2004.

2. Energy Use, Loss and Opportunities Analysis: U.S. Manufacturing \& Mining, U.S. Department of Energy, Energy Efficiency and Renewable Energy Industrial Technologies Program, Dec. 2004.

3. Hart, G.H., "How Many Barrels of Oil Can Mechanical Insulation Save?", Insulation Outlook, May, 2005.

4. Energy Use, Loss and Opportunities Analysis: U.S. Manufacturing \& Mining, U.S. Department of Energy, Energy Efficiency and Renewable Energy Industrial Technologies Program, Dec. 2004.

5. "Fabricated Insulation Products \& Specification Assistance by Extol of Ohio, Inc.", http://www.insulation.org/mtl/pdfs/000127_356.pdf, October, 2005.

6. Hart, G.H., "How Many Barrels of Oil Can Mechanical Insulation Save?", Insulation Outlook, May, 2005.

7. http://www.intelligentinsulation.com/pdfs/IIG-401.pdf

8. http://www.intelligentinsulation.com/pdfs/IIG-200.pdf

9. http://www.knaufusa.com/

10. Richardson, L.R; Brooks, M. “Combustibility of Building Materials”, Fire and Materials, 15, 1991, 131-136.

11. Saatdjian, E. ; Demars, Y. ; Klarsfeld, S. ; Bueck, Y. "Effects of Binder Decomposition on the High Temperature Performance of Mineral Wool Insulation” ASTM Special Technical Publication 789, 757-777.

12. Setzo, E. "Prevent Insulation from Punking" Hydrocarbon Processing, 1991, 70, 51-53.

13. (a) Zhang, S.; Shibata, T.; Haruna, T. Corrosion, 1999, 55, 462-468. (b) Andresen, P.L. "The Effects of Aqueous Impurities on Intergranular Stress Corrosion Cracking of Sensitized Type-304 Stainless Steel." Palo Alto, CA: Electric Power Research Institute, 1983, Final report No. EPRI NP-3384. 